Review Article

\title{
The Great Healing Potential Hidden in Plant Preparations of Antioxidant Properties: A Return to Nature?
}

\author{
Małgorzata Kiełczykowska (iD) and Irena Musik \\ Chair and Department of Medical Chemistry, Medical University of Lublin, 4A Chodźki Street, 20-093 Lublin, Poland \\ Correspondence should be addressed to Małgorzata Kiełczykowska; malgorzata.kielczykowska@umlub.pl
}

Received 29 July 2020; Revised 20 August 2020; Accepted 12 September 2020; Published 10 October 2020

Academic Editor: Patricia Morales

Copyright (c) 2020 Małgorzata Kiełczykowska and Irena Musik. This is an open access article distributed under the Creative Commons Attribution License, which permits unrestricted use, distribution, and reproduction in any medium, provided the original work is properly cited.

\begin{abstract}
The application of chemicals in industry and agriculture has contributed to environmental pollution and exposure of living organisms to harmful factors. The development of new pharmaceutical agents enabled successful therapy of various diseases, but their administration may be connected with side effects. Oxidative stress has been found to be involved into etiology of numerous diseases as well as harmful action of drugs and chemicals. For some time, plant origin substances have been studied as potential protective agents alleviating toxicity of various substances and symptoms of diseases. The aim of the current review was to present the diversity of the research performed during the last five years on animal models. The outcomes showed a huge protective potential inherent in plant preparations, including alleviating prooxidative processes, strengthening antioxidant defence, ameliorating immune parameters, and reversing histopathological changes. In many cases, plant origin substances were proved to be comparable or even better than standard drugs. Such findings let us suggest that in the future the plant preparations could make adjuvants or a replacement for pharmaceutical agents. However, the detailed research regarding dose and way of administration as well as the per se effects needs to be performed. In many studies, the last issue was not studied, and in some cases, the deleterious effects have been observed.
\end{abstract}

\section{Introduction}

In the recent centuries, a great change of the conditions of the human life has taken place, due to the development of industry, agriculture, medicine, and pharmacy. The new synthetic substances were applied to protection of crops as well as successful therapy of various diseases. However, except for beneficial influence, consisting in numerous facilitations of human existence and extending human life span, negative effects have also occurred $[1,2]$. A growing pollution of natural environment, resulting from the industry development, has been observed for many years [3-5]. Despite the efforts aiming at alleviating and preventing this phenomenon, it still belongs to the most important problems to be solved by the mankind. The application of plant protection products has made another contribution to environmental contamination [6-9]. As it is not possible to improve the situation immediately, many people, i.e., industrial workers or farmers are still exposed to harmful substances like heavy metals [4, 10-12], organic chemicals (e.g., $\mathrm{CCl}_{4}$ ) $[13,14]$, or pesticides and plant growth regulators $[8,15]$. Another problem results from introducing plenty of new pharmaceutical agents. They allowed to relieve suffering of many subject and successive treatment in cases of mortal diseases. However, on the other hand, plenty of side effects have also been observed [16, 17]. Analgesic and antipyretic drugs like acetaminophen or aspirin can induce liver and kidney damage [18-22]. The antineoplastic agents can cause severe disturbances like testicular damage [23], nephrotoxic [16, 24], cardiotoxic $[25,26]$, and hepatotoxic [27] effects. Antibiotics have also proved to show side effects including liver and kidney damage $[28,29]$. The widespread practice of using different additives to preserve and improve the taste of food makes another source of toxic action on human organisms [30]. The growing life span is connected with an increase in incidence of neurodegenerative disorders like Parkinson' disease [31] or 
Alzheimer's disease [32]. Furthermore, in the recent decades, obesity, hyperlipidemia, and connected disturbances have become a significant worldwide problem $[33,34]$.

All the presented facts have made the scientists search for any agents which could exert protective effects against toxic environmental pollutants and chemicals used in industry and agriculture and replace the standard drugs or make beneficial adjuvants. The return to natural products, sometimes used for thousands years in traditional medicine, has become one of the significant directions of this research [35-39]. It could be stated, without any exaggeration, that "a great return to nature" is recently being observed. Plant extracts and plant origin substances per se do not show so many side effects as pharmacological substances. On the other hand, they contain numerous compounds of anti-inflammatory and antioxidative properties like polyphenolic derivatives and flavonoids [40-42]. The presented facts prompted large-scale research on possibilities of application of plant preparations as protective agents against toxicity of various substances as well as adjuvants alleviating the symptoms of diseases, obesity, and traumata $[6,25,38,43-49]$. A great quantity of plant species have been investigated, and the obtained results seem to be very promising. Some studies have included the comparison of the investigated materials with standard drugs, and the outcomes suggest that in many cases the replacement would be possible $[20,31,35,50-53]$. However, many questions remain to be solved as to the best way of treatment and the most beneficial dose.

Oxidative stress-the disturbed balance between generation of reactive oxygen species (ROS) and antioxidants' level in an organism - has been found to be involved, less or more, into the etiology of most diseases [54-56]. This process involves the generation of ROS, active particles capable of injuring all bioactive compounds-protein, lipids, and nucleic acids in an organism. Lipid peroxidation caused by ROS may lead to damage of membrane lipids. Living organisms developed a wide range of endogenous substances, both enzymatic and low-molecular ones, which can neutralize ROS. Negative effects resulting from stress, exposure to toxic substances, side effects of the standard drugs, or even food supplements have also been proved connected with prooxidative processes and deterioration of antioxidant defence $[13,30,40,57,58]$. Plant origin preparations, in turn, have been found to exert a strong antioxidant action due to high content of components of antioxidative properties. Numerous studies have revealed their direct influence on oxidative processes by reducing lipid peroxidation or protein carbonylation as well as increase in antioxidant enzymes' activities and low-molecular antioxidant concentrations [34, 43, 59, 60].

Different pathways involved in oxidative and inflammatory processes have been found to be affected in the course of protective action of plant preparations.

The studies have shown the involvement of Nrf2 and Keap1 proteins. Nrf2 is regarded as a key transcription factor mediating the endogenous antioxidant response, and Keap1 is its negative regulator. Under oxidative stress conditions, Nrf2 is released and translocated to the nucleus where it binds to ARE regions in DNA and stimulates antioxidant enzyme gene expression. Both Nrf2 and Keap1 as well proteins regulated by $\mathrm{Nrf} 2$, responsible for defence against antioxidant stress like HO- 1 and $\gamma$-GCS, have been found to be disturbed by harmful factors (cadmium or high-fat diet) and regulated by plant preparations $[12,61]$. Plant origin substances have been reported to cause upregulation of $\mathrm{Nrf} 2, \mathrm{HO}-1$, and $\gamma$-GCS in both nonexposed and $\mathrm{Pb}$ exposed rats [62].

Another pathway connected with oxidative and inflammatory processes which have been proved involved into protective properties of plant preparations is NF- $\kappa \mathrm{B}$ pathway. $\mathrm{NF}-\kappa \mathrm{B}$ is a transcription factor responsible for expression of proinflammatory cytokines [56]. Its activation can be triggered by TLR receptors, belonging to pattern recognition receptors. The inflammation and redox balance have been found to be strongly connected with each other [63]. Interleukins, $\gamma$-interferon and tumour necrosis factor, have been found to affect ROS production [64]. The involvement of the LPS-TLR4-NF- $\kappa$ B pathway into protective action of plant materials has been reported $[56,65]$. Other authors have stated that a protective effect of a plant extract, resulting from antioxidative and anti-inflammatory influence observed in diabetes animal model, could be attributed to inhibition of $\mathrm{NF}-\kappa \mathrm{B}$ activation [66].

Mitogen-activated protein kinases (MAPK) belong to enzymes which make mediators of various processes occurring in cells like death, proliferation, or differentiation. The MAPK pathway begins from a signal from an extracellular receptor and through a cascade of subsequent protein phosphorylation leads to activation of different proteins including transcription factors (e.g., p53 protein) and finally to the expression of genes. ROS have been proven to be connected with particular steps of the MAPK pathway. There are three kinds of MAPK in mammals: p38 MAPK, ERK1 (extracellular signal-regulated kinase 1), and JNK (c-Jun N-terminal kinase) $[64,67]$. The studies on plant revealed the influence of the studied plant materials on some elements of the MAPK pathway [42].

The next pathway connected with oxidative stress which has been found affected by plant preparations is the JAK/STAT pathway. An outside signal, usually being a cytokine, binds to a membrane receptor resulting in its dimerization. The next stage is the activation of JAK which renders possible phosphorylation of receptor, which in turn enables STAT binding and phosphorylation. Activated by phosphorylation STAT is then translocated into the nucleus where it acts as a transcription factor [68]. The relationships between this pathway and ROS have been reported [69]. In the current study, disturbances of oxidative balance as well as bone marrow damage and reduction in pJAK2/JAK2 and pSTAT5a/STAT5a, caused by radiation exposure, have been found to be improved by a plant preparation, which made the authors suggest that the studied material can stimulate the JAK2/STAT5a signal pathway [70].

The aim of the current review is to present the results of the studies performed in the last five years regarding the protective and medicinal properties of plant origin preparations with particular emphasis on their antioxidant action. 


\section{The Protective Properties of Plant Preparations against Toxicity of Various Factors}

2.1. The Protective Influence of Plant Preparations against Chemicals Applied in Agriculture. The use of different chemicals in food production has been growing dramatically in the recent years, causing the contamination of the natural environment and increasing thread to human health. Neurotoxicity, hepatotoxicity, reproductive disturbances, and cancerogenesis belong to the negative effects exerted on organisms $[6,8,15,71]$. Moreover, chemicals of lipophilic character can be accumulated in membranes [9]. Enhanced generation of ROS was proved involved into their harmful influence $[6,9,71]$. Plant origin materials were revealed to show protective properties not only by strengthening the antioxidant barrier but also by reversing histopathological changes. A wide range of different materials was studied, including simple extracts $[2,6,7]$ as well as commercial products $[9,15]$. The saponins from Tribulus terrestris, which were reported to possess antiaging action, were found to exert protective effects against rotenoneinduced parkinsonism [15].

The details concerning the above mentioned studies are presented in Table 1.

2.2. The Protective Influence of Plant Preparations against Toxic Effects of Heavy Metals. Environmental pollution with heavy metals makes a great global problem. The most toxic ones are lead, cadmium, and mercury. Even low concentrations can cause severe disturbances of organism, including brain, hepatic, renal, and reproductive damage [10]. As their harmful action is connected with oxidative stress induction, plant extracts showing antioxidant properties were studied as possible protective agents and the obtained results were found to be promising [10,11], although the accumulation of a toxic metal could not be prevented in every case [62].

The ability of plant origin substances proanthocyanidins to prevent lead-induced hepatotoxicity was suggested to be connected with the Nrf2/ARE pathway (as an increase of mRNA expression levels of Nrf2 in the liver of mice administrated with proanthocyanidins and/or lead was observed) as well as with the reduction of endoplasmatic reticulum stress via a decrease in stress-related proteins GRP78 and CHOP [62].

In the experiments concerning the toxicity of mercury, plant extracts relieved the negative effects in the case of both an inorganic form (mercury (II) chloride) and organic one (dimethylmercury); at the same time, the beneficial influence included not only oxidant and immunological parameters but also histopathological changes $[4,72,73]$.

Plant extracts were also found to exert wide protective effects against the third most dangerous heavy metal cadmium, with the results being confirmed by in vitro studies with using murine hepatocytes [3]. Additionally, an animal study showed the involvement of the Nrf2/Keap1 pathway into the protective action of Pyrantha fortuneana extract as the plant material, given both alone and coadministered with cadmium caused a significant increase in expression of Nrf2 and decrease in expression of Keap 1 in the kidneys of rats vs. the control and Cd-exposed group, respectively [12].

Apart from lead, mercury, and cadmium the research concerning metals' toxicity included also liver injury caused by iron overload. $70 \%$ methanol extract of Drosera burmannii Vahl. showed a distinct, dose-dependent efficacy against iron-induced hepatoxicity. This effect, particularly in case of the highest dose, was comparable with that exerted by a standard drug desirox-an iron chelator. Additionally, the studied extract studied in vitro showed the ability to chelate $\mathrm{Fe}^{2+}$ ions. Such findings made the authors suggest that the studied preparation might be used as a medicine in cure of iron overload-induced diseases [50].

The details concerning the above-mentioned studies are presented in Table 2.

\subsection{The Protective Influence of Plant Preparations against} Various Chemicals. Plant origin substances, extracts and their particular fractions, essential oils, and seed powders were found to reverse or alleviate disturbances of organism resulting from exposure to different chemicals. The resent research included various compounds, e.g., hepatotoxic tetrachloromethane $\left(\mathrm{CCl}_{4}\right)$ used for years as a solvent and now regarded as an environmental pollutant [14], aluminium known for its neurotoxicity [74], aflatoxins produced by toxigenic fungi which made food contaminants [75], and chemicals used in industry and laboratory experiments like thioacetamide [76] or 1-chloro-2,4-dinitrobenzene [77]. Additionally, plant origin substances were proved to decrease mouse mortality resulting from the acute $\mathrm{CCl}_{4}$ toxicity [78] as well as from Concanavalin A exposure [79]. Furthermore, several studies included the influence of plant materials alone, and generally, no harmful effects were observed [14, 54, 74, 75, 78, 80, 81].

The details of the performed studies are presented in Table 3.

2.4. The Protective Influence of Plant Preparations against Carcinogens. Plant extracts were studied using animal model as for their possible application in tumour therapy due to the presence of anticancer and antioxidant components. The necessity of searching for new agents, suitable for tumour treatment, was challenged by the lack of effective chemotherapy and severe side effects associated with the used medicines. The obtained results seem to be promising as the studied materials alleviated carcinogen-induced oxidative stress as well as disturbances of immunological parameters $[47,88,89]$. Histolopathological studies confirmed the beneficial effects of the investigated preparations [46, 89].

The detailed results of the performed studies are presented in Table 4.

2.5. The Protective Influence of Plant Preparations against Ethanol. Alcohol excessive consumption and addiction leads to different negative effects: liver injuries including steatosis $[56,91]$, brain damage [92], and reproductive system damage [93]. The disturbances of oxidative balance were suggested to be one of the factors underlying alcohol toxicity, which was confirmed by intensification of lipid peroxidation as well as 


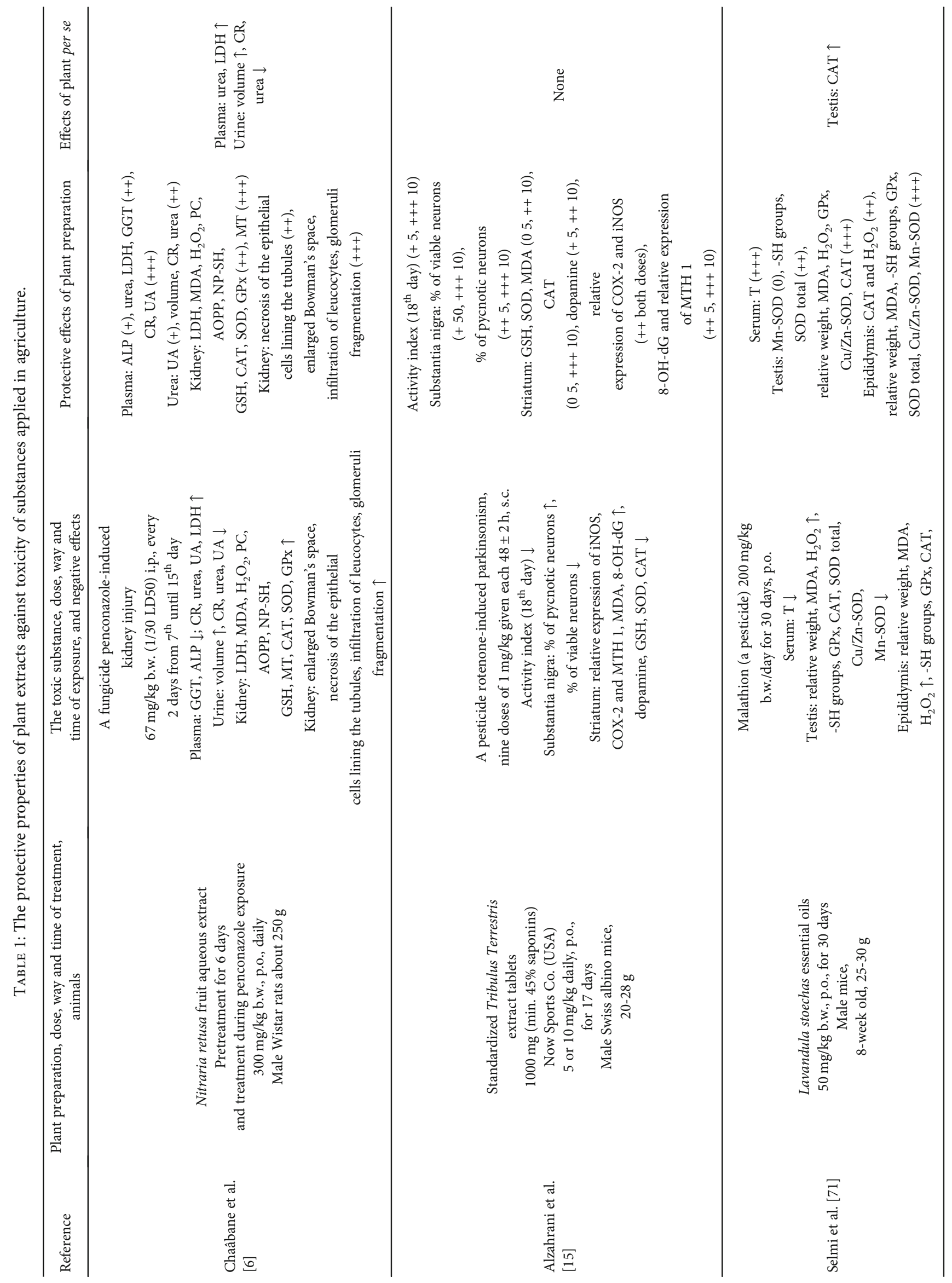




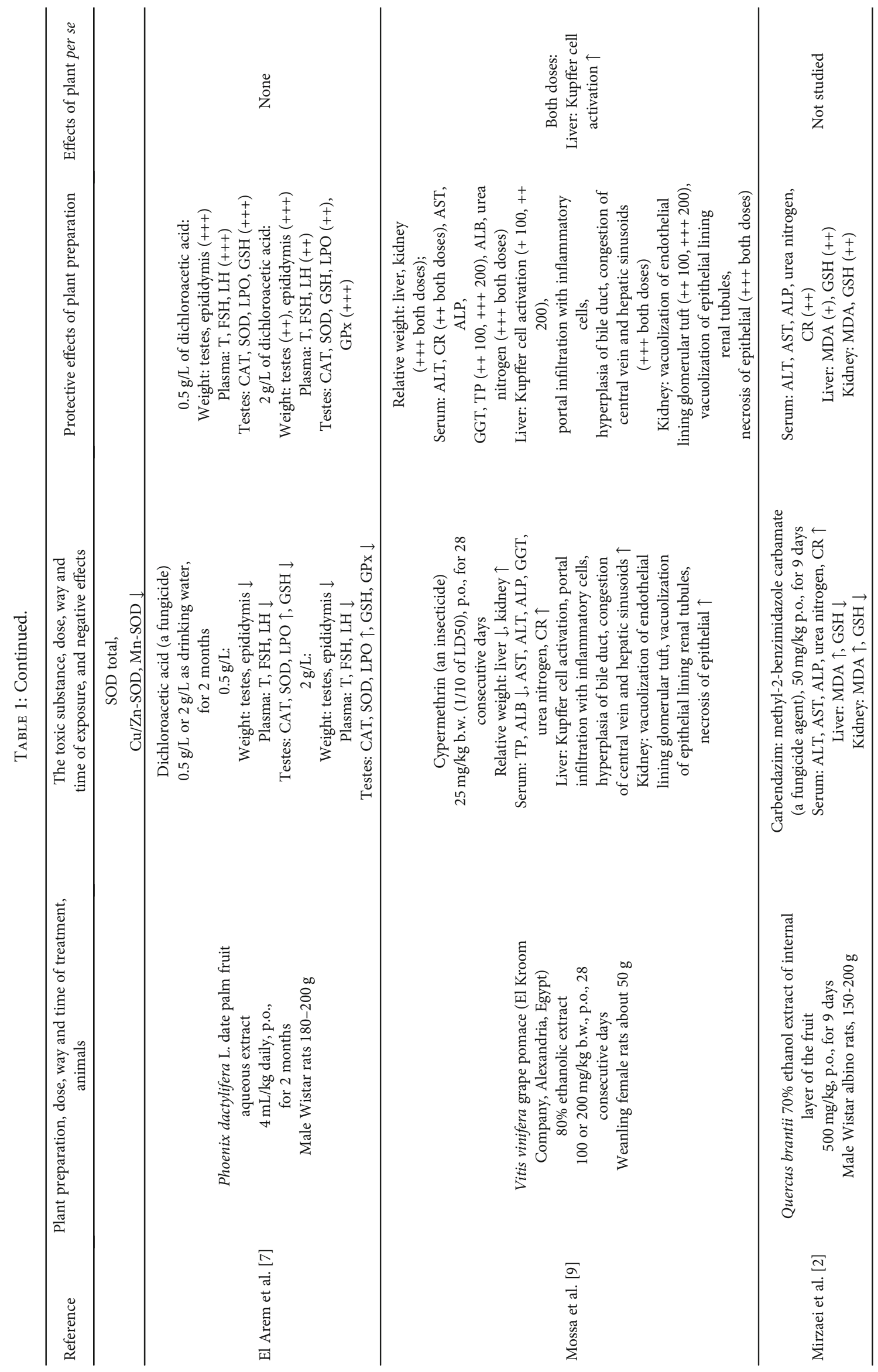




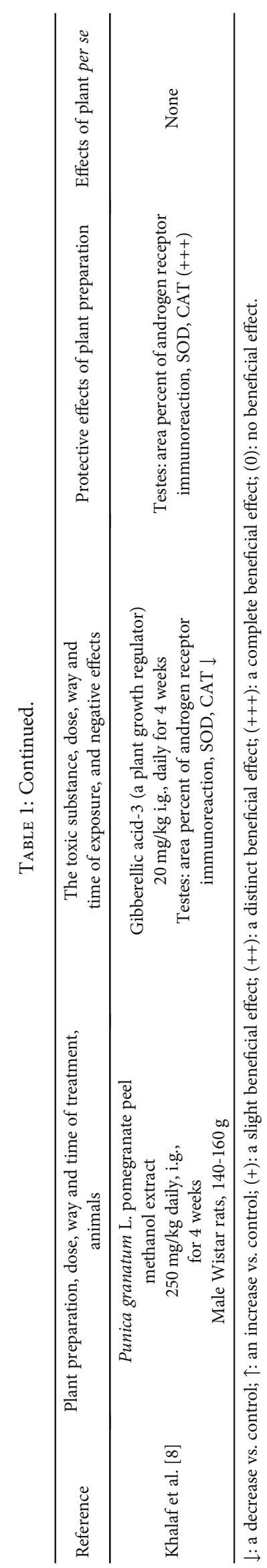



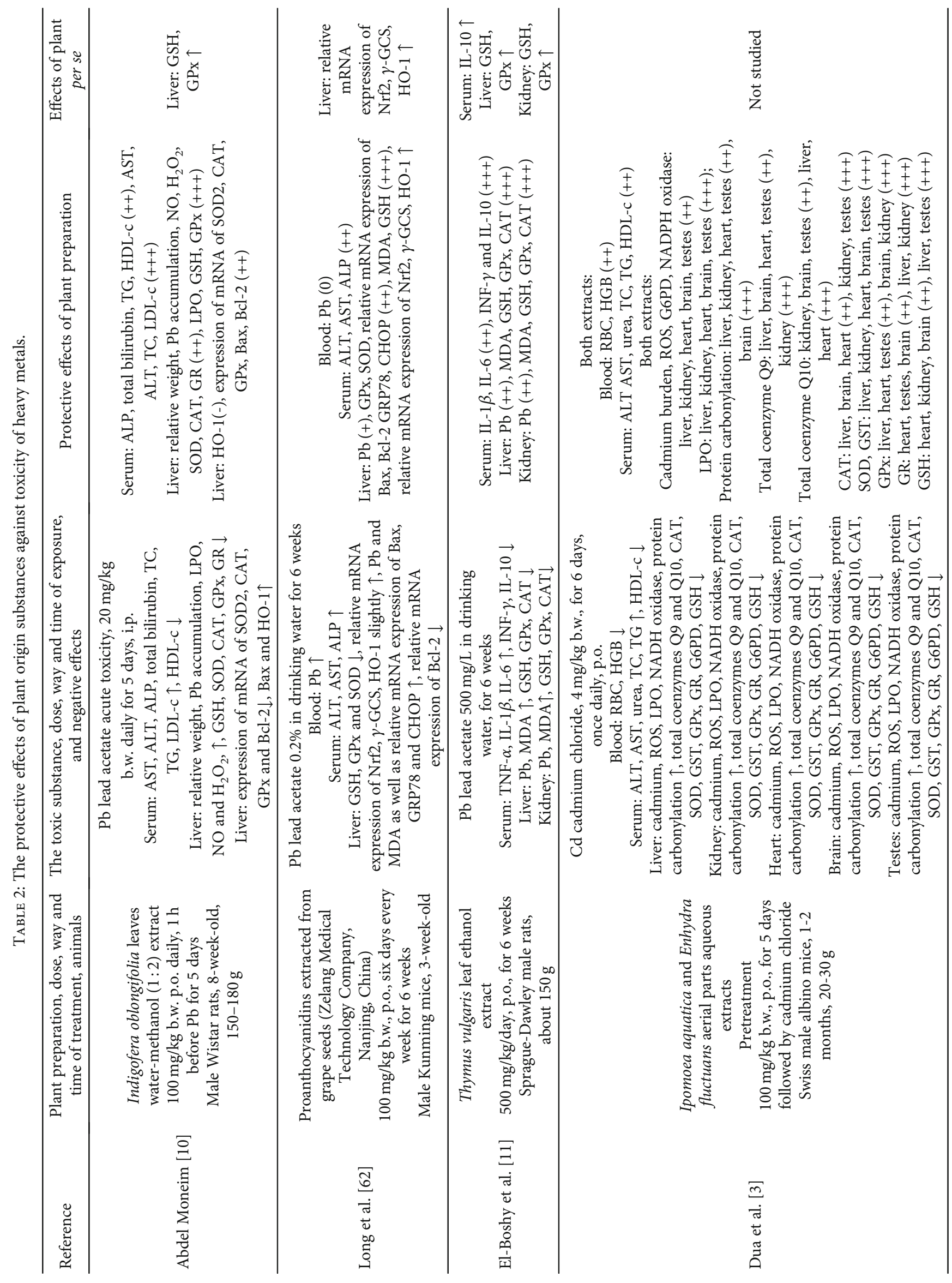


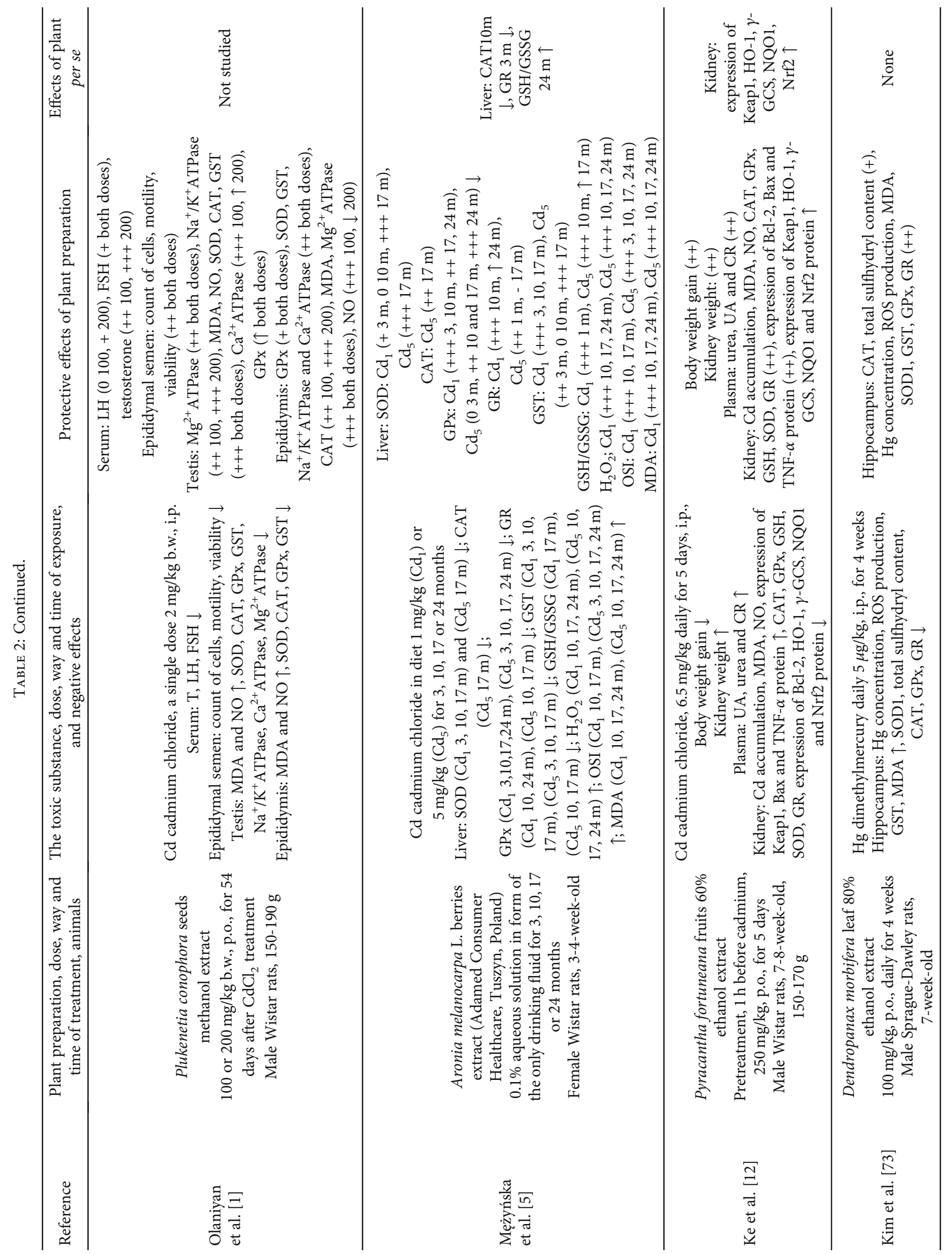




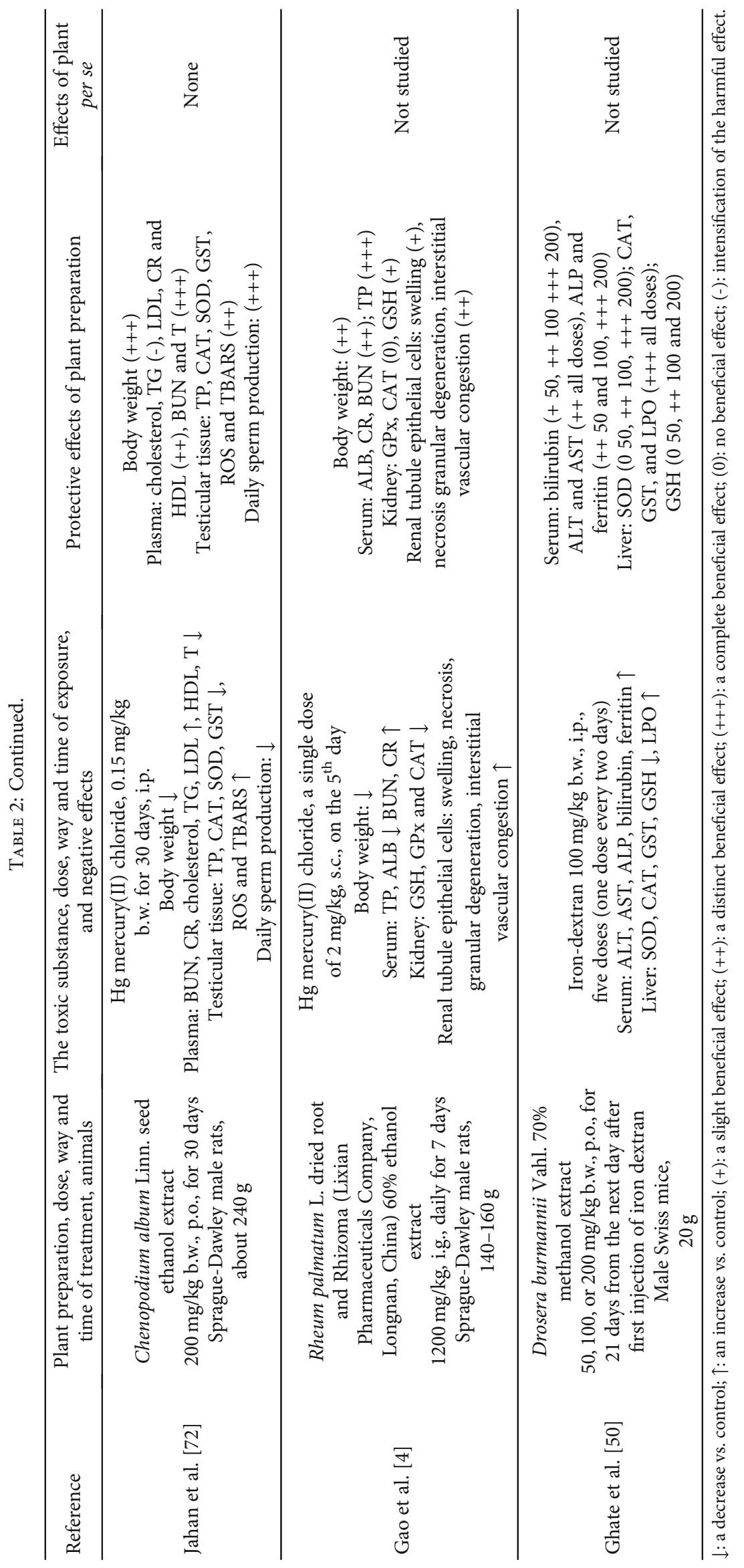




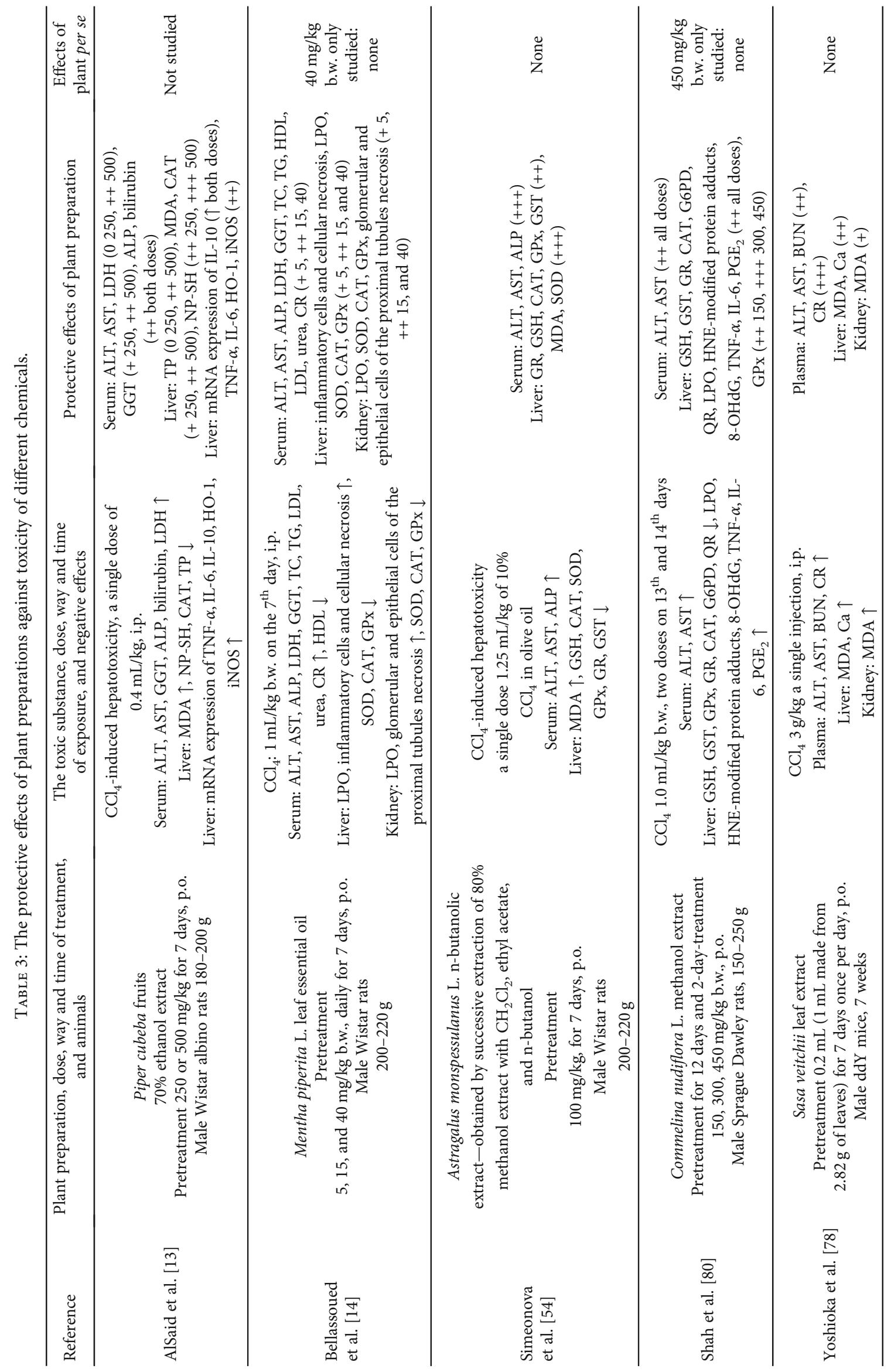




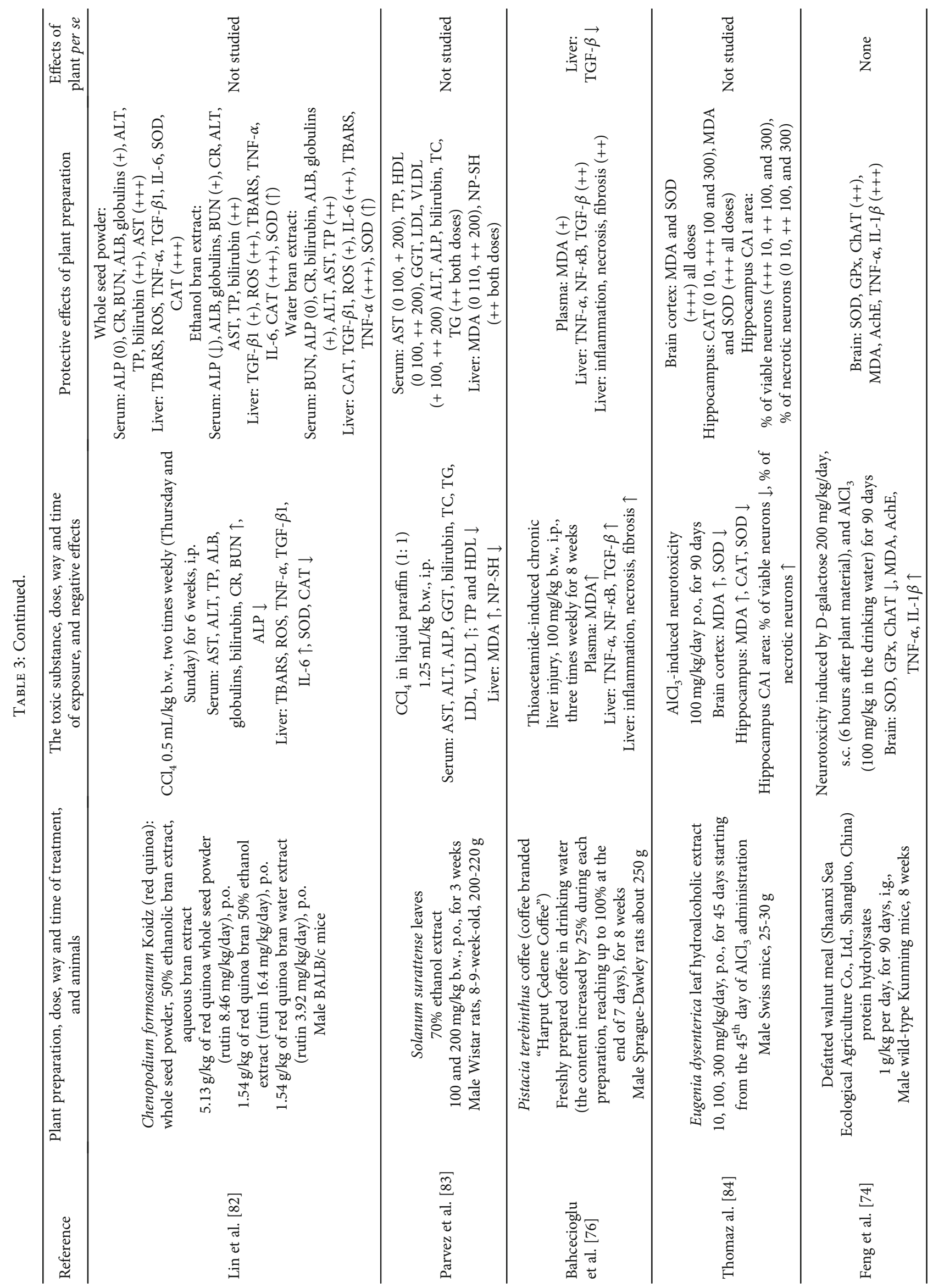




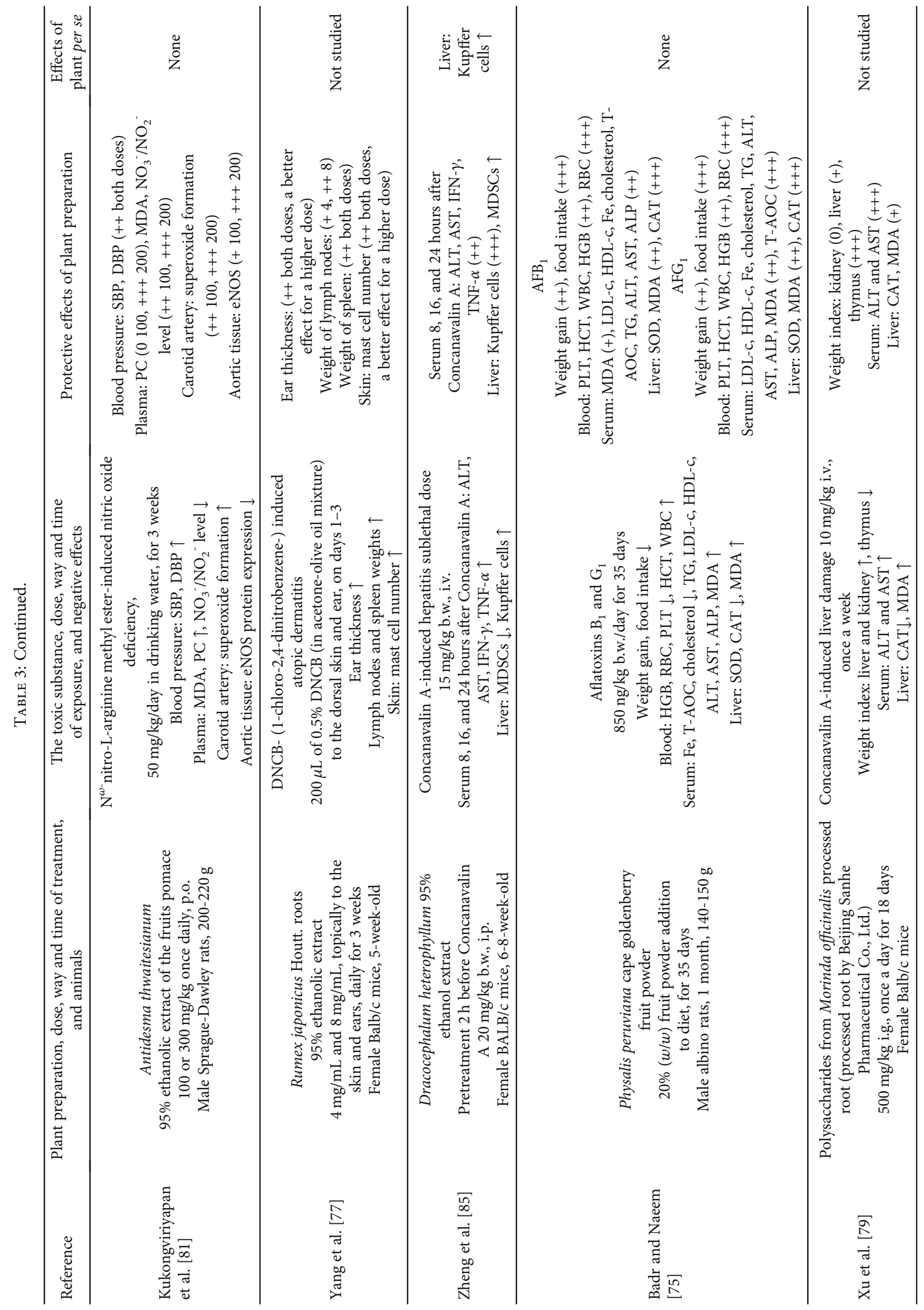




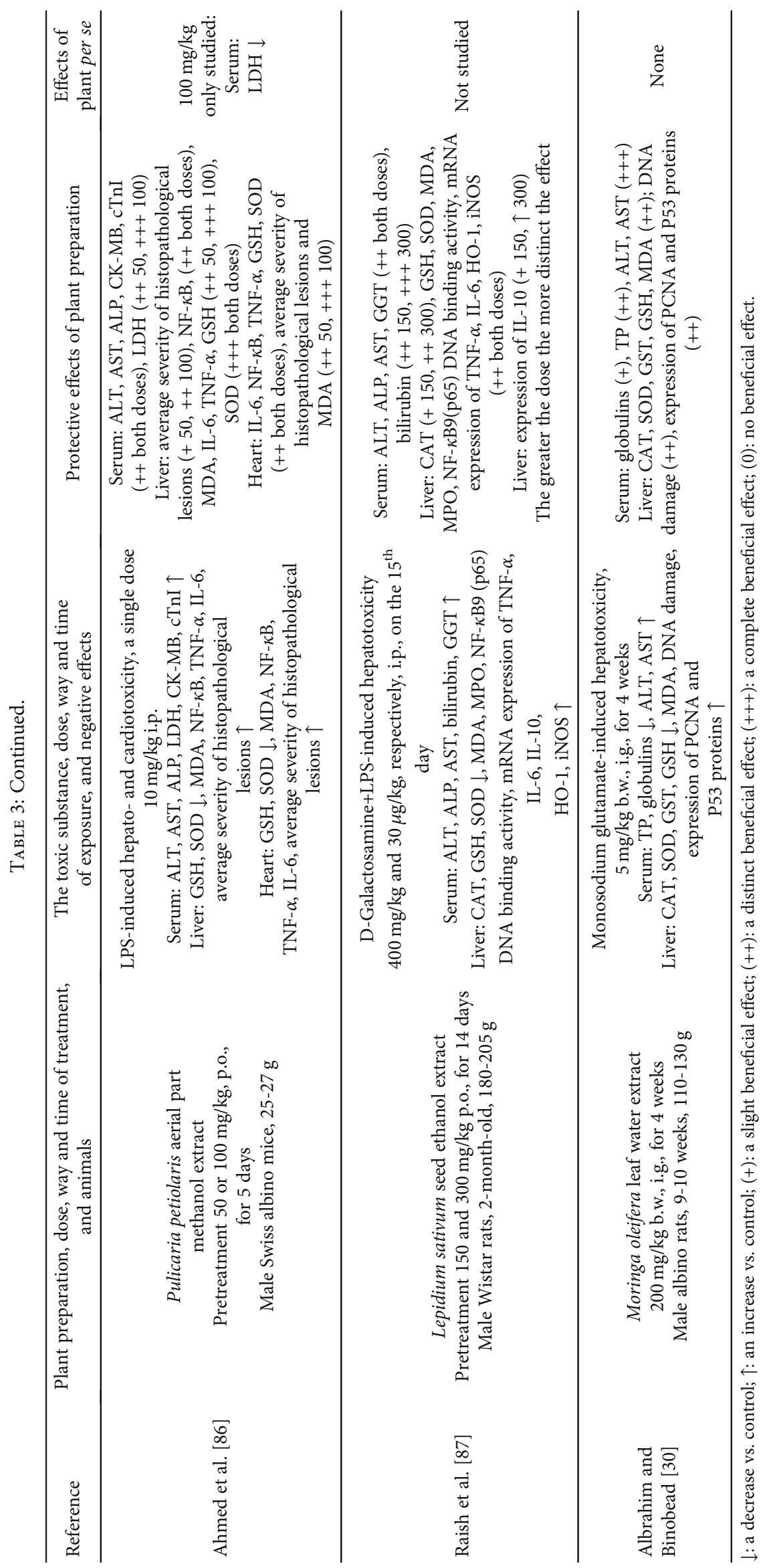




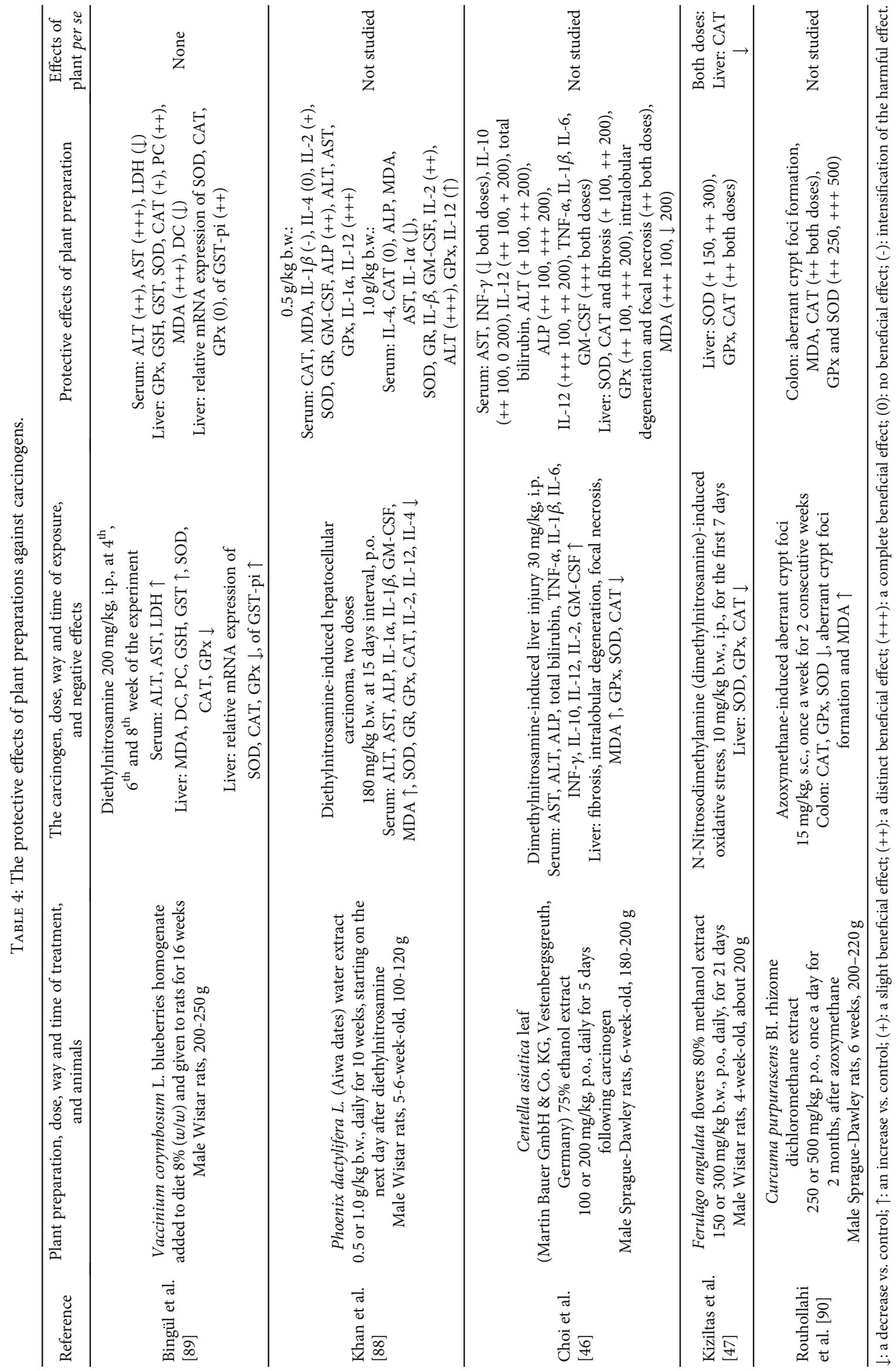


deterioration of antioxidant barrier, observed in animals exposed to ethanol $[44,56,91]$. The involvement of oxidant stress into ethanol toxicity was also showed by Phunchago et al. [92] who observed the protective influence of antioxidant vitamin C. The studies presented in the current review proved that plant materials showed a wide range of protective actions including ameliorating of liver markers, oxidative parameters, and alleviation of histopathological changes $[56,91,92]$. The involvement of LPS-TRL4-NF- $\kappa$ B pathway was also been proved $[56,65]$.

The detailed results of the performed studies are presented in Table 5.

\subsection{The Protective Influence of Plant Preparations against} Toxic Effects of Antipyretic and Analgesic Drugs. The application of antipyretic and analgesic drugs has been growing rapidly in recent years. Acetaminophen, known also as paracetamol, N-acetyl-p-aminophenol or APAP, a substitute of aspirin, is one of the most often used over-the-counter medicines. However, its application can cause severe hepatotoxicity, and this fact is all the more dangerous because of possible overdose resulting from self-administration $[18,22$, 40, 95]. Another side effect, connected with paracetamol application, is nephrotoxicity $[22,40]$. The harmful action of acetaminophen includes oxidative stress, particularly the depletion of GSH and protein sulfhydryl groups blocking [96]. Several studies revealed the possibility of plant extract application as protective adjuvants, wherein Moringa peregrine, Genista quadriflora, Teucrium polium geyrii, and Cassia surattensis showed the best influence which included not only amelioration of liver damage markers but also improvement of antioxidant parameters and reduction of the lipid peroxidation process $[19,20,96]$.

The details concerning the mentioned investigations are presented in Table 6.

\subsection{The Protective Influence of Plant Preparations against} Toxic Effects of Antibiotics. Not only are antibiotics used for the treatment of Gram-negative bacterial infection, but they also can cause side effects to occur [98, 99]. Gentamycin belongs to those which are used in case of strains resistant to other antibiotics, but its application can lead to hepato and nephrotoxicity [28]. The similar properties are shown by an antibiotic polymyxin, whose application was ceased because of its nephrotoxicity, but an increased drug resistance of Gram-negative strains has rendered it being used again [99]. Oxidative stress as well as inflammation processes was suggested to take part in the development of the mentioned negative effects $[29,98,99]$. Materials obtained from plants containing antioxidant components and affecting immune functions were investigated as to their possible protecting application, and the results seem to be promising although they also pointed to the necessity of taking proper precautions and precise choosing the dose as in some cases the higher dose showed a better influence $[29,98]$, while other authors reported quite opposite results [28].

The details concerning the above mentioned issues are presented in Table 7.
2.8. The Protective Influence of Plant Preparations against Toxic Effects of Anticancer Drugs. Cancer successful therapy is often a great problem because of the side effects of the applied agents which include deterioration of reproductive proficiency [23], nephrotoxicity [16, 100], and hepatotoxicity [37] and cardiotoxicity [26]. The results of the studies presented below clearly show that the toxic action of anticancer drugs is strongly connected with the prooxidative processes, deterioration of antioxidant barrier, and histopathological changes. The extracts of different plants, used as spices and drugs in traditional medicine for centuries, were studied for their protective potential [101]. Both simple extracts and particular fractions $[25,26]$ proved their protective properties which included the amelioration of the disturbed oxidant parameters. Antioxidant and antiapoptotic properties of plant extracts were confirmed by in vitro investigations performed on renal tubular epithelia cells [100] and cardiomyocytes [25]. Histopathological changes were also found to be relieved by plant materials $[16,23,24,26,102]$.

The details concerning the above mentioned issues are presented in Table 8.

\subsection{The Protective Influence of Plant Preparations against} Side Effects of Various Drugs. Many drugs' administration is accompanied with numerous side effects which cause life complication and may negatively influence patients' compliance. These facts prompted the searching for any adjuvants reversing or at least alleviating side effects. Recently, a growing interest in plant origin substances, often those used in traditional medicine, is being observed [104, 105]. The studies presented below revealed the effectiveness of plant extracts against toxicity of diverse drugs: psychiatric (lithium carbonate), thyrostatic (Propylthiouracil), and cardiac activity stimulators (Isoproterenol), a contrast medium (Iodixanol), and dermatological medicine (Triamcinolone acetonide). The negative influence of the studied drugs often included deterioration of antioxidant barrier [105, 106]. The studied preparations showed beneficial effects, and in vitro studies confirmed their antioxidant potential [104, 107].

The details concerning the above mentioned issues are presented in Table 9.

\subsection{The Protective Effects of Plant Preparations Observed in Animal Models of Different Disorders}

2.10.1. The Protective Effects of Plant Preparations Observed in Arthritis. Arthritis has recently become a serious, worldwide problem as this disease is related with pain and physical disability, and no effective therapy except for a surgery can be applied [49]. As the risk of it increases with age, the growing spam life contributes to the still enhancing incidence. Plant substances were found to prevent enhancement of the proinflammatory cytokines like IL- $1 \beta$, IL- 6 , and TNF- $\alpha$, involved into osteoarthritis pathogenesis of OA. Additionally, the reduction of metalloproteinases responsible for joint damage as well as upregulation of their inhibitors-TIMPs and extracellular matrix components-was observed [48, 49]. Furthermore, plant origin substances were reported to reverse 
oxidative parameters' disturbances, also taking part in osteoarthritis development [55].

The detailed outcomes of the performed studies are collected in Table 10.

2.10.2. The Protective Effects of Plant Origin Materials in Cases of Neurodegenerative Disorders. The next type of disorders studied with using an animal model was neurodegenerative diseases. ROS have been reported to be involved in the development of Alzheimer's, Huntington's, and Parkinson's diseases. Extracts obtained from plants used in traditional Chinese and Ayurveda medicine, possessing numerous therapeutic properties and containing antioxidant components, were shown to exert a considerable beneficial influence [31, 32, 39].

Traumatic brain injury, regarded as a worldwide grave challenge being a cause of many death and disability cases, is considered to need an effective therapy. Water extracts of plant commercial products were revealed to show a beneficial influence on immunological and oxidative parameters $[38,60]$.

Psychiatric disorders like anxiety or depression were also proved to be connected with neurodegenerative disturbances as well as changes of immunological and oxidative parameters which were alleviated by plant extracts $[111,112]$.

The detailed outcomes of the performed studies are collected in Table 11.

2.10.3. The Protective Effects of Plant Origin Materials in Cases of Animal Menopause Model. In menopausal women, the deficiency of sex hormones can lead to various disturbances of organism. The research concerning hormone replacement therapy showed that it can cause different side effects, so the attention was paid to nonpharmaceutical agents, all the more because plant flavonoids were proved to possess phytoestrogen properties [114]. In the performed studies, plant origin materials improved some elements of lipid profile and oxidative parameters deteriorated by ovariectomy [115]. Bone mineral density in rats was also ameliorated, although this effect became less distinct along with lengthening of the experiment [114]. However, in some cases, the obtained results were not so distinctly beneficial [116].

The details of the performed studies are collected in Table 12 .

2.10.4. The Protective Effects of Plant Origin Materials in Lung Disorders. Plant origin substances were shown to possess some efficacy against lung disorders, and the beneficial effect included the improvement of oxidative and inflammatory parameters, morphological disturbances, and factors controlling extracellular matrix functions and vascular homeostasis [117-119].

The details of the performed studies are collected in Table 13 .

2.10.5. The Protective Effects of Plant Origin Materials in Lipid Profile Disturbances. Lipid profile disturbance is associated with severe diseases like diabetes as well as hepatic and cardiovascular disorders [120]. It is rated among the main factors causing disability and death [34]. Factors which were used to induce such a condition were also found to cause intensification of prooxidative processes connected with deterioration of antioxidant defence and DNA damage. Plant preparations proved to display beneficial effects, although only in one case per se influence was studied [120].

The detailed results of the performed studies are collected in Table 14.

2.10.6. The Protective Effects of Plant Origin Materials in Ischaemia/Reperfusion Model. Ischaemia/reperfusion damage is a serious problem which can occur as a consequence of surgery, e.g., transplantation or coronary bypass, and may lead to severe injuries, resulting among other things from increase in ROS generation. Pretreatment with plant materials, obtained from species used in traditional medicine, was found to be effective against prooxidative processes and histopathological changes observed in ischaemia/reperfusion animal model [123-126].

The detailed results of the performed studies are collected in Table 15.

2.10.7. The Protective Effects of Plant Origin Materials in Animal Model Diabetes. Plant origin substances were observed to be effective at reversing disturbances observed in the course of diabetes. A wide range of agents was studied, simple extracts, combinations of two extracts as well as an oil, banana pasta or substances separated from plant material. A great variety of species was investigated, including herbs, fruits, or vegetables. Many of them had been known as being useful in different fields of medicine, sometimes from ancient times [66, 127-129]. In several studies, biochemical, oxidant, and inflammatory parameters in the blood and organs including the lens, brain, liver, pancreas, kidney, and heart were found considerably improved or restored by different materials [42, 57, 66, 128, 129]. Histopathological investigation revealed that plant preparations showed a considerable ability to attenuate pancreas, kidney, and liver damage observed in the animal model of diabetes [127, 128, 130]. The beneficial influence of plant extracts on the deterioration of sperm quality [131], diabetes-associated cataract, and retinopathy and an ability to suppress MAPK signal transduction [42] and the amyloidogenic pathway [57] were reported. However, there are limitations of these investigations as in most of them the effect of the applied plant substance was not studied.

The detailed results of the performed studies are collected in Table 16.

2.10.8. The Protective Effects of Plant Origin Materials in Animal Model of Obesity. Plant origin preparations were also investigated as to their potential to prevent pathological processes connected with obesity. This direction seems to be of great importance as obesity and related disturbances, resulting from sedentary lifestyle as well as excessive consumption, are becoming more and more serious world problem [132, 133]. Diet-induced obesity was found to be connected with different disturbances of various parameters including liver markers and lipid profile as well as inflammation, lipogenesis, and oxidative balance. The performed research revealed 


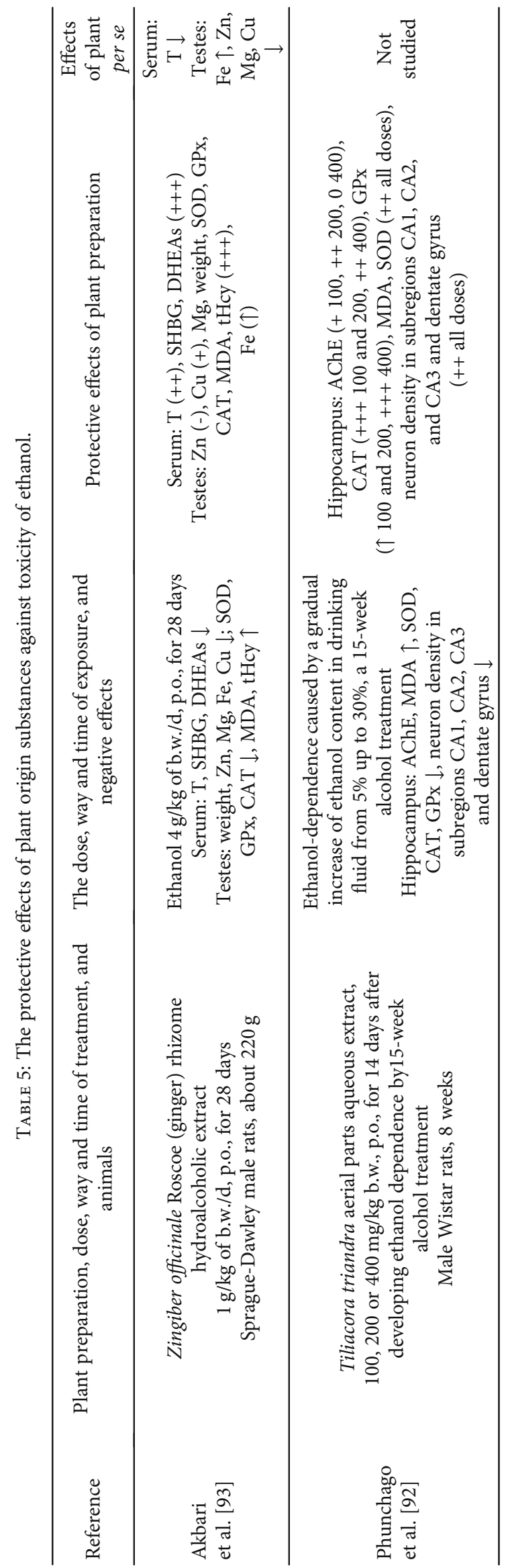

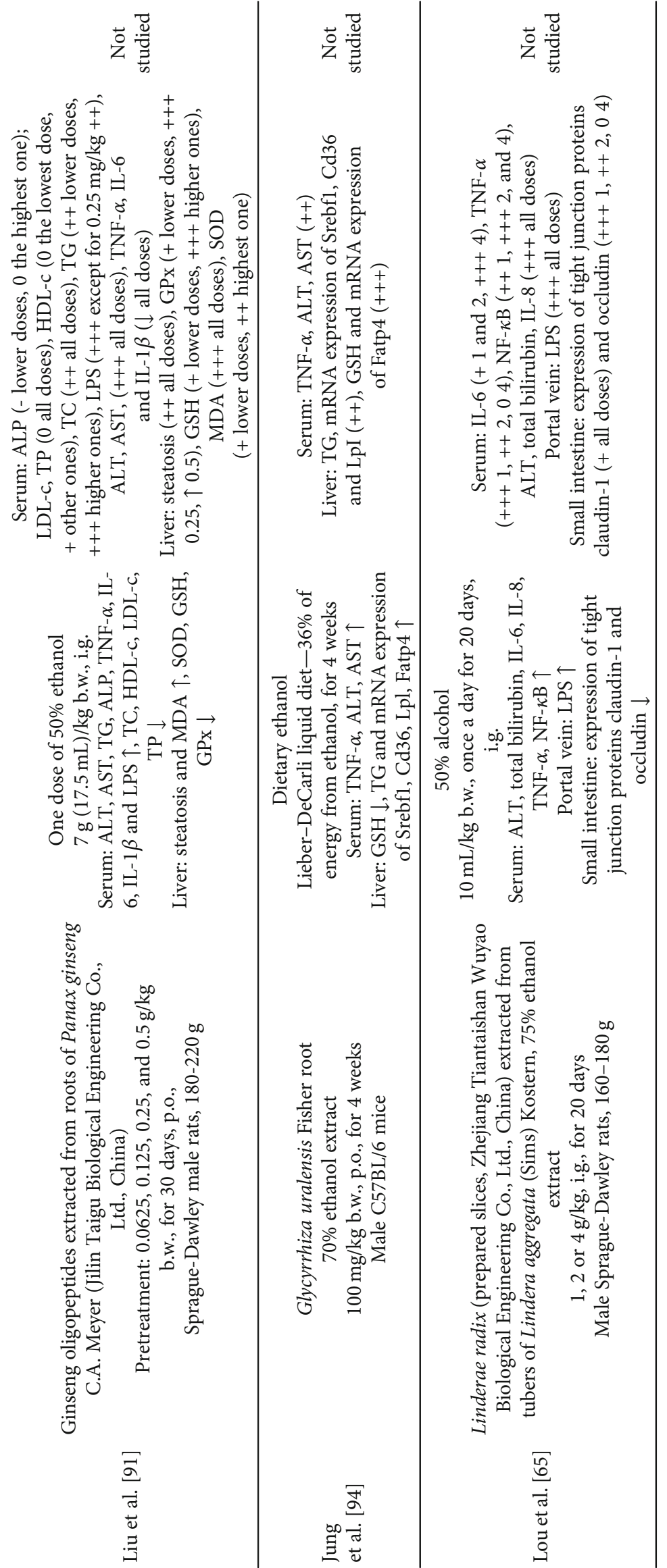




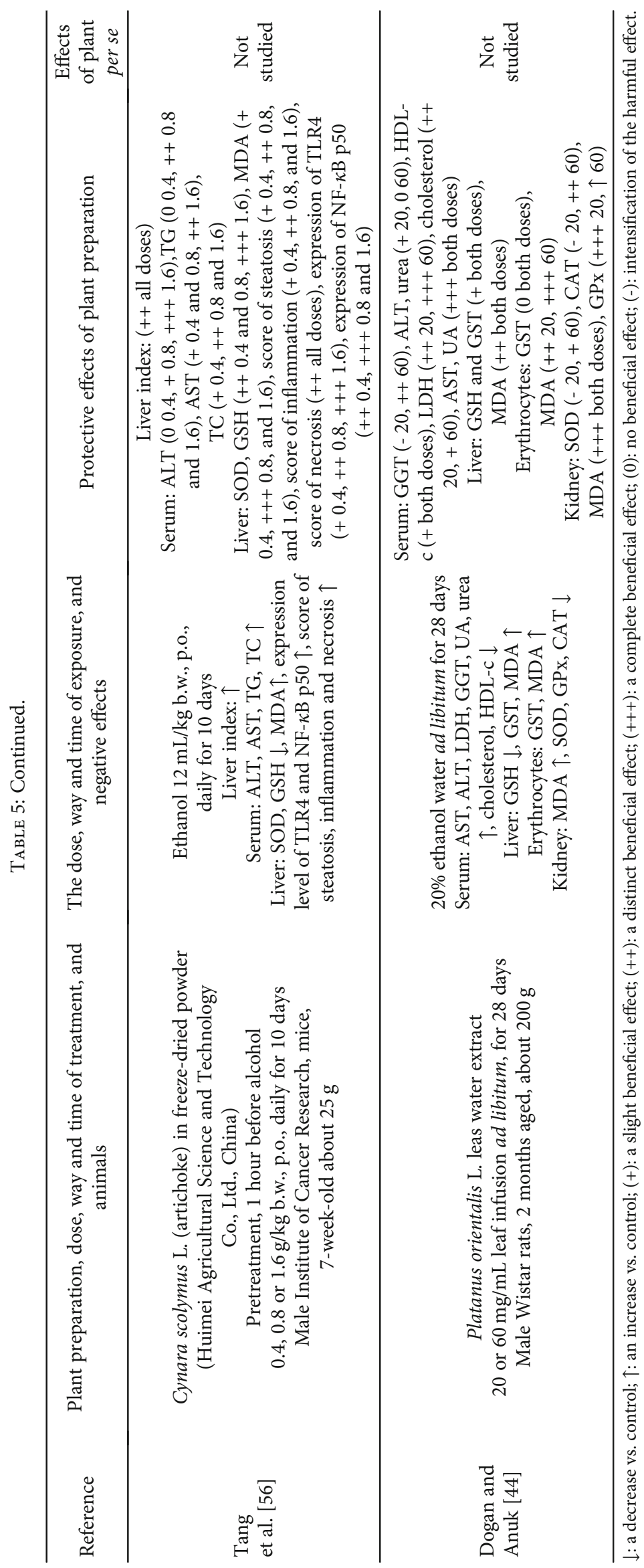




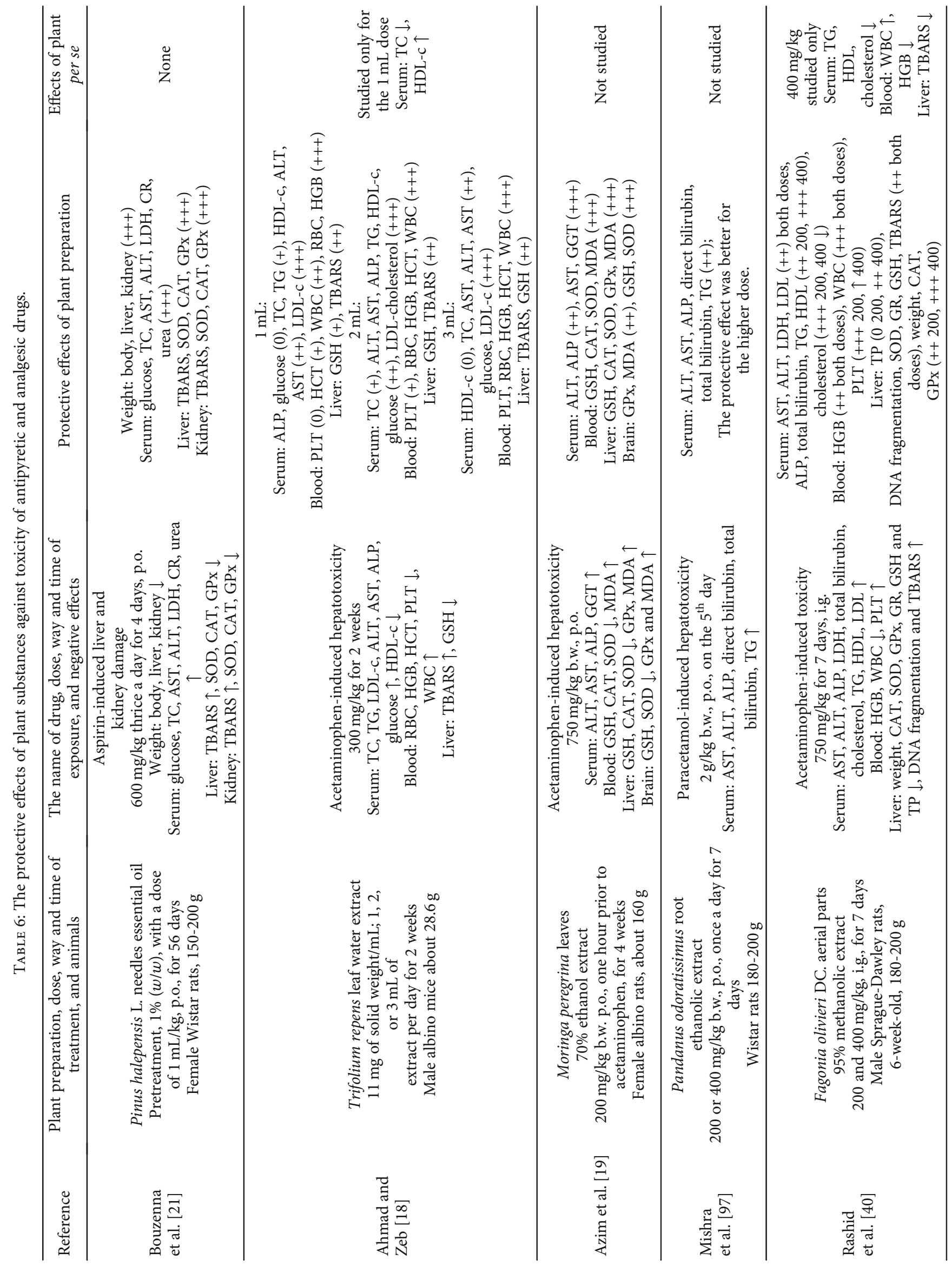




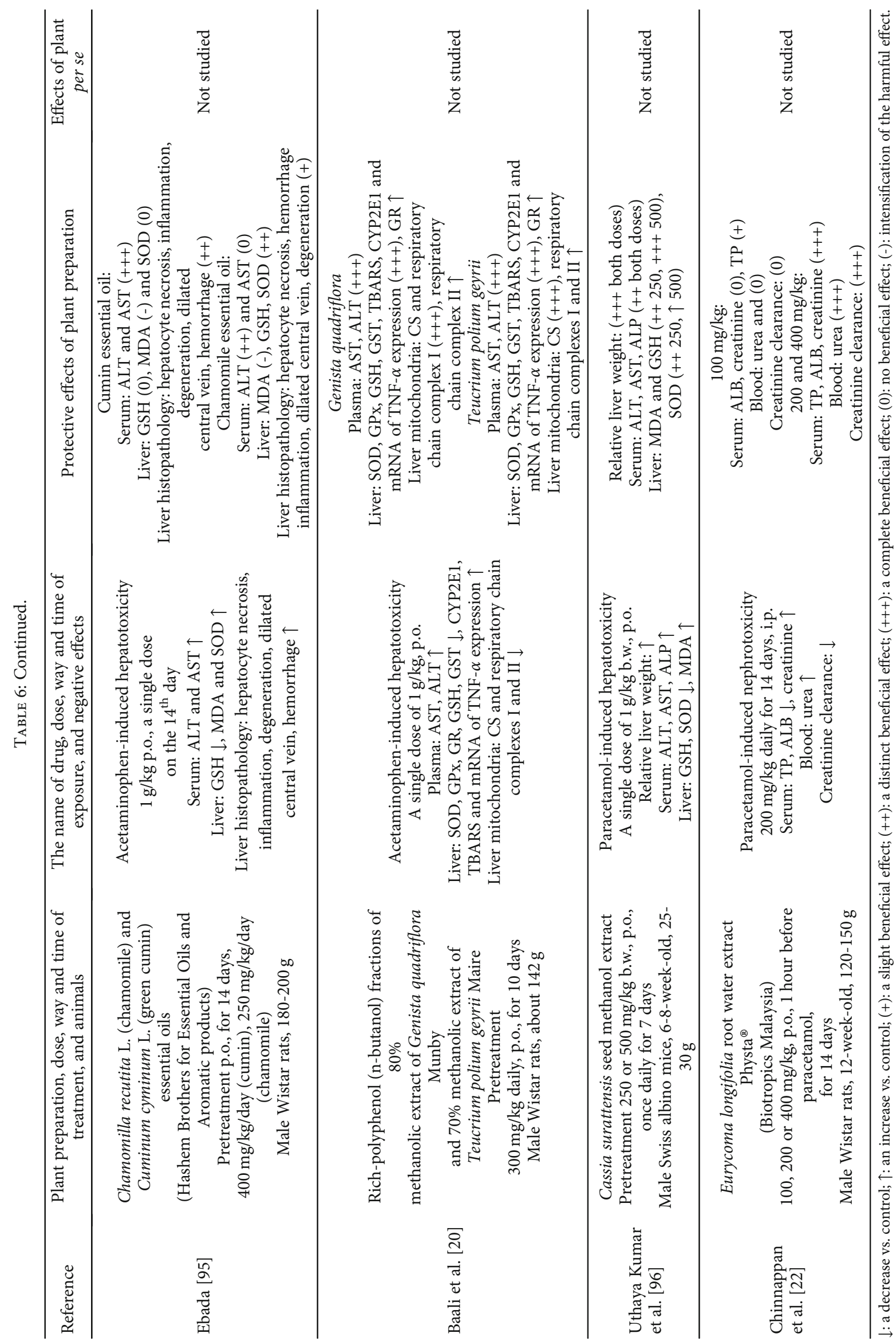




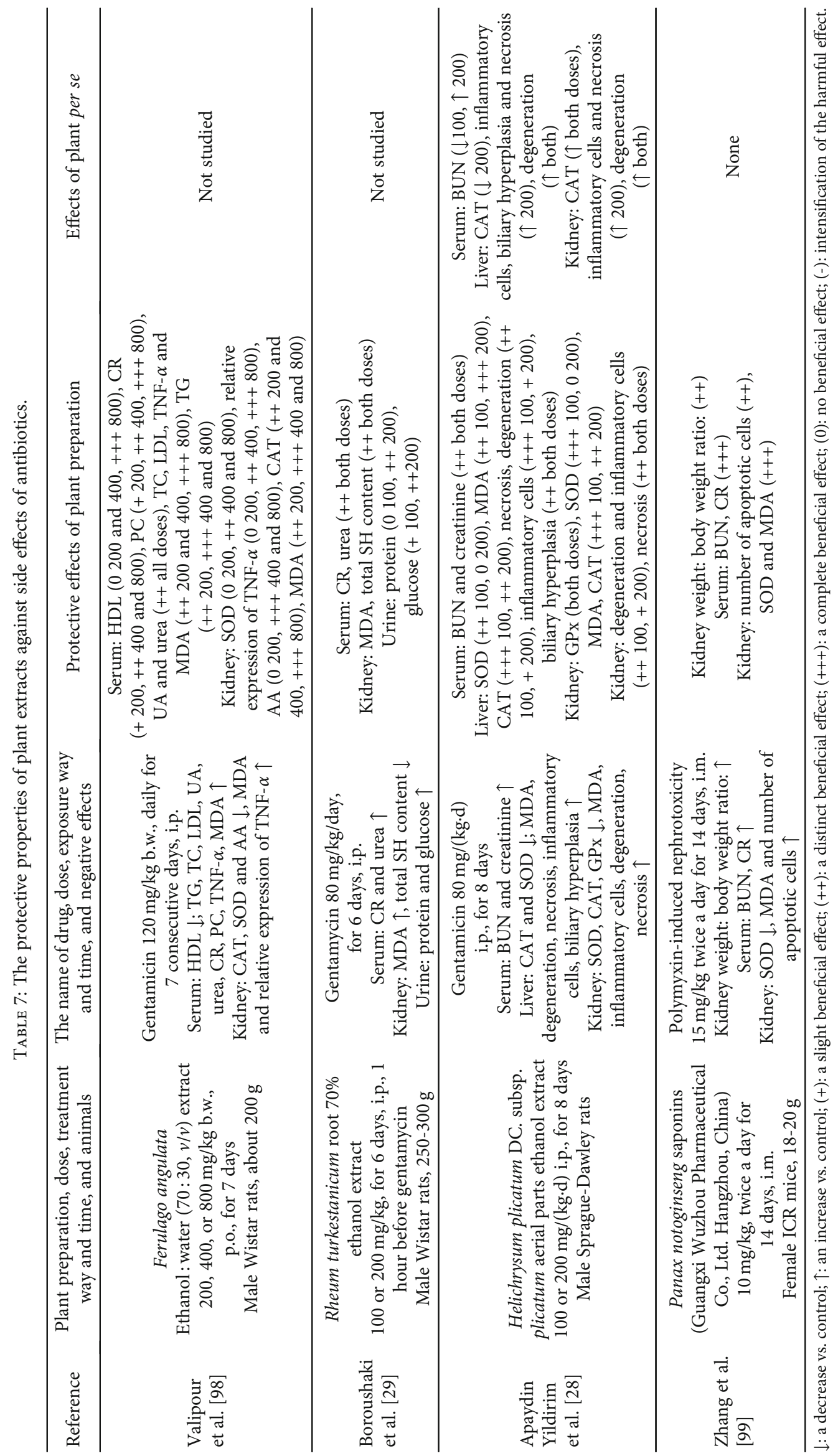




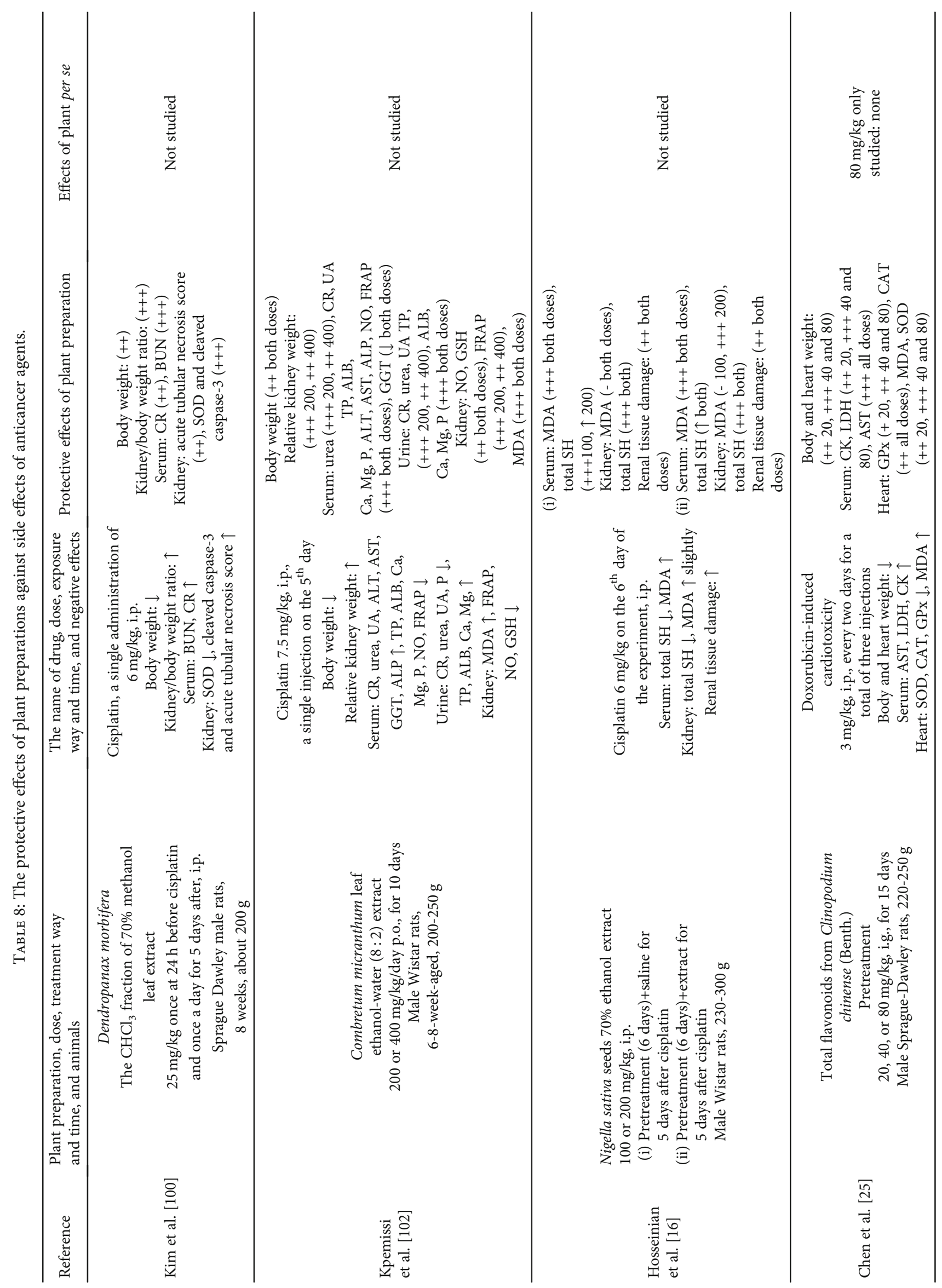




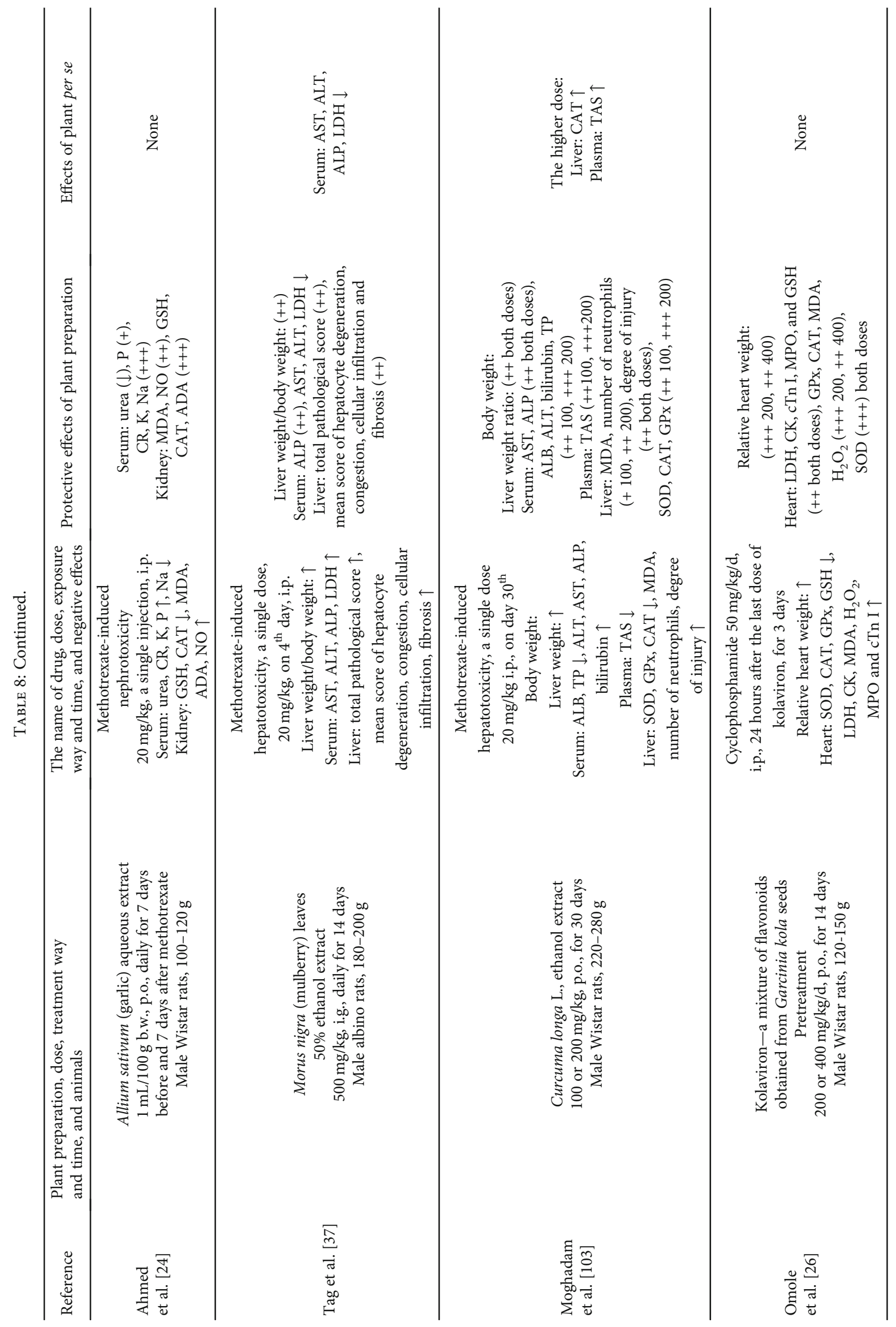




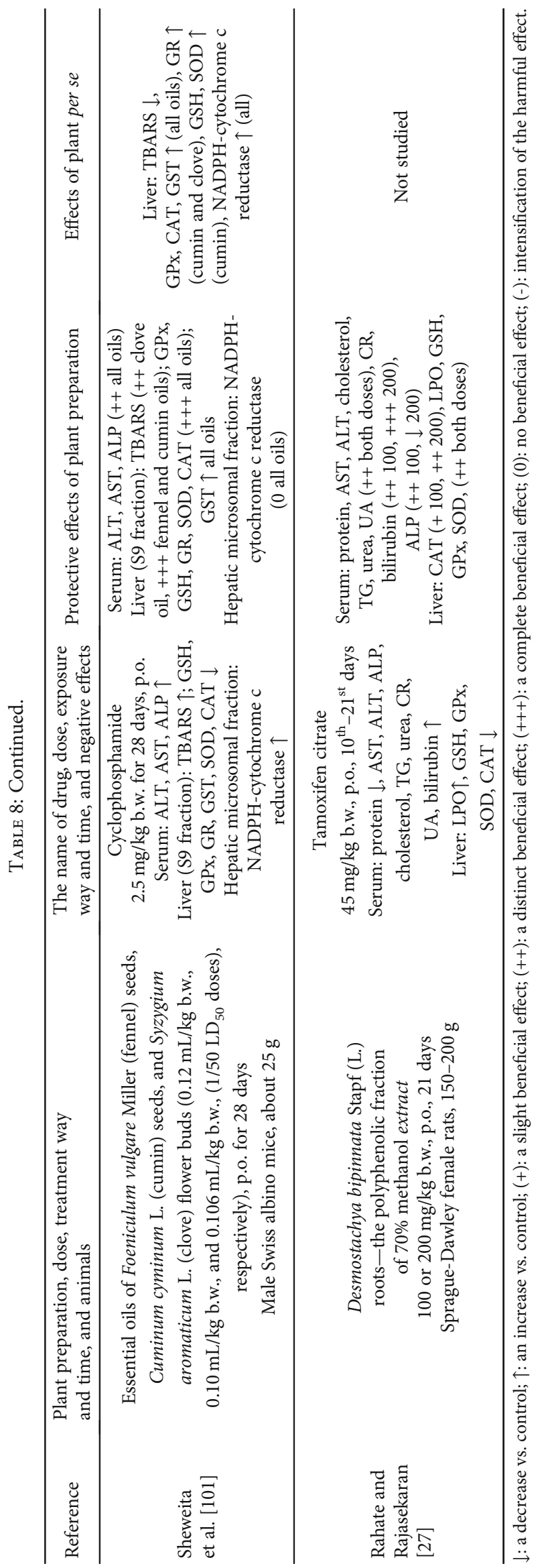




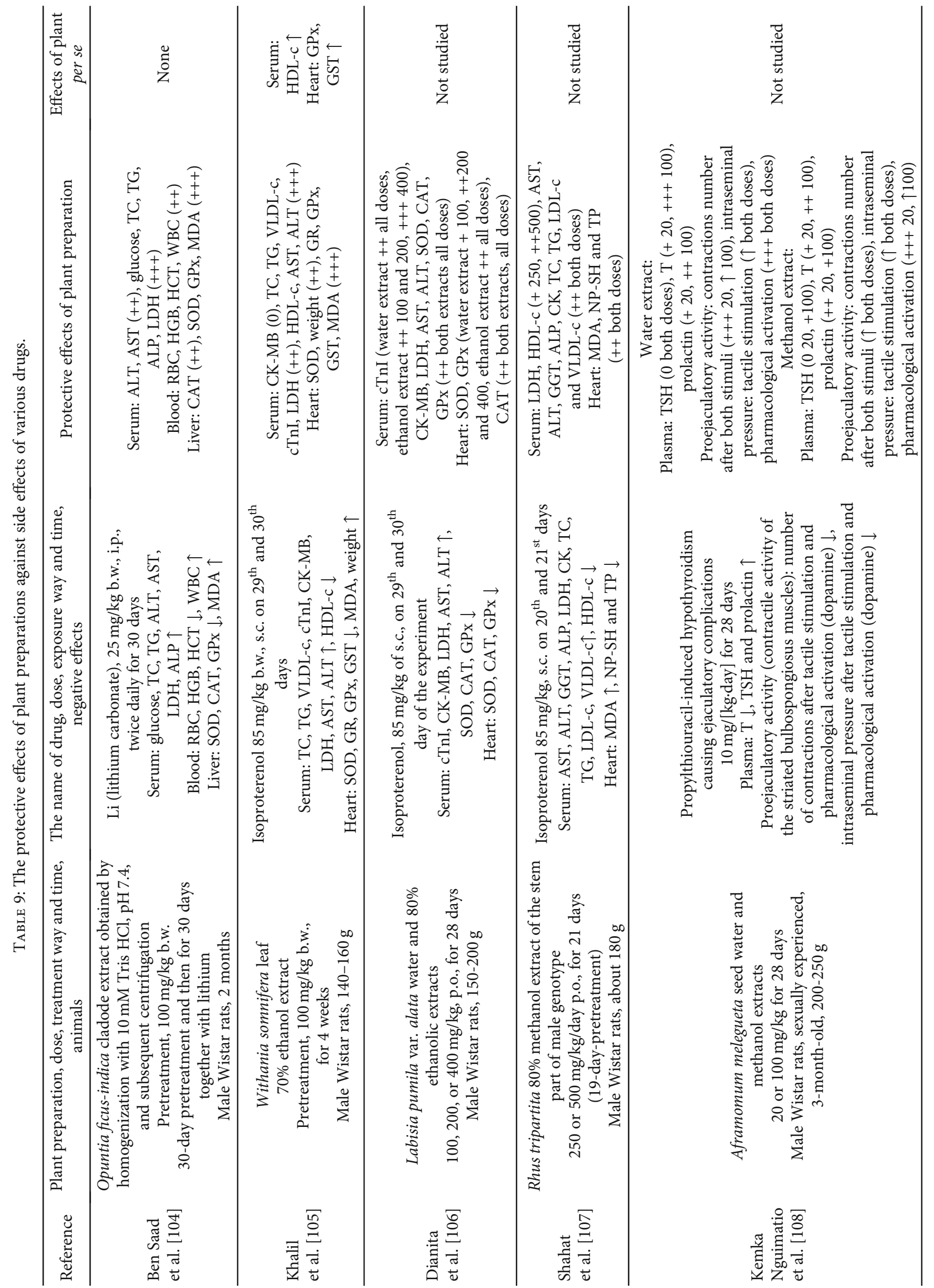




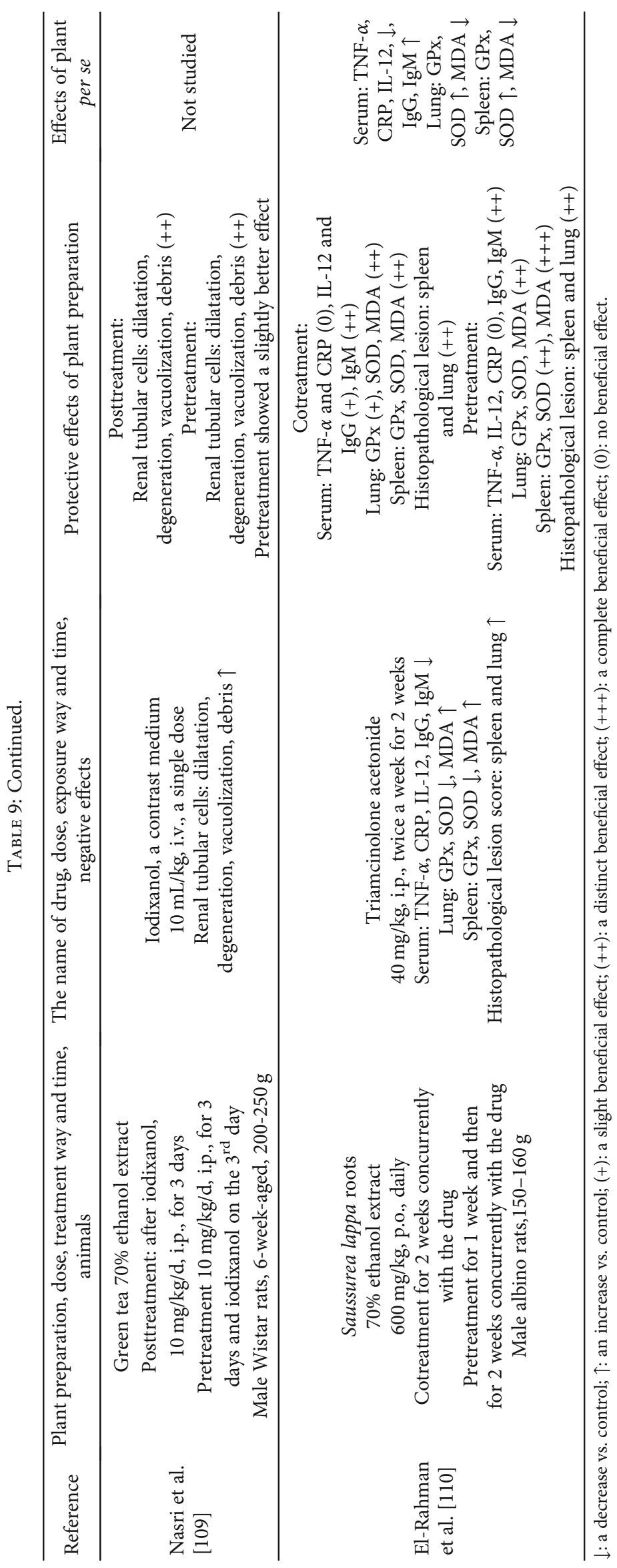




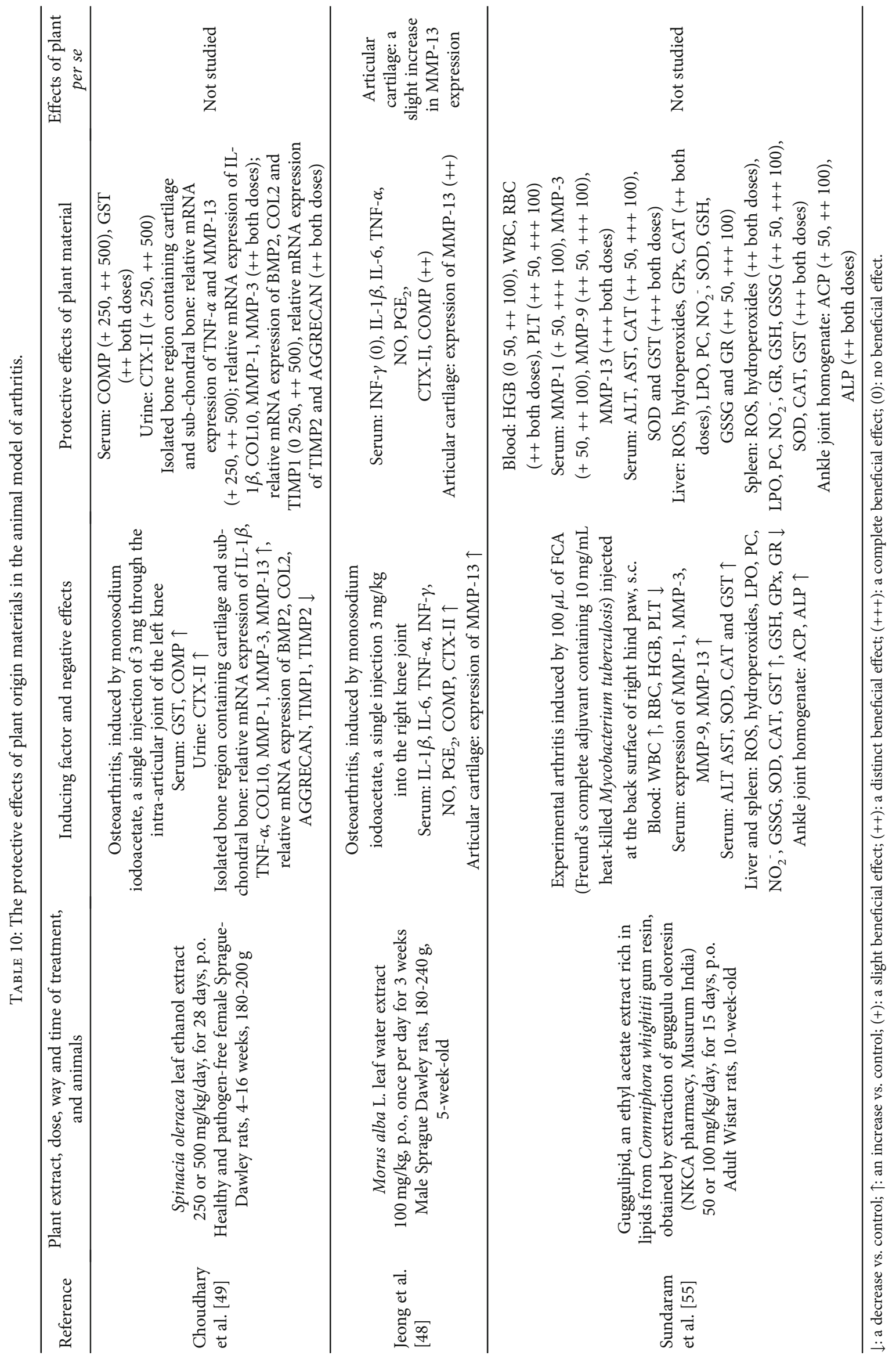




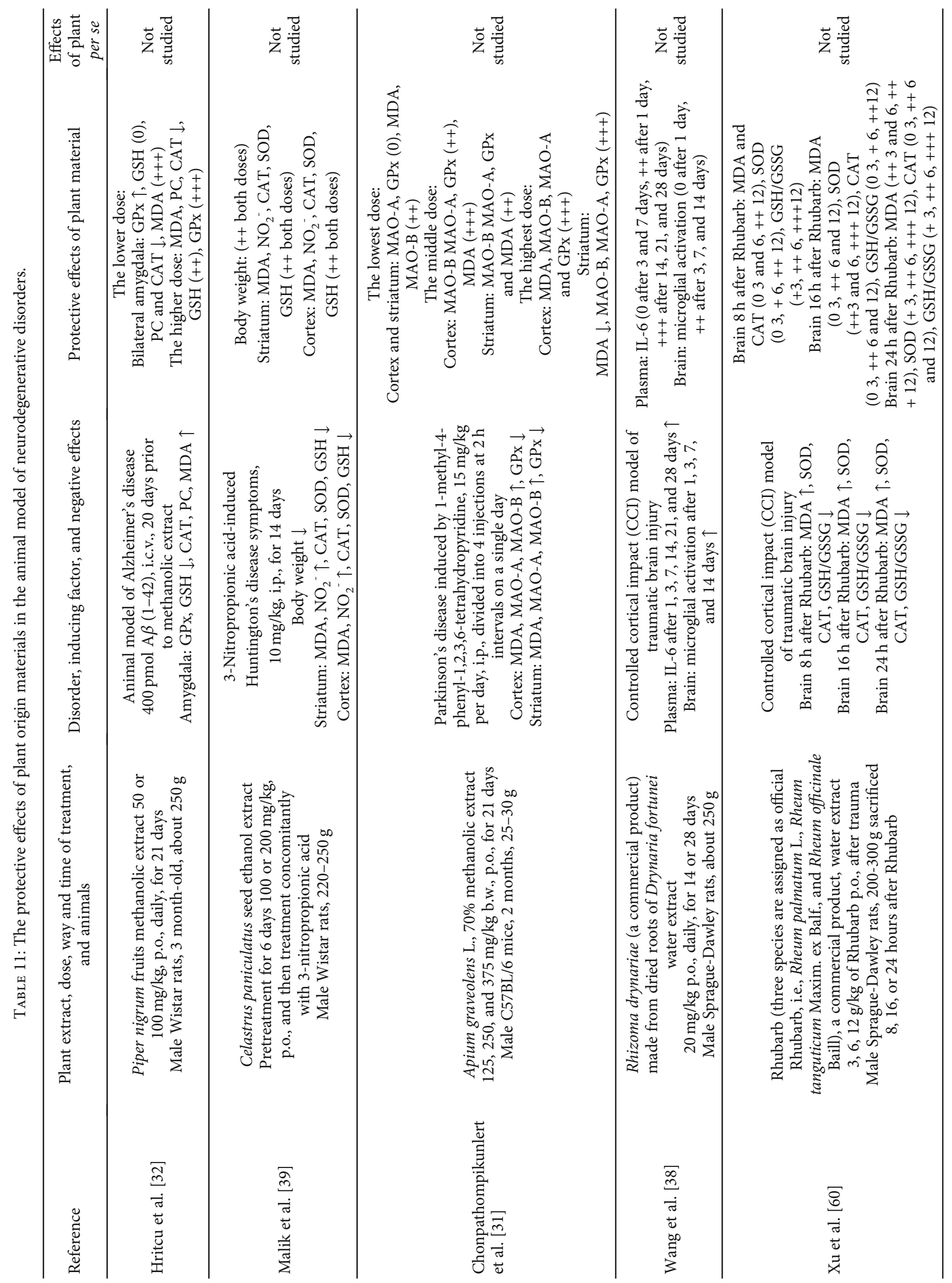




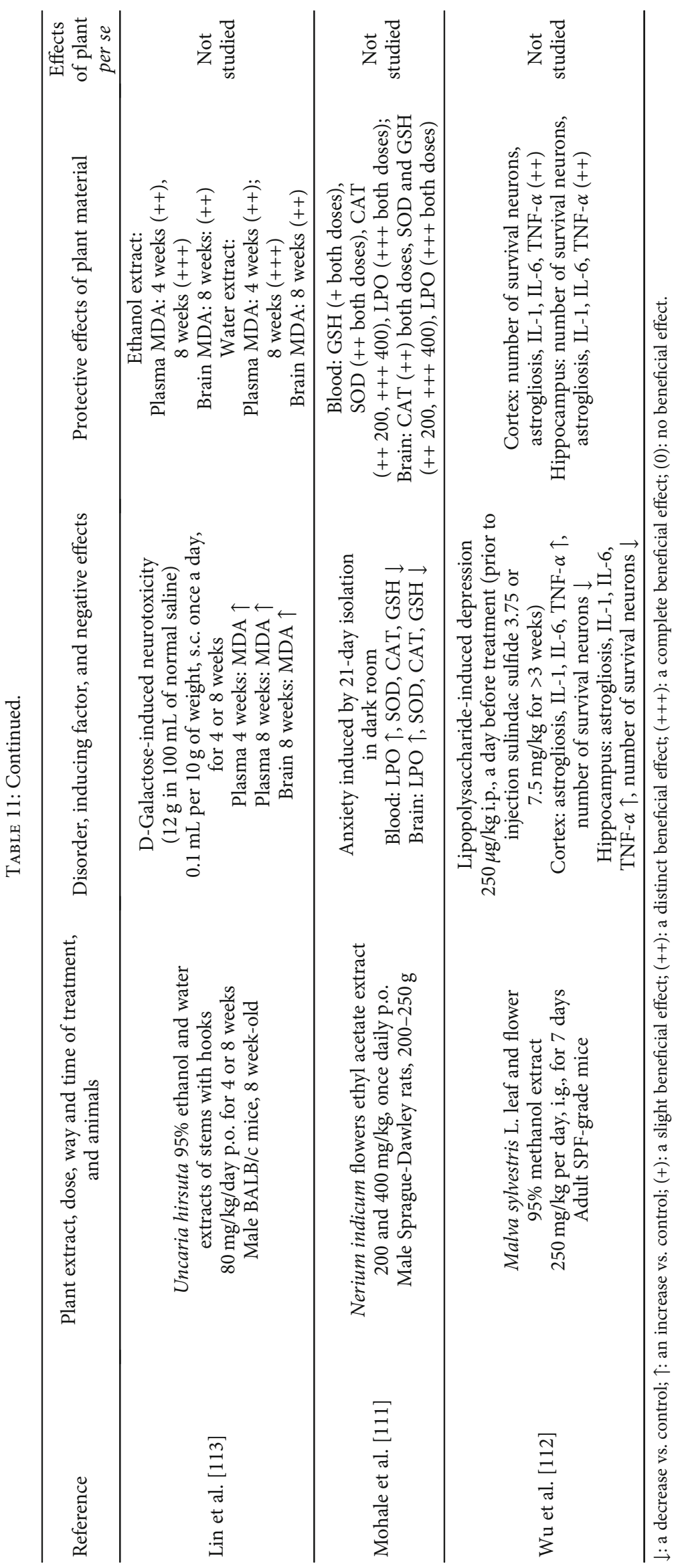




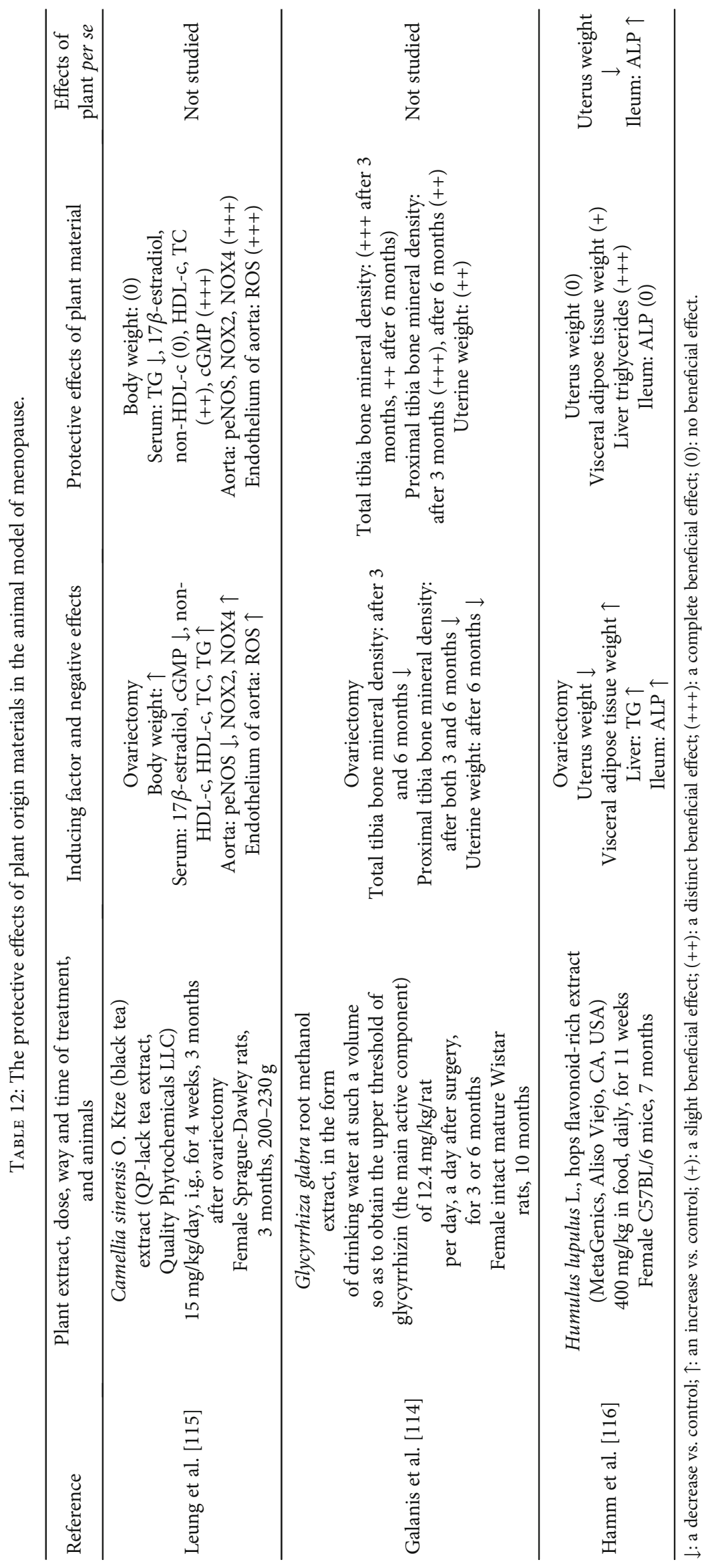




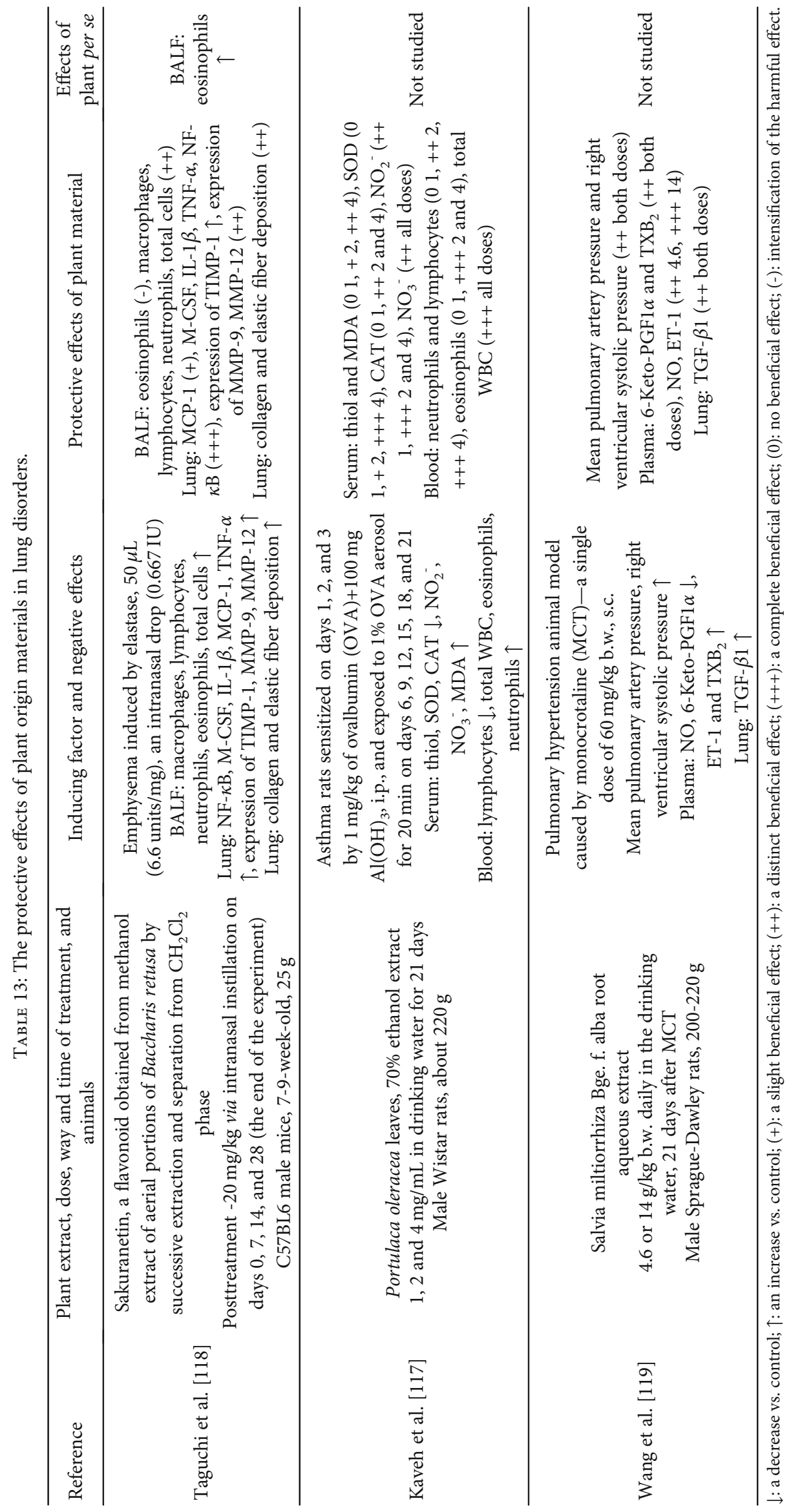




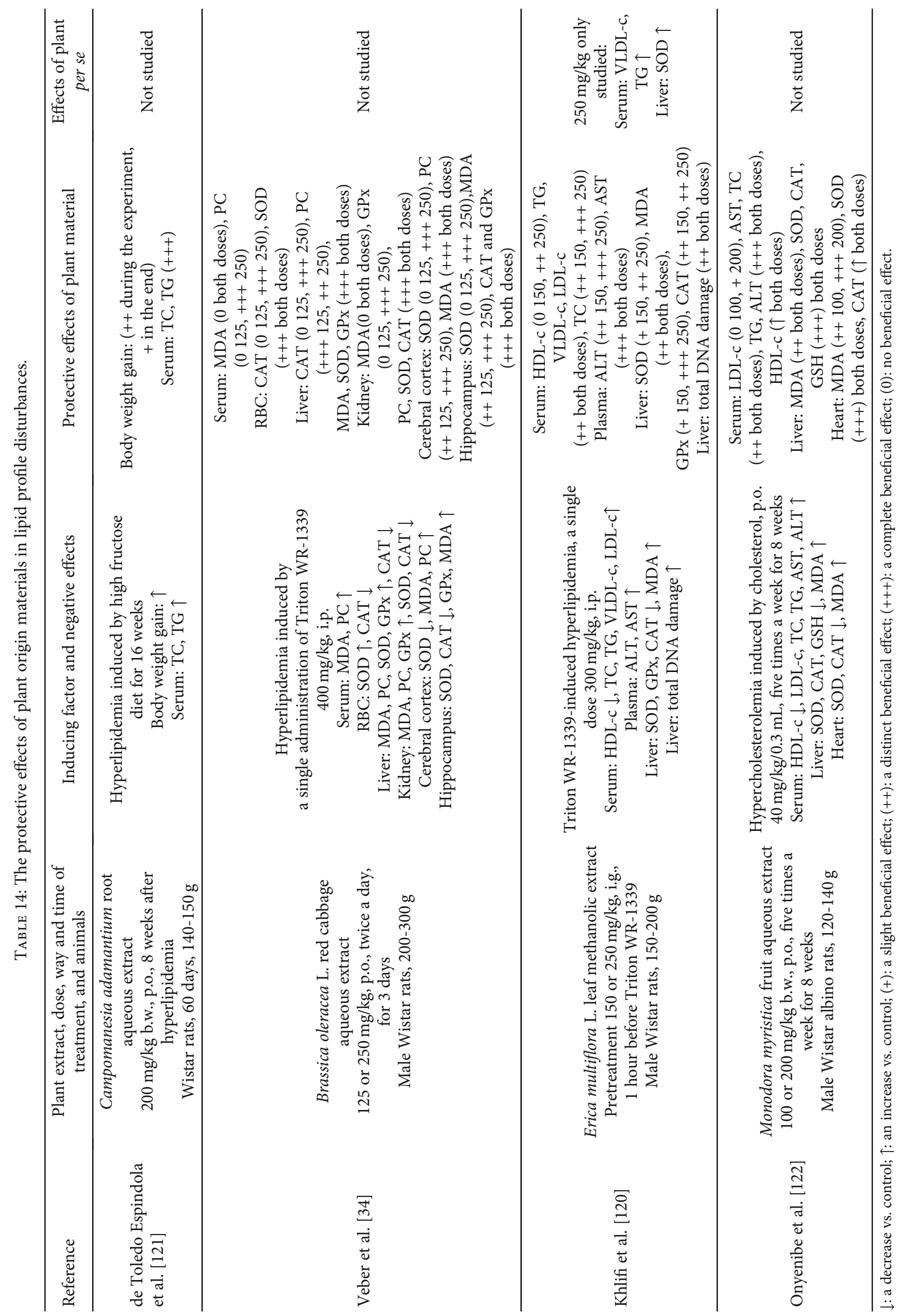




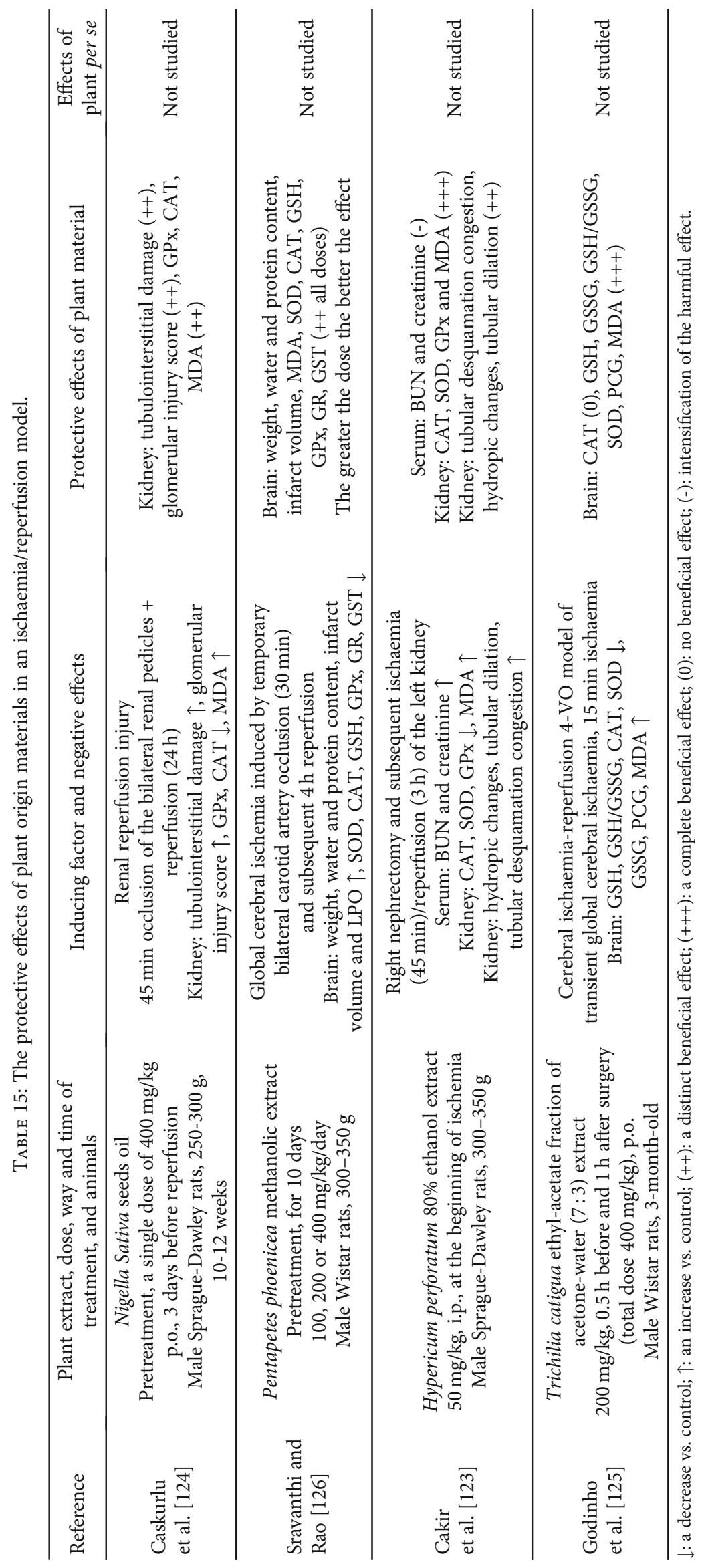




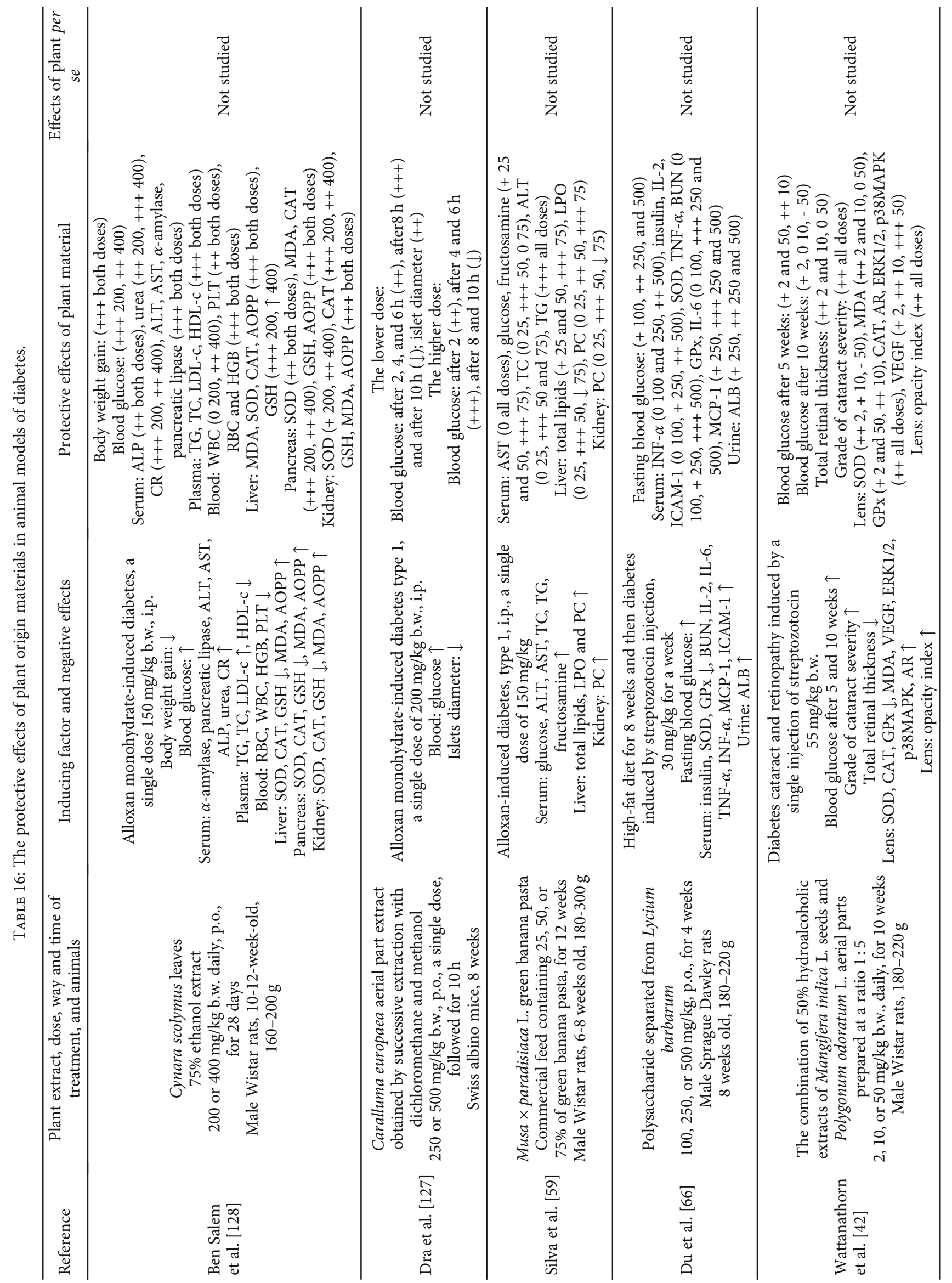




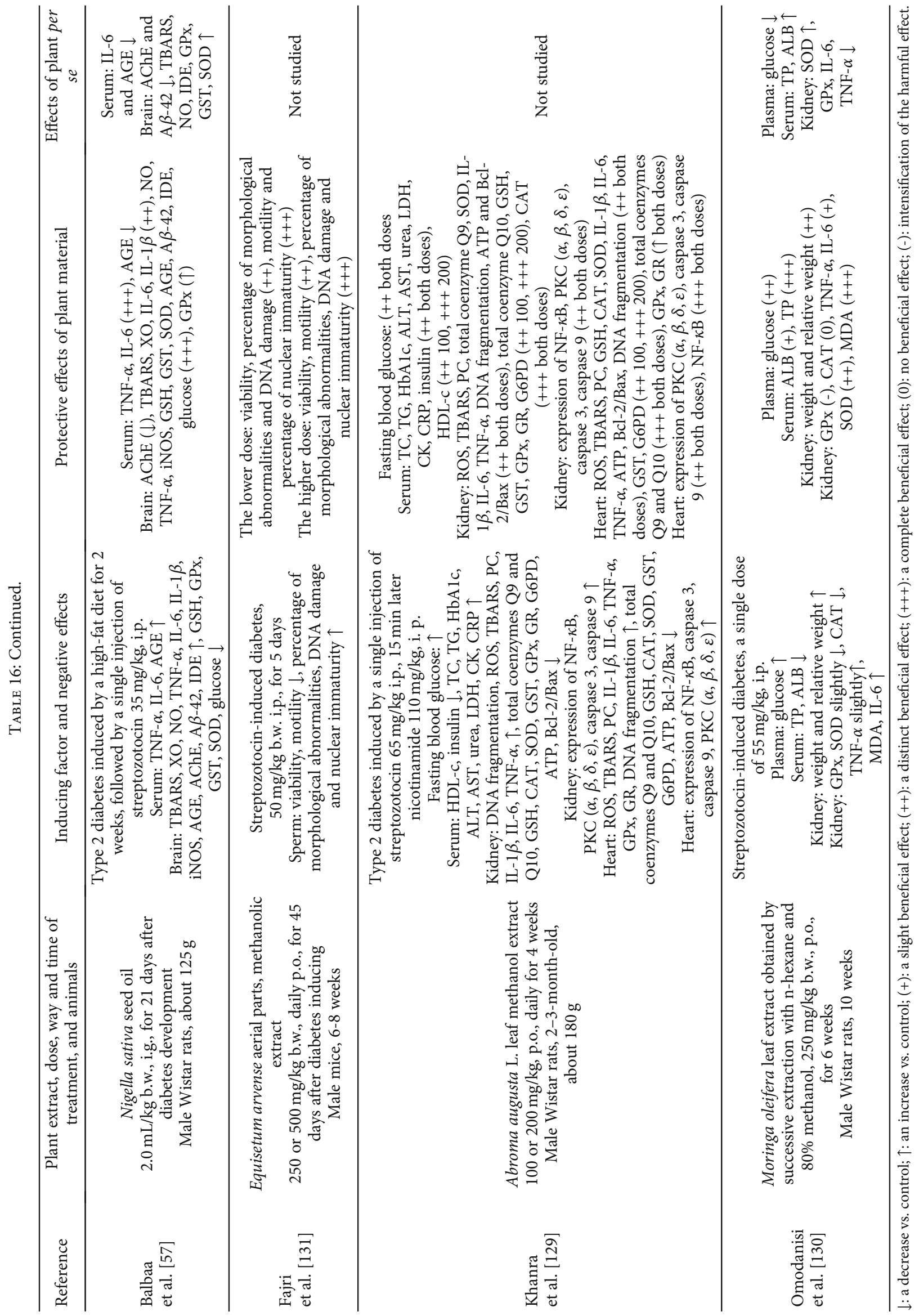


the protective effect of plant preparations which involved improvement of oxidative balance by activation of the Nrf2/HO-1 antioxidant pathway [61] and the ameliorating effect on lipid status $[132,133]$. The latter was also confirmed in vitro as the lipolysis-promoting influence in 3T3-L1 cells was observed [61]. In mice fed a high-fat diet, coadministration of Euterpe oleracea extract reversed the changes of lipogenic proteins expression in the liver. Additionally, the investigated preparation increased hepatic expression of ABCG5 and ABCG8 transporters responsible for removing excess of cholesterol by secretion into bile [43].

The detailed results of the performed studies are collected in Table 17.

\subsubsection{The Protective Influence of Plant Preparations against} Gastric Ulcer-Inducing Factors. The gastric ulcers are regarded as the most common disease of gastrointestinal tract, but they can be caused by many various factors. Therapy of different disorders with using nonsteroidal antiinflammatory drugs like indomethacin and excessive consumption of alcohol belong to important ones $[45,134]$. As pharmaceutical agents are not fully effective and their application may also be connected with development of side effects, an alternative ways of treatment became the subject of research. Plant origin substances showed a wide range of beneficial effects, including alleviated or reversed oxidative stress which was found to be involved into gastric ulcer etiology as well as mechanism of indomethacin toxicity [135-137].

The detailed results of the performed studies are presented in Table 18.

2.10.10. The Protective Effects of Plant Origin Materials in Animal Model of Different Disorders. The symptoms of many other various disturbances were affected in a positive way by using plant materials of experimentally confirmed antioxidant properties and containing acknowledged antioxidants like phenolic acids and flavonoids [36, 41, 138]. A wide range of diseases: lithiasis, thyroid disorders, retinal degeneration, irritable bowel syndrome, hyperthyroidism, periodontitis, and mammary gland hyperplasia, were studied, pointing to great possibilities "hidden" in plant origin agents.

The details of the performed studies are presented in Table 19.

2.11. The Protective Effects of Plant Origin Materials against Radiation. Plant extracts also showed some efficacy against radiation-induced damage. The research revealed the involvement of JAK-STAT pathway into the mechanism of the protective influence on the hematopoietic system [70]. Animal studies also showed the reversing effect of plant material on the disturbances of antioxidant defence caused by $\gamma$-radiation in blood and organs $[145,146]$. One of the recent in vitro investigations, performed on keratinocyte cells, confirmed the antioxidant action of a plant preparation against UVB radiation, which could contribute to development of new skin protective strategies [147].

The details of the performed studies are presented in Table 20.

\section{The Comparison of Plant Preparations with Standard Drugs and Supplements: The Dependence of Effects on Treatment Way and Doses}

The effects of plant origin materials were often investigated in comparison with those shown by standard drugs. The results clearly show that there may be a possibility to replace different medicines with plant preparations which do not cause so many severe side effects, but the detailed research must be performed before the final conclusions can be made.

The question of advantage of plant origin extracts over any standard drug is complicated, and a univocal answer is very difficult as in some cases the differences in the influence of the compared agents were strongly dependent on the applied dose $[45,135]$ and studied parameters $[115,129]$.

Hamm et al. [116] found that hops (Humulus lupus L.) flavonoid-rich extract protected against ovariectomyinduced visceral adiposity and increase in liver triglycerides observed in 7-month-old retired breeder C57BL/6 mice. However, particularly in case of the former parameter, the observed effect was not so distinct as that noted in animals receiving 17- $\beta$-estradiol. Additionally, hops extract could not prevent the loss of uterus weight caused by the surgery while estrogen showed quite a considerable reversing effect.

Leung et al. compared the effect of black tea extract with that exerted by estrogen in ovariectomized rats. The results were characterized by a considerable diversity. In case of body weight reduction, estradiol's benefit influence was much better. In contrast, aortic cGMP and serum TC and peNOS, NOX2, NOX4, and ROS generation in the aorta were affected in similar or even entirely the same way by both agents. Additionally, in case of serum TG the plant materials proved to possess much better ability to restore the values observed in sham-operated control animals [115].

3.1. The Comparison of Crude Extracts and the Particular Substances Separated from Plant Materials. The plant extract can show better properties than particular compounds administered alone as there may occur some synergistic effects among its components. Such an assumption could be supported by the results reported by He et al. [148] who compared the influence of Paeonia suffruticosa seed extract and 10 compounds (oligostilbenes) isolated from it with using an in vitro IL- $1 \beta$-induced osteoarthritis model. In the study performed on rabbit chondrocytes, IL- $1 \beta$ caused a significant decrease in viability and 10 studied components used alone showed an improving effect, but the intensity of this effect was markedly different, depending on the structure. However, the application of the extract containing all the oligostilbenes showed the best effect, comparable with that observed for diacerein-a drug of IL- $1 \beta$-inhibition action, used in osteoarthritis therapy. Such results made the authors suggest the possibility of synergism among the particular oligostilbenes.

3.2. Plant Preparations as Lipid Profile Regulating Agents The Comparison with Standard Drugs. Plan preparations were studied in regard to the possibility of their application 


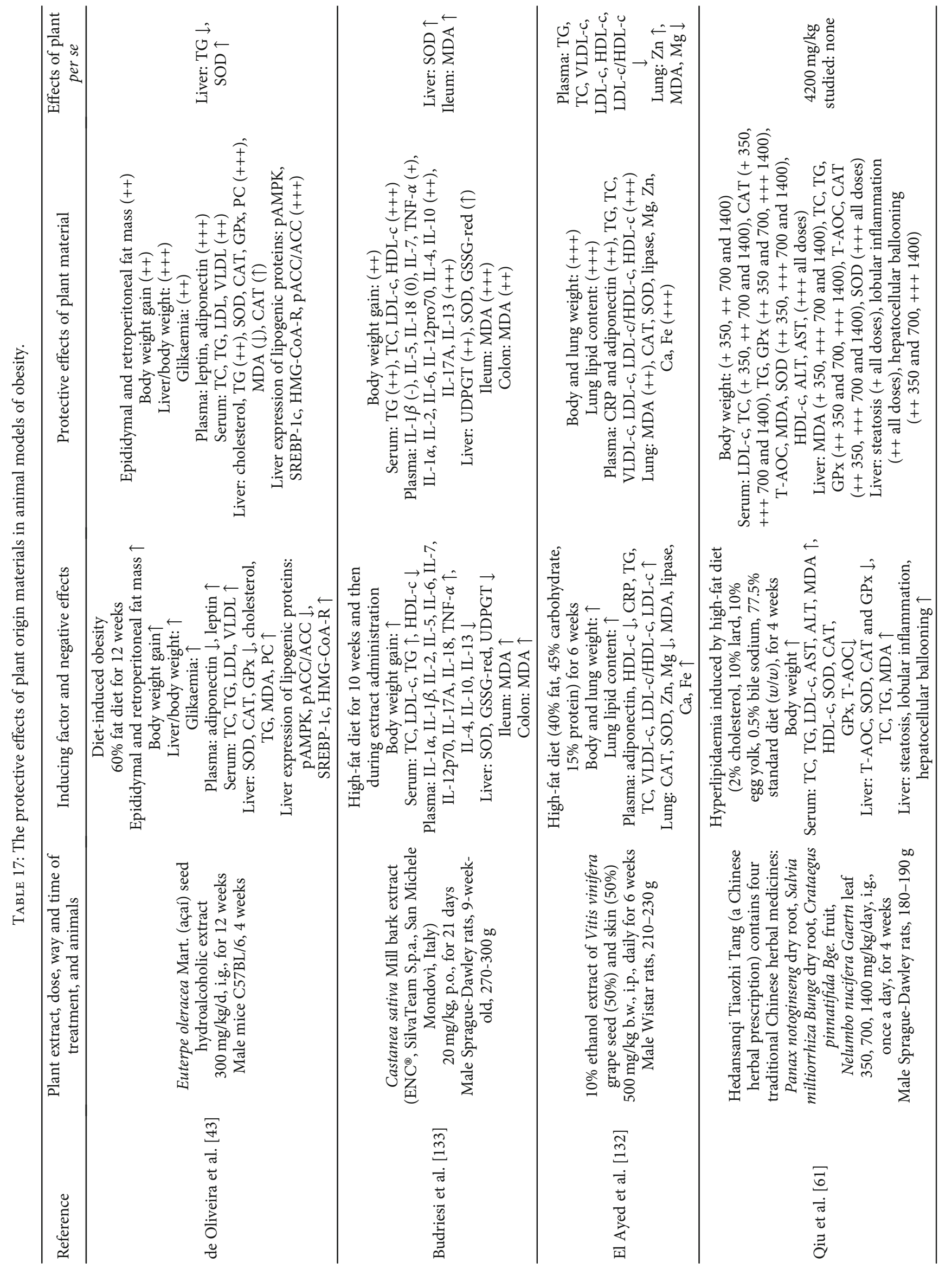




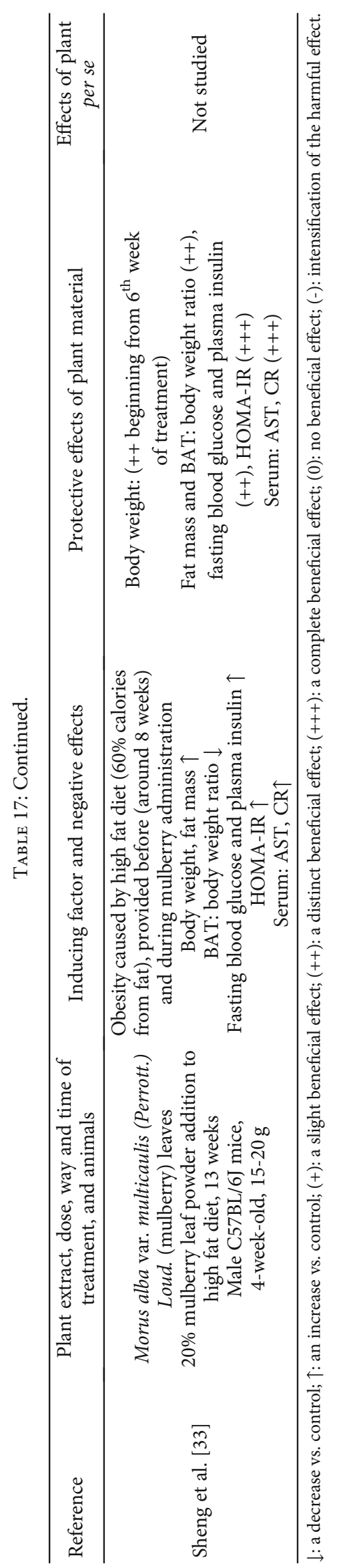




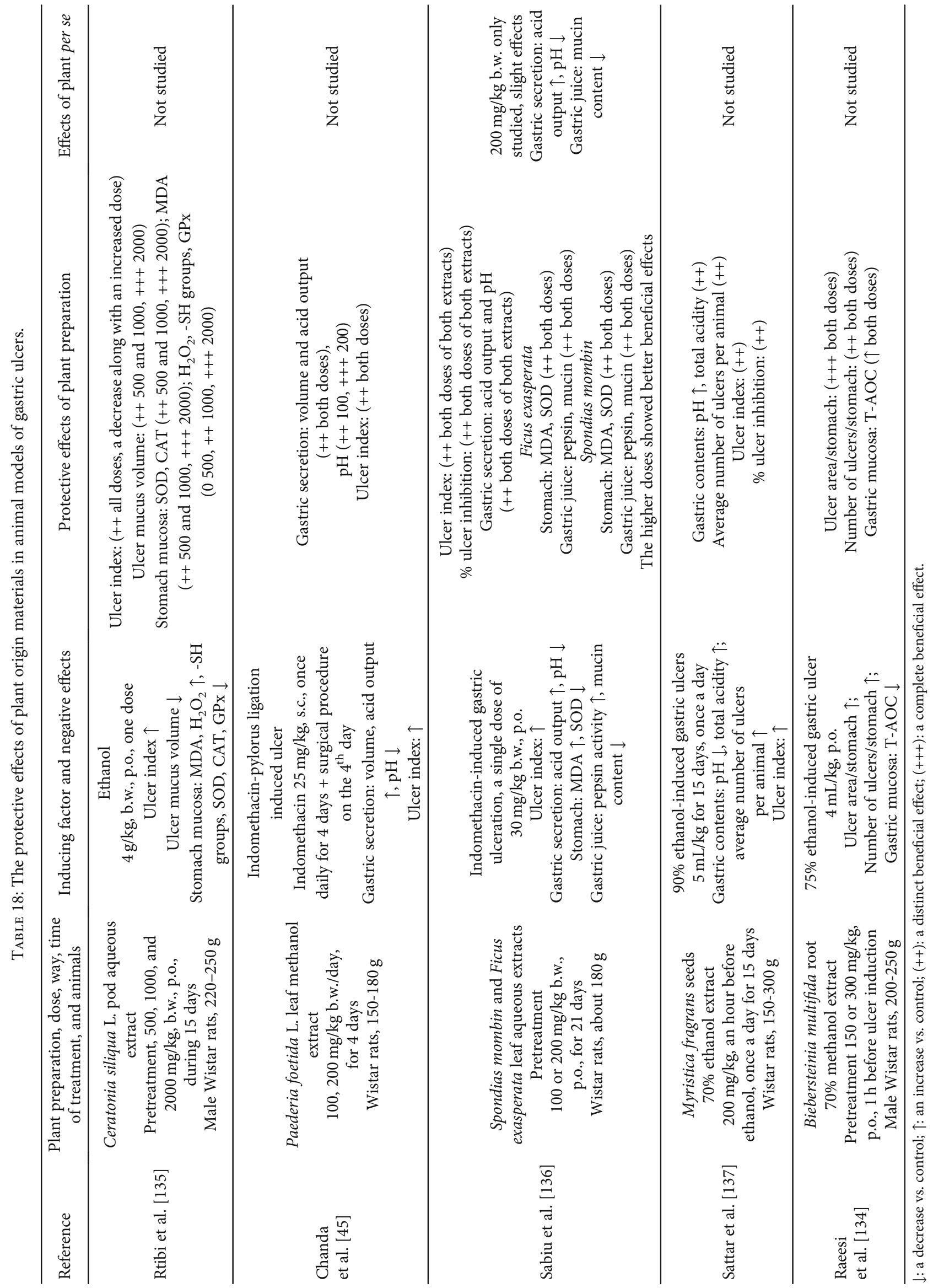




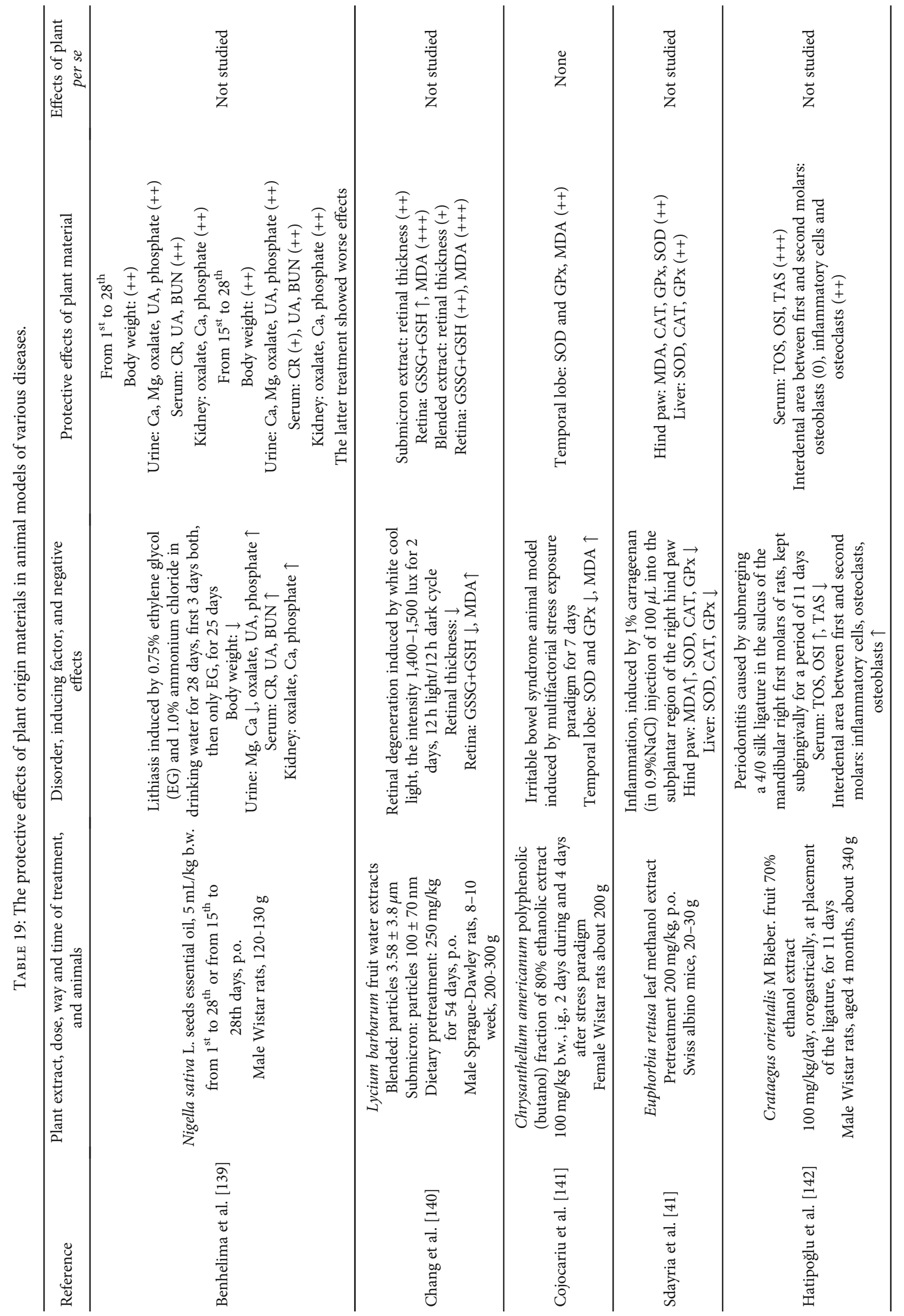




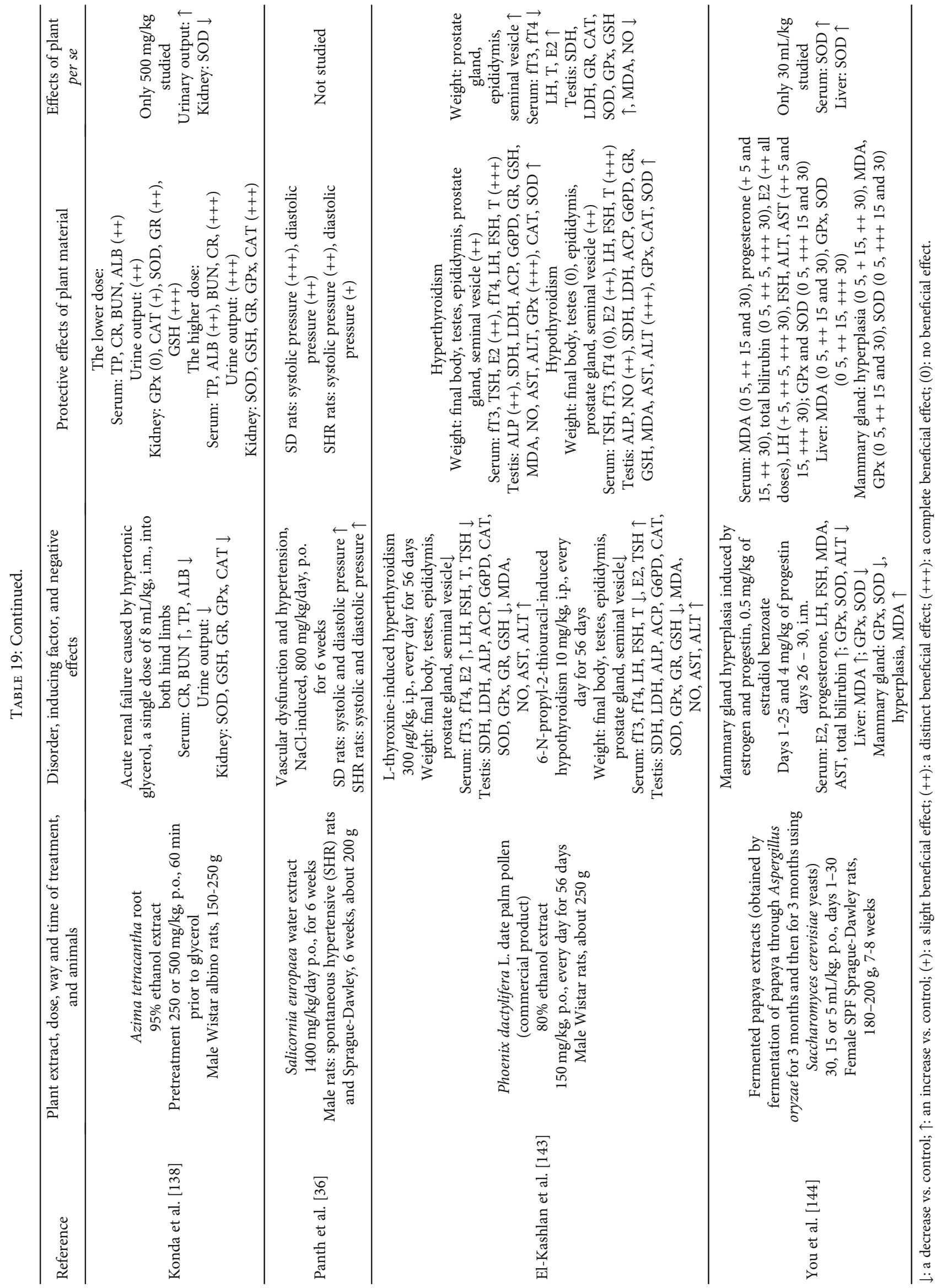




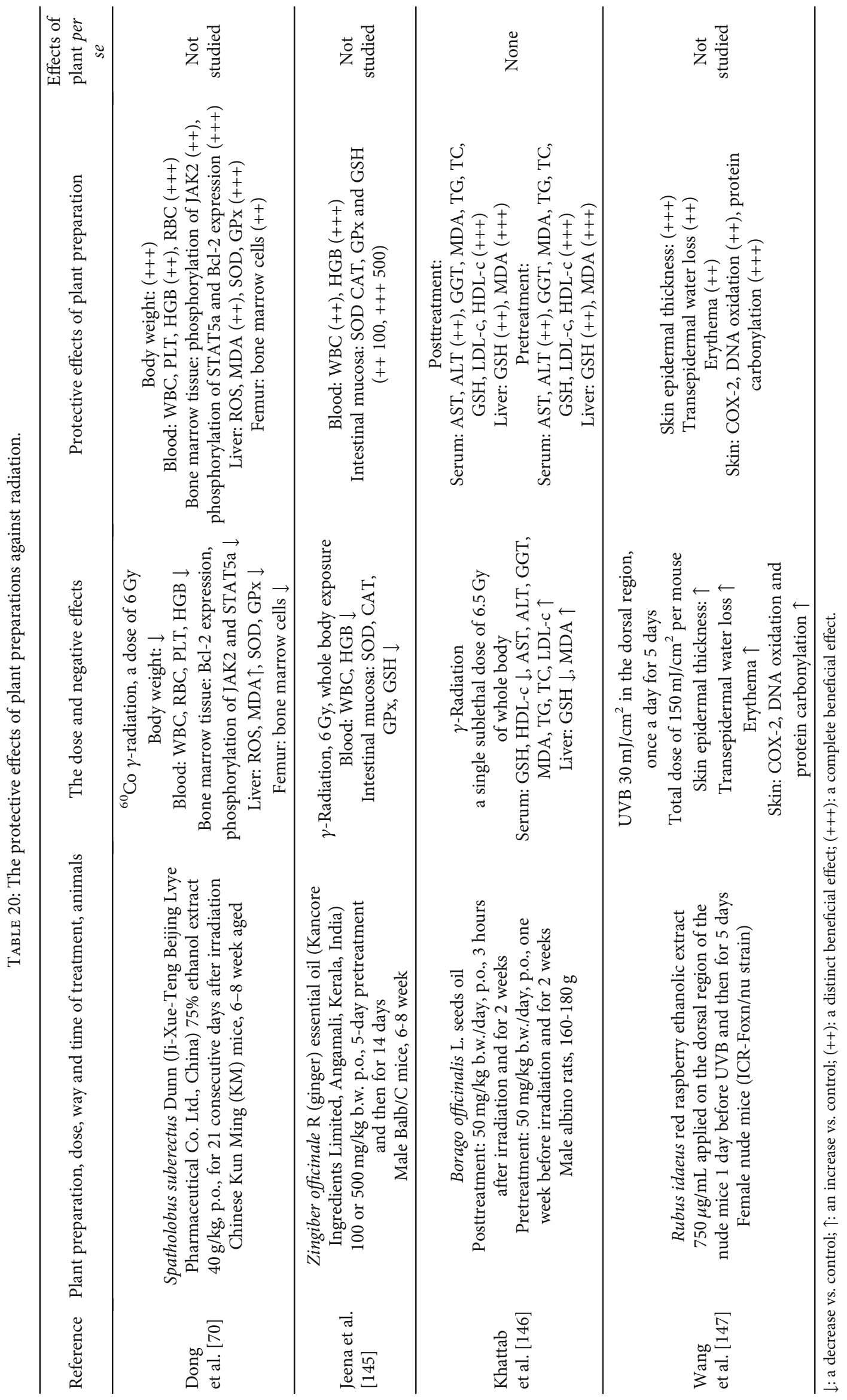


as lipid profile normalizing agents, and the results seem to be auspicious [120-122]. Additionally, the researchers performed comparisons with standard drugs. The outcomes showed that the efficacy of plant material needs not be worse than that showed by acknowledged pharmaceutical agents. However, it should be emphasized that the final effects may be different, depending on the applied dose.

Veber et al. [34] compared the effects of two doses (125 or $250 \mathrm{mg} / \mathrm{kg}$ ) of aqueous extract of red cabbage with that showed by fenofibrate, a drug used in therapy of abnormal lipids in the blood, on oxidative stress parameters in rats with hyperlipidemia caused by Triton WR-1339. Although the higher dose proved to possess protective properties generally comparable with the drug, the lower one in some cases showed no efficiency.

Erica multiflora L. leaf methanolic extract (150 or $250 \mathrm{mg} / \mathrm{kg}$ ) effect was studied in rats with Triton WR-1339induced hyperlipidemia in comparison with fenofibrate taking into account chosen lipid and antioxidant parameters. The higher dose showed comparable or even better protective action than the medicine. In contrast, total DNA damage was alleviated much better by the used drug [120].

Onyenibe et al. [122] investigated the efficiency of two doses of Monodora myristica aqueous extract as a protective agent in case of deterioration of lipid profile and oxidative parameters in hypercholesterolemic rats and compared the obtained results with those noted for a standard drug Questran. The authors found that generally two doses of plant preparation, namely, 100 and $200 \mathrm{mg} / \mathrm{kg}$ b.w., showed a better influence.

The effects of lipid-lowering drugs simvastatin and ciprofibrate as well as aqueous extract of Campomanesia adamantium O. Berg root were compared in rats with high-fructose diet-induced hyperlipidemia. The plant material exerted the entirely comparable influence in case of lipid parameters and even better as regards body weight gain lowering [121].

\subsection{The Comparison of Plant Extracts of Hepatoprotective} Properties with Pharmaceutical Agents. Liu et al. [51] compared the protective action of pretreatment with Sonneratia apetala fruit water extract $(100,200$, and $400 \mathrm{mg} / \mathrm{kg})$ against hepatic damage caused by acetaminophen in mice with the effect of an acknowledged antidote NAC (N-acetyl-L-cysteine). The scientists observed the protective influence of plant preparation, which was not only comparable but in some cases better-particularly for serum ALT and AST as well as hepatic lipid peroxidation, antioxidant enzymes, TNF- $\alpha$, and IL-6.

Similarly, the rich polyphenol fractions of methanolic extracts of Genista quadriflora Munby and Teucrium polium geyrii Maire showed a protective effect against hepatoxicity of acetaminophen (APAP) and the comparison with $N$-acetylcysteine showed their comparable properties with the drug, except for histological changes where Teucrium polium geyrii Maire exerted a better influence than two other studied agents [20].

3.4. The Comparison of Plant Extracts with Silymarin, an Acknowledged Dietary Supplement of Hepatoprotective Properties. Many drugs and chemicals are distinguished by their hepatoxic effects. In view of the increasing environmental pollution as well as more and more common application of different drugs, often over-the-counter ones, the protective agents are highly desirable [18]. Silymarin, a preparation obtained from Silybum marianum L., has been used as a hepatoprotective adjuvant for years. Currently, the attention has been pointed to other plants, often those used since antiquity in traditional medicine [44]. Different hepatotoxicity animal models were used to perform comparison with silymarin.

The possibility of replacing silymarin by an extract of Cassia fistula L. leaves was studied by Kaur et al. [35] in rats exposed to thioacetamide. The studied extract was applied at three doses (50, 100, and $200 \mathrm{mg} / \mathrm{kg}$ b.w.), and beneficial effects of the two higher ones were not worse than those observed in rats receiving silymarin.

The similar observations were reported by Fahmi et al. [53] who compared the protective properties of dietary ginger against diethylnitrosamine hepatotoxicity in rats with those showed by silymarin and found that the studied material in the form of ginger powder or essential oil exerted the same or even better beneficial action.

Choi et al. [46] studied the possibility of Centella asiatica leaf ethanol extract (100 or $200 \mathrm{mg} / \mathrm{kg}$ ) using as a protective agent against dimethylnitrosamine-induced hepatotoxicity in rats. The authors determined different inflammatory cytokines and mediators, liver injury markers, oxidant parameters, and histophological changes. In some cases (liver histology, serum IL-1 $\beta$, TNF- $\alpha$, and IL-2), both doses of the extract showed a better action than silymarin. In case of AST, ALP, IL-6, and INF- $\gamma$ or liver MDA, both agents displayed the similarly significant properties. Furthermore, liver antioxidant enzymes were best ameliorated by the higher dose of plant preparation.

El-Hadary and Ramadan [52] in turn stated that Moringa oleifera leaf extract displayed protective properties against hepatotoxic action of diclofenac sodium. The comparison with silymarin proved that the plant preparation exerted comparable or even better effect.

Ahmad and Zeb [18] in turn compared an effectiveness of silymarin and different doses of water extract of Trifolium repens leaves against acetaminophen-induced hepatoxicity in mice. The authors reported that in case of most studied hematological, serum biochemical, and liver oxidative parameters, the effect of the highest dose was not worse than that shown by silymarin.

However, the comparison of protective action of leaf extract of Solanum surattense with that observed for silymarin in $\mathrm{CCl}_{4}$-exposed rats revealed that the latter had entirely better effect regarding liver injury markers and lipid profile in serum as well as lipid peroxidation process in the liver [83].

On the other hand, Dogan and Anuk [44] observed that in ethanol-exposed rats water extract of leaves of Platantus orientalis L. generally showed the protective effects comparable or even better than those observed in silymarin-given animals. Interestingly, in case of some parameters, both silymarin and extracts showed insufficient effectiveness. 
The possibility of applying a plant extract as an adjuvant which could augment an action of an acknowledged agent was also studied on an example of silymarin. Azim et al. [19] investigated effects of silymarin alone, Moringa peregrina leaf extract alone, and coadministration of those substances in rats subjected to acetaminophen. Generally, as regards plasma liver injury markers and oxidative parameters, the protective influence of all three treatments was found to be practically complete, but in some cases, the combination of both agents exerted the best effect. Interestingly, DNA damage was most markedly alleviated by plant extract alone while silymarin showed the slightest efficacy.

3.5. Immunosuppressive and Anti-Inflammatory Drugs vs. Plant Preparations. Pistacia weinmannifolia root extract was compared regarding anti-inflammatory effects with roflumilast-a drug used in the therapy of lung inflammatory disorders, in mice with pulmonary inflammation induced by cigarette smoke and lipopolysaccharide. The results of the experiment showed that the studied preparation possessed protective properties absolutely comparable with the applied medicine [149].

Sundaram et al. [55] studied the protective effect of guggulipid (an extract from Commiphora whighitii gum resin) against morphology changes, cartilage degradation, and prooxidative processes in rats with experimental arthritis. Along with the evaluation of the plant preparation properties, the authors performed the comparison with a standard nonsteroidal anti-inflammatory drug ibuprofen. The influence of the studied extract proved to be comparable or even much more effective, particularly in cases of hematological and oxidative parameters.

In a study performed on mice subjected to 1-chloro-2,4dinitrobenzene with the aim of inducing atopic dermatitislike skin lesion, the effect of Rumex japonicus Houtt. root extract was compared with the efficacy of a synthetic glucocorticoid dexamethasone. The alleviation of the disease severity caused by the topical application of the plant extract was not much worse (particularly in the case of the higher dose) than that observed in animals treated intraperitoneally with dexamethasone [77].

Kaveh et al. [117] in turn compared the influence of different doses of hydroethanolic extract of Portulaca oleracea with that exerted by dexamethasone in rats with experimental asthma. According the authors, the effect of the highest dose $(4 \mathrm{mg} / \mathrm{mL}$ in drinking water) was comparable with the drug. However, the lowest dose $(1 \mathrm{mg} / \mathrm{mL}$ in drinking water) in some cases showed no beneficial influence.

In some cases, the pharmaceutical agents showed a better effect. Sdayria et al. [41] reported that in mice with carrageenan-induced paw edema pretreatment with a nonsteroidal anti-inflammatory drug indomethacin or Euphorbia retusa methanol extract showed comparable effects concerning \% edema inhibition, although indomethacin displayed a little better properties. However, in case of oxidant parameters in the liver and paw, the drug exerted more distinct beneficial influence.

In the experiment performed by Jeong et al. [48], a nonsteroidal anti-inflammatory drug celecoxib proved to be much better in reversing the changes of biochemical parameters observed in rats with monosodium iodoacetate-induced osteoarthritis than a water extract of leaves of Morus alba L. Histological examinations confirmed the drug advantage.

3.6. Standard Drugs vs. Plant Preparations in Stomach Ulcer Animal Model. Sattar et al. [137] performed a comparison of protective action of Myristica fragrans extract and sucralfate (a drug used for stomach ulcer treatment) in rats with ethanol-induced gastric ulcers. Although the plant preparation was not so effective with regard to amelioration of total acidity of stomach contents as well as macroscopic evaluation of gastric mucosa, ulcer index, and percentage of protection, its application did not cause serious increase in $\mathrm{pH}$ of stomach content as sulfacrate (4.25 vs. 5.0$)$.

On the other hand, Biebersteinia multifida hydromethanolic extract showed a quite comparable or better protective effect than another drug-namely, omeprazole-in cases of gastric ulcers caused by $75 \%$ ethanol in rats. This effect included a decrease in ulcer area and number as well as enhancement of total antioxidant capacity in gastric mucosa [134].

Ateufack et al. [150] compared the effect of Piptadeniastrum africanum stem bark aqueous and methanol extracts $(125,250$, or $500 \mathrm{mg} / \mathrm{kg})$ in rat gastric ulcer induced by the $\mathrm{HCl} /$ ethanol mixture, indomethacin, and acetic acid with that showed by standard drugs (Maalox, Misoprostol, or Ranitidine). Plant extracts, particularly aqueous one when applied in the highest dose, displayed the protective action even better than the investigated drugs in case of animals exposed to $\mathrm{HCl} /$ ethanol mixture or indomethacin, but not in those treated with acetic acid.

Rtibi et al. [135] reported that in rats exposed to ethanol, pretreatment with Ceratonia siliqua L. aqueous extract (500, 1000 , and $2000 \mathrm{mg} / \mathrm{kg}$ b.w.) showed a better or comparable effect with the standard drug famotidine when applied at the highest dose, while the lowest one was found to be either less effective or even ineffective at all.

The interesting results were reported by Chanda et al. [45]. The scientists studied the possibility of using Paederia foetida Linn. leaf methanol extract (100 and $200 \mathrm{mg} / \mathrm{kg}$ b.w.) as a gastroprotective agent in rats with gastric ulcers induced by indomethacin-pylorus ligation, alcohol, or water immersion stress. The effects were compared with those obtained for standard drugs ranitidine, sucralfate, and lansoprazole, respectively. As concerns ulcer protection, in the first and third models, there were no distinct differences between the plant material (particularly the higher dose) and the applied drug. In contrast, in the second model, the higher dose of extract showed much better effectiveness than the lower one, but nonetheless not so high as sucralfate.

3.7. The Comparison of Plant Preparations with Cytoprotective Adjuvants Used in Radio and Chemotherapy. The advantage of plant origin substances over drugs was also shown by Dong et al. [70]. Ethanol extract of JXT (a traditional herb obtained from the Spatholobus suberectus Dunn dry rattan) given orally to mice caused a significant improvement of the biochemical parameters previously disturbed by 
${ }^{60}$ Co $\gamma$-radiation, i.e., morphology, bone marrow cell number, and liver lipid peroxidation level as well as activity of antioxidant enzymes. This effect was comparable or better than that exerted by amifostine, an agent applied in cases of radiation syndrome during radiotherapy.

3.8. Plant Preparations vs. Drugs and Supplements Applied in Neurological and Psychiatric Disorders. Pharmaceutical agents used for the treatment of psychiatric and neurodegenerative disorders may cause side effects worsening the condition of patients. Plant preparations, often used for centuries in traditional medicine, have been found to possess anxiolytic and antistress properties, and the comparison with acknowledged drugs and supplements showed their comparable efficacy $[17,58]$.

Plant materials, namely, extracts from two Hypericum species, were studied with regard to their effect on oxidative stress and inflammatory cytokines in an experimental anxiety animal model. The comparison with pure quercetin and a control drug alprazolam was also performed. In most cases, the disturbed brain parameters were positively influenced in a comparable or more distinct way by plant materials than by two other studied substances. It should be emphasized that in some cases the worst effect was observed in animals treated with alprazolam [17].

Almeida et al. [58] compared the protective effect of Clitoria ternatea extract with that shown by cotreatment with dietary supplements choline and docosahexanoic acid against brain oxidative stress caused by separation from mothers in rat pups. During 30-day experiment including the stressing factor and treatments as well as during the subsequent 330-day follow-up, both agents revealed comparable properties regarding the prevention of lipid peroxidation increase and thiol group content depletion.

Chonpathompikunlert et al. [31] compared the neuroprotective effect of Apium graveolens L. extract with that showed by a standard drug Tidomet Plus in an animal model of Parkinson disease. The efficacy of two doses (250 and $375 \mathrm{mg} / \mathrm{kg}$ b.w.) proved to be quite comparable (the lower one) or even better (the higher one) with the medicine as regards improvement of behavioral performance, oxidative parameters, and activities of monoamine oxidases A and B.

3.9. Antidiabetic Drugs vs. Plant Preparations. The possibility of plant preparations application in diabetic subjects was also studied. It was prompted by side effects occurring in patients treated by pharmacological agents. The outcomes seem to be promising although in view of the reported results the accurate research is needed to determine mechanism of action and the most beneficial dose $[66,127]$.

Khanra et al. [129] stated that Abroma augusta L. leaf methanol extract $(100$ or $200 \mathrm{mg} / \mathrm{kg}$ ) was not so efficient at reversing the serum parameters disturbed in rats by type 2 diabetes course, particularly in the case of the lower dose, as a standard drug glibenclamide. However, in the case of alleviating DNA fragmentation, ATP level, chosen oxidant parameters, and expression of NF- $\kappa \mathrm{B}$ in the kidney and heart, the prevalence of the drug was not so distinct.
The comparison of glibenclamide and methanolic extract of Caralluma europaea was performed by Dra et al. [127] on diabetic mice. The higher dose of plant material $(500 \mathrm{mg} / \mathrm{kg}$ b.w.) was better effective in the reduction of blood glucose than a drug, beginning from the $4^{\text {th }}$ hour after administration, while a lower one $(250 \mathrm{mg} / \mathrm{kg}$ b.w.) showed a comparable effect. Additionally, according to the authors, the lower dose showed a more distinct beneficial influence in case of histopathological damage observed in diabetic animals.

The similar results were obtained by $\mathrm{Du}$ et al. [66] who compared the protective properties of a standard drug metformin hydrochloride and different doses (100, 250, and $500 \mathrm{mg} / \mathrm{kg}$ ) of polysaccharide separated from Lycium barbarum in the rat model of diabetes induced by high-fat diet +streptozotocin. Metformin showed a better effect in case of fasting blood glucose and INF- $\alpha$. As for insulin and ICAM-1, the highest dose of plant origin material proved to possess better ameliorating properties, while serum GPx was more improved by two higher doses.

Balbaa et al. [57] investigated the differences in effects of administration of Nigella sativa seeds oil, standard drugs metformin and glimepiride, and their combinations to diabetic rats. The oil had a better protective action when administrated alone than in combination with metformin or glimepiride against oxidative stress and neuroinflammatory cytokines' increase. When the results of administration of those three agents alone to diabetic rats were compared, the best properties of a plant material were also confirmed.

3.10. Plant Extract or a Single Substance of Antioxidant Properties? As beneficial effects of plant preparations were attributed to their antioxidative properties, some researches performed the comparisons with simple substances of acknowledged antioxidant character. The results showed that plant materials could exert a better influence due to the presence of many component which might cooperate with one another.

Jahan et al. [72] studied the possibility of application of Chenopodium album Linn. seed extract as a protective agent against the damage of reproductive functions caused by mercury exposure. They compared the effect of the plant extract with that showed by a known antioxidant vitamin $\mathrm{C}$ which was reported to exert beneficial influence on male fertility. Except for plasma cholesterol and triglycerides as well as GST and TBARS in testicular tissue, the benefit influence of the studied plant material was comparable or even better. The similar observations were reported as regards the testicular morphometric parameters.

The comparison of the protective influence of Nigella sativa extract and vitamin $\mathrm{E}$ against cisplatin nephrotoxicity was performed by Hosseinian et al. [16]. The cisplatininduced negative changes, i.e., renal damage and thiol group decrease, and lipid peroxidation enhancement in the serum and kidney, were alleviated in a rather comparable way, except for serum thiols, where the prevalence of plant extract was indisputable.

The effects of two Hypericum (H. maculatum and $H$. perforatum) species extracts on oxidative stress and 
inflammatory cytokines were studied in an experimental anxiety animal model and compared with pure quercetin. The beneficial influence of plant extracts was mostly comparable and in many cases better, particularly in the case of Hypericum maculatum [17]. Such results could point to synergistic action of various components of extracts, acting as confirmation of the conclusions made by He et al. [148].

\subsection{The Action of a Plant Preparation Depending on Its Dose, Time and Form of Treatment}

3.11.1. The Relationships between the Dose and the Effects. In many studies, the protective effects of plant extracts and constituents showed a direct dependency on the used dose [15, $29,31,56,80,107,117]$.

However, sometimes, the similar effects were observed for a considerable wide range of the applied doses. Liu et al. [91] studied an effect of various doses $(0.0625,0.125,0.25$, $0.5 \mathrm{~g} / \mathrm{kg}$ b.w.) of ginseng oligopeptides against ethanol toxicity, and the observed differences were quite slight considering the size of the applied range.

Malik et al. [39] performed a study on animals with Huntington's disease like symptoms and observed practically the same influence of two different doses (100 and $200 \mathrm{mg} / \mathrm{kg}$ ) of Celastrus paniculatus seed ethanol extract on memory functions, locomotor activity, and oxidative parameters in the brain parts.

The relationships between used doses and an exerted influence were also studied in the experiment concerning the protective properties of water extract of Sonneratia apetala fruit against liver damage caused by acetaminophen exposure in mice. The effects of pretreatment with different doses $(100,200$ and $400 \mathrm{mg} / \mathrm{kg}$ ) were very interesting as in the case of some parameters a strong dose dependency was observed (e.g., liver GSH and MDA), while some other ones were affected in the same way, regardless of the applied dose (liver GSH, T-AOC, and TNF- $\alpha$ ) [51].

In another study, Wang et al. [119] investigated the protective properties of two doses ( 4.6 or $14 \mathrm{~g} / \mathrm{kg}$ b.w.) of aqueous extract of Salvia Miltiorrhiza Bge. f. alba in the monocrotaline-induced animal model of pulmonary hypertension. Various parameters were studied: mean pulmonary artery pressure, right ventricular systolic pressure, pulmonary artery remodelling, plasma vasoactive factors NO, 6Keto-PGF1 $\alpha$, ET- 1 , and $\mathrm{TXB}_{2}$, and lung TGF- $\beta 1$, but the observed differences were not as considerable as one could expect taking into account the difference between the applied doses.

The similar observations were reported by El-Hadary and Ramadan [52] who studied two doses of Moringa oleifera leaf extract (150 and $300 \mathrm{mg} / \mathrm{kg}$ b.w.) against hepatotoxicity of diclofenac sodium. Both doses displayed protective properties, but again, the difference between them was not so great as one could predict considering their range.

Onyenibe et al. [122] studied the efficacy of two doses of Monodora myristica aqueous extract at preventing impairment of lipid profile and oxidative parameters in hypercholesterolemic rats and generally found no difference between $100 \mathrm{mg} / \mathrm{kg}$ b.w. and $200 \mathrm{mg} / \mathrm{kg}$ b.w.
Such results point to the necessity of complex research of any possible protective agent with using a wide range of doses. The issue of dependency between the used dose and its effects proved to be additionally complicated as not always a direct relationship was found. The effects of different doses were sometimes divergent as in the experiment performed by Khan et al. [88], who studied the influence of two doses $0.5 \mathrm{~g} / \mathrm{kg}$ b.w. and $1.0 \mathrm{~g} / \mathrm{kg}$ b.w. of ajwa dates (Phoenix dactylifera L.) water extract on the biochemical parameters in rats with diethylnitrosamine-induced liver cancer. The lower one in some cases showed even a harmful effect (potentializing the changes caused by the carcinogen), while the higher one showed considerable protective properties. Additionally, the lower dose effect was characterized by a significant diversity as apart from showing the above-mentioned harmful influence, it also exerted a beneficial action, ranging from slight to strong.

In some cases, the higher dose had the worse effect than a lower one. In the study performed by Omole et al. [26], concerning the possible use of pretreatment with kolaviron (a mixture of flavonoids obtained from Garcinia kola seeds, 200 or $400 \mathrm{mg} / \mathrm{kg} / \mathrm{d}$ ) against toxicity of cyclophosphamide, the higher dose proved to be less beneficial, not only exerting less protective properties but also causing a slight increase in lipid peroxidation in the heart tissue.

The similar observations were reported by Apaydin Yildirim et al. [28] who studied the influence of Helichrysum plicatum DC. subsp. plicatum extract (100 or $200 \mathrm{mg} /(\mathrm{kg} \cdot \mathrm{d}$ ) against nephrotoxic as well as hepatotoxic effects of gentamicin in rats. The authors stated that the higher dose showed much less beneficial influence. Additionally, the higher dose exerted some harmful effects, particularly regarding histopahological changes, when administered alone.

In some studies, it would be really very difficult to decide which dose should be chosen for usage. In the experiment performed by Wattanathorn et al. [42], the beneficial influence of the combination of extracts of Mangifera indica $\mathrm{L}$. and Polygonum odoratum L. against diabetes cataract and retinopathy was distinctly showed, but the effect of different doses $(2,10$, or $50 \mathrm{mg} / \mathrm{kg}$ b.w.) was found to be highly diverse.

Phunchago et al. [92] studied the possible protective effect of Tiliacora triandra water extract against ethanolinduced hippocampus damage in rats. The authors compared three doses: 100, 200, and $400 \mathrm{mg} / \mathrm{kg}$ b.w., and found that the middle one showed the best influence in improving some studied parameters while in few cases the worst influence was found for the highest one.

3.11.2. The Relationships between the Period of Treatment and the Effects. The period of the treatment with the studied substances also proved to be a factor of importance. Xu et al. [60] investigated the effect of Rhubarb extract on the oxidative parameters in rats with traumatic brain injury. According to the reported results, the degree of improvement in lipid peroxidation intensity as well as antioxidants levels showed a dependency on the time of experiment. The animals sacrificed after a longer period, starting from surgery and plant material treatment, showed a better amelioration of the studied parameters. 
3.11.3. The Relationships between the Way of Preparing Plant Materials and Their Effects. As plant extracts contain many active substances of different solubilities in various solvents, the way of the preparation of the used substances also proved to be an issue of importance.

Malik et al. [39] studied the fractions of Celastrus paniculatus seed ethanol extract, obtained by suspending it in water and sequential partitioning with using petroleum ether, ethyl acetate and n-butanol. These materials were investigated as to their ability to ameliorate the neurotoxic effect of 3-nitropropionic acid by reversing changes of oxidative parameters in striatum and cortex of experimental rats. In the case of improvement of enhanced MDA and nitrites as well as decreased CAT, SOD, and GSH, ethanol extract and aqueous fraction proved to be the most effective; the petroleum ether fraction showed much less efficacy while n-butanol and ethyl acetate ones practically none.

3.11.4. Treatment of Pretreatment? The way of treatment, i.e., pre or post, in some cases was shown to be a crucial factor influencing the observed effect to a considerable degree. Afsar et al. [23] studied the effects of ethyl acetate fraction of Acacia hydaspica methanol extract against cisplatin toxicity and observed that the protective influence observed in the case of posttreatment started concomitantly with cisplatin and continued for five days was decidedly less distinct than that of 15-day pretreatment combined with posttreatment.

On the other hand, some authors did not report any differences between the mentioned two ways. Khattab et al. [146] did not observe any differences between pre- and posttreatment with Borago officinal L. seed oil in rats exposed to $\gamma$-radiation.

The similar effects were observed by Nasri et al. [109] in rats subjected to a contrast medium iodixanol and $70 \%$ ethanol green tea extract. The plant agent alleviated iodixanol-induced histopathological kidney changes, but no significant differences between pre- and posttreatment were observed.

Hosseinian et al. [16] studied the possible protective effect against cisplatin nephrotoxicity of Nigella sativa extract $(100$ and $200 \mathrm{mg} / \mathrm{kg}$ ) using the design, whereby two ways of administration were applied-pretreatment alone or with the addition of posttreatment. The outcomes were really interesting. In case of renal SH groups and tissue damage as well as serum SH groups and MDA plant material proved to possess beneficial effect, regardless of the way of administration.

\section{The Effects of Plant Preparations Per Se}

The fact that generally effects of plant preparations per se were observed occasionally makes the considerable limitation of the studies presented in the current review. Only a few scientists reported observations considering any influence of the studied materials. Sheweita et al., for instance, investigated the effects of application of essential oils of Foeniculum vulgare (fennel) Miller seeds, Cuminum cyminum L. (cumin) seeds, and Syzygium aromaticum L. (clove) flower and reported that the used oils themselves caused several beneficial effects like decrease in liver TBARS as well as enhancement of liver antioxidants [101].

El-Kashlan et al. [143] found the decrease in lipid peroxidation as well as reinforcement of antioxidant defence in rats receiving commercial date palm pollen.

El-Rahman et al. [110] reported alleviation of prooxidative processes as well as the increase in antioxidants in rats given Saussurea lappa root extract.

Furthermore, the beneficial influence of plant preparations included not only improvement in biochemical parameters. Sheng et al. [33] reported that, apart from positive effect on body and adipose tissue weight and insulin sensitivity, liver, and kidney functions, addition of mulberry leaves powder to diet also caused amelioration of microbiota community structure in gut of obese mice.

Balbaa et al. [57] investigated the differences in the effects of administration of Nigella sativa seeds oil, antidiabetic drugs metformin and glimepiride, and their combinations to rats. In some cases, the plant oil per se showed the least or no negative effect in nondiabetic rats when compared to medicines. The reduction of brain $\beta$-amyloid- 42 as well as the increase in antioxidants' level was observed. On the other hand, brain lipid peroxidation was found to be enhanced.

However, some authors reported the negative effects of plant preparations on experimental animal organisms.

Apaydin Yildirim et al. [28] observed histopathological changes in organs of animals treated with Helichrysum plicatum DC. subsp. plicatum extract.

In one of the recently published articles, Nahdi et al. [151] observed that leaf Hypericum humifusum aqueous (200 or $400 \mathrm{mg} / \mathrm{kg}$ b.w.) and methanolic $(10$ or $20 \mathrm{mg} / \mathrm{kg}$ b.w.) extracts, given to rats, induced histopathological changes as well as impaired biochemical parameters including an increase in WBC, liver MDA, plasma ALT, AST, and LDH. Additionally, activities of hepatic antioxidant enzymes CAT and SOD were markedly decreased vs. control with no treatment. Interestingly, in case of the aqueous extract, the worse effect was exerted by the lower dose while the methanolic one was found to be more harmful when given in the higher dose.

\section{Conclusions}

The outcomes of the studies presented in the current review showed a huge potential inherent in plant preparations. They were revealed to reverse or alleviate toxicity of different factors, side effects of drugs, and symptoms of various diseases. In many cases, they were proved to be comparable or better than standard drugs which let us suggest that in future the plant origin substances could make a replacement for pharmaceutical agents. However, the presented above results of some experiments point to the fact that the proper precautions must be undertaken before applying any plant material. The detailed research regarding the per se effects, dose, and way of administration needs to be performed. 


\section{Abbreviations}

AA:

$\mathrm{A} \beta$ :

ABCG:

ACC:

AChE:

ACP:

ADA:

AGE:

AGGRECAN:

ALB:

$\mathrm{AlCl}_{3}$ :

ALP:

ALT:

AOPP:

AR:

ARE:

AST:

ATP:

BALF:

BAP:

BAT:

Bcl-2:

BMP2:

BUN:

b.w.:

Ca:

$\mathrm{Ca}^{2+}$ ATPase:

CAT:

$\mathrm{CCl}_{4}$ :

$\mathrm{Cd}$ :

Cd36:

cGMP:

ChAT:

CHOP:

CK-MB:

COL2:

COL10:

COMP:

COX-2:

CR:

CRP:

CS:

cTnI:

CTX-II:

$\mathrm{Cu}:$

CYP2E1:

DBP:

DC:

DHEAs:

DNA:

E2:

eNOS:

ERK1/2:

ET-1:
Ascorbic acid

$\beta$-Amyloid peptide

ATP-biding cassette, subfamily G

transporters

Acetyl-CoA carboxylase

Acetylcholine esterase

Acid phosphatase

Adenosine deaminase activity

Advanced glycation end product

Cartilage-specific proteoglycan core protein

Albumin

Aluminium chloride

Alkaline phosphatase

Alanine aminotransferase

Advanced oxidation protein products

Aldose reductase

Antioxidant-responsive element

Aspartate aminotransferase

Adenosine triphosphate

Bronchoalveolar lavage fluid

Biological antioxidant power

Brown adipose tissue

B-cell lymphoma 2

Bone morphogenetic protein 2

Blood urea nitrogen

Body weight

Calcium

Calcium-activated adenosine $5^{\prime}$

-triphosphatase

Catalase

Tetrachlorometan (carbon tetrachloride)

Cadmium

Cluster of differentiation 36

Cyclic guanosine- $3^{\prime}, 5^{\prime}$-monophosphate

Choline acetyltransferase

C/EBP homologous protein

Creatinine kinase-MB

Collagen type-II

Collagen type 10

Cartilage oligomeric matrix protein

Cyclooxygenase- 2

Creatinine

C-reactive protein

Citrate synthase

Cardiac troponin I

C-telopeptide of type II collagen

Copper

Cytochrome P450-2E1

Diastolic blood pressure

Diene conjugate

Dehydroepiandrosterone sulfate

Deoxyribonucleic acid

Estradiol

Endothelial nitric oxide synthase

Extracellular signal-regulated kinase 1 and 2

Endothelin-1
Fatp4:

Fe:

FFA:

FRAP:

FSH:

fT3:

fT4:

$\gamma$-GCS:

GGT:

GM-CSF:

G6PD:

GPx:

GR:

GRP78:

GSH:

GSSG:

GSSG-red:

GSSP:

GST:

HA:

$\mathrm{HbA}_{1} \mathrm{c}$ :

HCT:

HDL:

HDL-c:

$\mathrm{Hg}$ :

HGB:

HMG-CoA-R:

HNE:

HO- 1 :

$\mathrm{H}_{2} \mathrm{O}_{2}$ :

HOMA-IR:

ICAM-1:

i.c.v.:

IDE:

IFN- $\alpha$ :

IFN- $\gamma$ :

i.g.:

IgG:

IgM:

IL:

i.m.:

iNOS:

i.p.:

i.v.:

JAK:

$\mathrm{K}$ :

KEAP1: $\quad$ Kelch-like ECH-associated protein 1

6-Keto-PGF1 $\alpha$ : 6-Keto-prostaglandin F1 alpha

LDH:

LDL:

LDL-c:

LH:

Lpl:

LPO:

LPS:

Fatty acid transport protein 4

Iron

Free fatty acids

Ferric reducing ability of plasma

Follicle-stimulating hormone

Free T3

Free T4

$\gamma$-Glutamyl cysteine synthetase

$\gamma$-Glutamyl transferase

Granulocyte-macrophage colony-

stimulating factor

Glucose-6-phosphate dehydrogenase

Glutathione peroxidase

Glutathione reductase

$78 \mathrm{kDa}$ glucose-regulated protein

Reduced glutathione

The oxidized form of glutathione

Oxidized glutathione reductase

Glutationylated proteins

Glutathione-S-transferase

Hyaluronidase

Glycated hemoglobin

Haematocrit

High-density lipoprotein

High-density lipoprotein cholesterol

Mercury

Haemoglobin

3-Hydroxy-3-methylglutaryl CoA

reductase

4-Hydroxy-2-nonenal

Heme oxygenase 1

Hydrogen peroxide

Homeostasis model assessment-insulin

resistance

Intercellular adhesion molecule

Intracerebroventricular

Insulin degradation enzyme

Interferon- $\alpha$

Interferon- $\gamma$

Intragastrically

Immunoglobulina $\mathrm{G}$

Immunoglobulina $\mathrm{M}$

Interleukin

Intramuscularly

Inducible nitric oxide synthase

Intraperitoneally

Intravenously

Janus kinase

Potassium

Lactate dehydrogenase

Low-density lipoprotein

Low-density lipoprotein cholesterol

Luteinizing hormone

Lipoprotein lipase

Lipid peroxidation

Lipopolysaccharide 


\begin{tabular}{|c|c|c|c|}
\hline MAO-A: & Monoamine oxidase type B & ROS: & Reactive oxygen species \\
\hline MAO-B: & Monoamine oxidase type B & SBP: & Systolic blood pressure \\
\hline MCP-1: & Monocyte chemoattractant protein 1 & S.c.: & Subcutaneously \\
\hline M-CSF: & Macrophage colony-stimulating factor & SDH: & Sorbitol dehydrogenase \\
\hline MDA: & Malondialdehyde & SH: & Thiol groups \\
\hline MDSCs: & Myeloid suppressor cells & SHBG: & Sex hormone-binding globulin \\
\hline Mg: & Magnesium & SOD: & Superoxide dismutase \\
\hline \multirow[t]{2}{*}{$\mathrm{Mg}^{2+}$ ATPase: } & \multirow{2}{*}{$\begin{array}{l}\text { Magnesium-activated adenosine } 5^{\prime} \\
\text {-triphosphatase }\end{array}$} & SPF: & Specific pathogen free \\
\hline & & Srebf1: & Sterol regulatory element-binding tran- \\
\hline MIP: & Macrophage inflammatory protein & & scription factor 1 \\
\hline MMP-1: & $\begin{array}{l}\text { Matrix metalloproteinase- } 1 \text {, interstitial } \\
\text { collagenase }\end{array}$ & SREBP-1c: & $\begin{array}{l}\text { Sterol-regulatory-element binding protein- } \\
1 \mathrm{c}\end{array}$ \\
\hline MMP-3: & Matrix metalloproteinase-3, stromelysin-1 & STAT: & Signal transducer and activator of \\
\hline MMP-13: & Matrix metalloproteinase-13, collagenase 3 & & transcription \\
\hline MMP: & Matrix metalloproteinase & $\mathrm{T}:$ & Testosterone \\
\hline MPO: & Myeloperoxidase & T-AOC: & Total antioxidant capacity \\
\hline mRNA: & Messenger ribonucleic acid & TAS: & Total antioxidant status \\
\hline MT: & Metallothionein & TBARS: & Thiobarbituric acid reactive substances \\
\hline \multirow[t]{2}{*}{ MTH 1: } & \multirow{2}{*}{$\begin{array}{l}\text { A gene encoding 8-oxo-7,8-dihydrodeoxy- } \\
\text { guanosine triphosphatase }\end{array}$} & TC: & Total cholesterol \\
\hline & & TG: & Triglycerides \\
\hline Na: & Sodium & TGF- $\beta$ : & Transforming growth factor beta \\
\hline \multirow[t]{2}{*}{ NADH: } & \multirow{2}{*}{$\begin{array}{l}\text { Nicotinamide adenine dinucleotide } \\
\text { reduced form }\end{array}$} & tHcy: & Total homocysteine \\
\hline & & TIMP: & Tissue inhibitor of metalloproteinases \\
\hline \multirow[t]{2}{*}{$\mathrm{Na}^{+} / \mathrm{K}^{+}$ATPase: } & \multirow{2}{*}{$\begin{array}{l}\text { Sodium- and potassium-activated adeno- } \\
\text { sine } 5^{\prime} \text {-triphosphatase }\end{array}$} & TLC: & Total leukocytic count \\
\hline & & TLR: & Tall-like receptor \\
\hline NASH: & Nonalcoholic steatohepatitis & TNF- $\alpha$ : & Tumor necrosis factor alpha \\
\hline $\mathrm{NF}-\kappa \mathrm{B}:$ & Nuclear factor-kappa B & TOS: & Total oxidant status \\
\hline NO: & Nitric oxide & TP: & Total protein \\
\hline $\mathrm{NO}_{3}:$ & Nitrate & TSH: & Thyroid-stimulating hormone \\
\hline $\mathrm{NO}_{2}$ : & Nitrite & $\mathrm{TXA}_{2}$ : & Thromboxane A2 \\
\hline NOX: & NADPH oxidase & $\mathrm{TXB}_{2}$ : & Thromboxane B2 \\
\hline NP-SH: & Nonprotein sulfhydryl groups & UA: & Uric acid \\
\hline NQO1: & $\mathrm{NAD}(\mathrm{P}) \mathrm{H}$ :quinone oxidoreductase 1 & UDPGT: & UDP-glucuronosyl transferase \\
\hline Nrf2: & Nuclear erythroid 2-related factor 2 & VEGF: & Vascular endothelial growth factor \\
\hline 8-OHdG: & 8 -Hydroxy-2' deoxyguanosine & VLDL: & Very low-density lipoprotein \\
\hline OSI: & Oxidative stress index & VLDL-c: & Very low-density lipoprotein cholesterol \\
\hline P: & Phosphorus & WBC: & White blood cells \\
\hline P53: & p53 protein & $\mathrm{XO}:$ & Xanthine oxidase \\
\hline $\mathrm{pAC}$ & Phosphorylated acetyl-CoA carboxylase & $\mathrm{Zn}:$ & Zinc. \\
\hline
\end{tabular}

\section{pAMPK: $\quad \begin{aligned} & \text { Phosphorilated adenosine- } \\ & \text { monophosphate-activated protein kinase } \quad \text { Conflicts of Interest }\end{aligned}$}

$\begin{array}{ll}\text { Pb: } & \text { Lead } \\ \text { PC: } & \text { Protein carbonyls } \\ \text { PCG: } & \text { Protein carbonyl groups } \\ \text { PCNA: } & \text { Proliferating cell nuclear antigen } \\ \text { peNOS: } & \text { Phosphorylated eNOS } \\ \text { PGE }: & \text { Prostaglandin } E_{2} \\ \text { PGI2: } & \text { Prostacyclin } \\ \text { PHGPx: } & \text { Phospholipid hydroxyperoxide GPx } \\ \text { PKC: } & \text { Protein kinase C } \\ \text { PLT: } & \text { Platelets } \\ \text { P38 MAPK: } & \text { p38 mitogen-activated protein kinase } \\ \text { pNF- } \kappa \text { B: } & \text { Phospho-NF- } \kappa \text { B } \\ \text { p.o.: } & \text { Orally } \\ \text { QR: } & \text { Quinone reductase } \\ \text { RANTES: } & \text { Regulated on Activation, Normal T-cell } \\ & \text { Expressed and Secreted } \\ \text { RBC: } & \text { Red blood cells }\end{array}$

The authors declare that there is no conflict of interest regarding the publication of this article.

\section{References}

[1] O. T. Olaniyan, O. T. Kunle-Alabi, and Y. Raji, "Protective effects of methanol extract of Plukenetia conophora seeds and 4H-pyran-4-one 2, 3-dihydro-3, 5-dihydroxy-6-methyl on the reproductive function of male Wistar rats treated with cadmium chloride," JBRA Assisted Reproduction, vol. 22, no. 4, pp. 289-300, 2018.

[2] A. Mirzaei, S. Sepehri, H. Sadeghi, and A. Alamdari, "Protecting impact of Jaft against carbendazim induced biochemical changes in male Wistar rats," Journal of Medicine and Life, vol. 8, no. Spec Iss 3, pp. 96-100, 2015.

[3] T. K. Dua, S. Dewanjee, R. Khanra et al., "The effects of two common edible herbs, Ipomoea aquatica and Enhydra 
fluctuans, on cadmium-induced pathophysiology: a focus on oxidative defence and anti-apoptotic mechanism," Journal of Translational Medicine, vol. 13, no. 1, article 245, 2015.

[4] D. Gao, L. N. Zeng, P. Zhang et al., "Rhubarb anthraquinones protect rats against mercuric chloride $\left(\mathrm{HgCl}_{2}\right)$ induced acute renal failure," Molecules, vol. 21, no. 3, p. 298, 2016.

[5] M. Mężyńska, M. M. Brzóska, J. Rogalska, and B. Piłat-Marcinkiewicz, "Extract from Aronia melanocarpa L. berries prevents cadmium-induced oxidative stress in the liver: a study in a rat model of low-level and moderate lifetime human exposure to this toxic metal," Nutrients, vol. 11, no. 1, p. 21, 2019.

[6] M. Chaâbane, M. Koubaa, N. Soudani et al., "Nitraria retusa fruit prevents penconazole-induced kidney injury in adult rats through modulation of oxidative stress and histopathological changes," Pharmaceutical Biology, vol. 55, no. 1, pp. 1061-1073, 2017.

[7] A. El Arem, L. Lahouar, E. B. Saafi et al., "Dichloroacetic acidinduced testicular toxicity in male rats and the protective effect of date fruit extract," BMC Pharmacology and Toxicology, vol. 18, no. 1, article 17, 2017.

[8] H. A. Khalaf, E. A. Arafat, and F. M. Ghoneim, "A histological, immunohistochemical and biochemical study of the effects of pomegranate peel extracts on gibberellic acid induced oxidative stress in adult rat testes," Biotechnic \& Histochemistry, vol. 94, no. 8, pp. 569-582, 2019.

[9] A. T. Mossa, F. M. Ibrahim, S. M. Mohafrash, D. H. Abou Baker, and S. El Gengaihi, "Protective effect of ethanolic extract of grape pomace against the adverse effects of cypermethrin on weanling female rats," Evidence-based Complementary and Alternative Medicine, vol. 2015, Article ID 381919, 10 pages, 2015.

[10] A. E. Abdel Moneim, "Indigofera oblongifolia prevents lead acetate-induced hepatotoxicity, oxidative stress, fibrosis and apoptosis in rats," PLoS One, vol. 11, no. 7, article e0158965, 2016.

[11] M. E. El-Boshy, B. Refaat, A. H. Qasem et al., "The remedial effect of Thymus vulgaris extract against lead toxicityinduced oxidative stress, hepatorenal damage, immunosuppression, and hematological disorders in rats," Environmental Science and Pollution Research International, vol. 26, no. 22, pp. 22736-22746, 2019.

[12] Y. Ke, K. Yu, W. Zeng, and G. Lian, "Protective roles of Pyracantha fortuneana extract on acute renal toxicity induced by cadmium chloride in rats," Acta Cirúrgica Brasileira, vol. 34, no. 7, article e201900706, 2019.

[13] M. AlSaid, R. Mothana, M. Raish et al., "Evaluation of the effectiveness of Piper cubeba extract in the amelioration of CCl4-induced liver injuries and oxidative damage in the rodent model," BioMed Research International, vol. 2015, Article ID 359358, 11 pages, 2015.

[14] K. Bellassoued, A. Ben Hsouna, K. Athmouni et al., "Protective effects of Mentha piperita L. leaf essential oil against $\mathrm{CCl}_{4}$ induced hepatic oxidative damage and renal failure in rats," Lipids in Health and Disease, vol. 17, no. 1, article 9, 2018.

[15] S. Alzahrani, W. Ezzat, R. E. Elshaer et al., "Standarized Tribulus terrestris extract protects against rotenone-induced oxidative damage and nigral dopamine neuronal loss in mice," Journal of Physiology and Pharmacology, vol. 69, no. $6,2018$.
[16] S. Hosseinian, M. A. Hadjzadeh, N. M. Roshan et al., "Renoprotective effect of Nigella sativa against cisplatin-induced nephrotoxicity and oxidative stress in rat," Saudi Journal of Kidney Diseases and Transplantation, vol. 29, no. 1, pp. 1929, 2018.

[17] A. C. Sevastre-Berghian, V. A. Toma, B. Sevastre et al., "Characterization and biological effects of Hypericum extracts on experimentally-induced - anxiety, oxidative stress and inflammation in rats," Journal of Physiology and Pharmacology, vol. 69, no. 5, 2018.

[18] S. Ahmad and A. Zeb, "Effects of phenolic compounds from aqueous extract of Trifolium repens against acetaminopheninduced hepatotoxicity in mice," Journal of Food Biochemistry, vol. 43, no. 9, article e12963, 2019.

[19] S. A. A. Azim, M. T. Abdelrahem, M. M. Said, and A. Khattab, "Protective effect of Moringa peregrina leaves extract on acetaminophen-induced liver toxicity in albino rats," African Journal of Traditional, Complementary, and Alternative Medicines, vol. 14, no. 2, pp. 206-216, 2017.

[20] N. Baali, Z. Belloum, S. Baali et al., "Protective activity of total polyphenols from Genista quadriflora Munby and Teucrium polium geyrii Maire in acetaminophen-induced hepatotoxicity in rats," Nutrients, vol. 8, no. 4, p. 193, 2016.

[21] H. Bouzenna, N. Samout, E. Amani et al., "Protective effects of Pinus halepensis L. essential oil on aspirin-induced acute liver and kidney damage in female Wistar albino rats," Journal of Oleo Science, vol. 65, no. 8, pp. 701-712, 2016.

[22] S. M. Chinnappan, A. George, P. Thaggikuppe et al., "Nephroprotective effect of herbal extract Eurycoma longifolia on paracetamol-induced nephrotoxicity in rats," Evidencebased Complementary and Alternative Medicine, vol. 2019, Article ID 4916519, 6 pages, 2019.

[23] T. Afsar, S. Razak, A. Almajwal, M. R. Khan, and R. Acacia hydaspica, "Acacia hydaspica R. Parker ameliorates cisplatin induced oxidative stress, DNA damage and morphological alterations in rat pulmonary tissue," BMC Complementary and Alternative Medicine, vol. 18, no. 1, p. 49, 2018.

[24] W. Ahmed, A. Zaki, and T. Nabil, "Prevention of methotrexate-induced nephrotoxicity by concomitant administration of garlic aqueous extract in rat," Turkish Journal of Medical Sciences, vol. 45, no. 3, pp. 507-516, 2015.

[25] R. C. Chen, X. D. Xu, X. Zhi Liu et al., "Total flavonoids from Clinopodium chinense (Benth.) O. Ktze protect against doxorubicin-induced cardiotoxicity in vitro and in vivo," Evidence-based Complementary and Alternative Medicine, vol. 2015, Article ID 472565, 17 pages, 2015.

[26] J. G. Omole, O. A. Ayoka, Q. K. Alabi et al., "Protective effect of kolaviron on cyclophosphamide-induced cardiac toxicity in rats," Journal of Evidence-Based Integrative Medicine, vol. 23, article 2156587218757649, 2018.

[27] K. P. Rahate and A. Rajasekaran, "Hepatoprotection by active fractions from Desmostachya bipinnata stapf (L.) against tamoxifen-induced hepatotoxicity," Indian Journal of Pharmacology, vol. 47, no. 3, pp. 311-315, 2015.

[28] B. Apaydin Yildirim, S. Kordali, K. A. Terim Kapakin, F. Yildirim, E. Aktas Senocak, and S. Altun, "Effect of Helichrysum plicatum DC. subsp. plicatum ethanol extract on gentamicin-induced nephrotoxicity in rats," Journal of Zhejiang University. Science. B, vol. 18, no. 6, pp. 501-511, 2017.

[29] M. T. Boroushaki, S. Fanoudi, H. Mollazadeh, S. BoroumandNoughabi, and A. Hosseini, "Reno-protective effect of Rheum turkestanicum against gentamicin-induced nephrotoxicity," 
Iranian Journal of Basic Medical Sciences, vol. 22, no. 3, pp. 328-333, 2019.

[30] T. Albrahim and M. A. Binobead, "Roles of Moringa oleifera leaf extract in improving the impact of high dietary intake of monosodium glutamate-induced liver toxicity, oxidative stress, genotoxicity, DNA damage, and PCNA alterations in male rats," Oxidative Medicine and Cellular Longevity, vol. 2018, Article ID 4501097, 11 pages, 2018.

[31] P. Chonpathompikunlert, P. Boonruamkaew, W. Sukketsiri, P. Hutamekalin, and M. Sroyraya, "The antioxidant and neurochemical activity of Apium graveolens L. and its ameliorative effect on MPTP-induced Parkinson-like symptoms in mice," BMC Complementary and Alternative Medicine, vol. 18, no. 1, article 103, 2018.

[32] L. Hritcu, J. A. Noumedem, O. Cioanca, M. Hancianu, P. Postu, and M. Mihasan, "Anxiolytic and antidepressant profile of the methanolic extract of Piper nigrum fruits in beta-amyloid (1-42) rat model of Alzheimer's disease," Behavioral and Brain Functions, vol. 11, no. 1, article 13, 2015.

[33] Y. Sheng, J. Liu, S. Zheng et al., "Mulberry leaves ameliorate obesity through enhancing brown adipose tissue activity and modulating gut microbiota," Food \& Function, vol. 10, no. 8, pp. 4771-4781, 2019.

[34] B. Veber, A. Camargo, A. P. Dalmagro et al., "Red cabbage (Brassica oleracea L.) extract reverses lipid oxidative stress in rats," Anais da Academia Brasileira de Ciências, vol. 92, no. 1, article e20180596, 2020.

[35] S. Kaur, D. Sharma, A. P. Singh, and S. Kaur, "Amelioration of hepatic function, oxidative stress, and histopathologic damages by Cassia fistula L. fraction in thioacetamideinduced liver toxicity," Environmental Science and Pollution Research International, vol. 26, no. 29, pp. 29930-29945, 2019.

[36] N. Panth, S. H. Park, H. J. Kim, D. H. Kim, and M. H. Oak, "Protective effect of Salicornia europaea extracts on high salt intake-induced vascular dysfunction and hypertension," International Journal of Molecular Sciences, vol. 17, no. 7, p. 1176, 2016.

[37] H. M. Tag, "Hepatoprotective effect of mulberry (Morus nigra) leaves extract against methotrexate induced hepatotoxicity in male albino rat," BMC Complementary and Alternative Medicine, vol. 15, no. 1, article 252, 2015.

[38] W. Wang, H. Li, J. Yu et al., "Protective effects of Chinese herbal medicine Rhizoma drynariae in rats after traumatic brain injury and identification of active compound," Molecular Neurobiology, vol. 53, no. 7, pp. 4809-4820, 2016.

[39] J. Malik, M. Karan, and R. Dogra, "Ameliorating effect of Celastrus paniculatus standardized extract and its fractions on 3-nitropropionic acid induced neuronal damage in rats: possible antioxidant mechanism," Pharmaceutical Biology, vol. 55, no. 1, pp. 980-990, 2017.

[40] U. Rashid, M. R. Khan, and M. Sajid, "Hepatoprotective potential of Fagonia olivieri DC. against acetaminophen induced toxicity in rat," BMC Complementary and Alternative Medicine, vol. 16, no. 1, article 449, 2016.

[41] J. Sdayria, I. Rjeibi, A. Feriani et al., "Chemical composition and antioxidant, analgesic, and anti-inflammatory effects of methanolic extract of Euphorbia retusa in mice," Pain Research \& Management, vol. 2018, article 4838413, pp. 111, 2018.
[42] J. Wattanathorn, P. Thiraphatthanavong, W. Thukham-Mee, S. Muchimapura, P. Wannanond, and T. Tong-Un, "Anticataractogenesis and antiretinopathy effects of the novel protective agent containing the combined extract of mango and Vietnamese coriander in STZ-diabetic rats," Oxidative Medicine and Cellular Longevity, vol. 2017, Article ID 5290161, 13 pages, 2017.

[43] P. R. de Oliveira, C. A. da Costa, G. F. de Bem et al., "Euterpe oleracea Mart.-derived polyphenols protect mice from dietinduced obesity and fatty liver by regulating hepatic lipogenesis and cholesterol excretion," PLoS One, vol. 10, no. 12, article e0143721, 2015.

[44] A. Dogan and O. O. Anuk, "Investigation of the phytochemical composition and antioxidant properties of chinar (Platanus orientalis L.) leaf infusion against ethanol-induced oxidative stress in rats," Molecular Biology Reports, vol. 46, no. 3, pp. 3049-3061, 2019.

[45] S. Chanda, L. Deb, R. K. Tiwari, K. Singh, and S. Ahmad, "Gastroprotective mechanism of Paederia foetida Linn. (Rubiaceae) - a popular edible plant used by the tribal community of North-East India," BMC Complementary and Alternative Medicine, vol. 15, no. 1, article 304, 2015.

[46] M. J. Choi, H. M. Zheng, J. M. Kim, K. W. Lee, Y. H. Park, and D. H. Lee, "Protective effects of Centella asiatica leaf extract on dimethylnitrosamine-induced liver injury in rats," Molecular Medicine Reports, vol. 14, no. 5, pp. 4521-4528, 2016.

[47] H. Kiziltas, S. Ekin, M. Bayramoglu et al., "Antioxidant properties of Ferulago angulata and its hepatoprotective effect against N-nitrosodimethylamine-induced oxidative stress in rats," Pharmaceutical Biology, vol. 55, no. 1, pp. 888-897, 2017.

[48] J. W. Jeong, H. H. Lee, J. Kim et al., "Mori folium water extract alleviates articular cartilage damages and inflammatory responses in monosodium iodoacetate-induced osteoarthritis rats," Molecular Medicine Reports, vol. 16, no. 4, pp. 3841-3848, 2017.

[49] D. Choudhary, P. Kothari, A. K. Tripathi et al., "Spinacia oleracea extract attenuates disease progression and subchondral bone changes in monosodium iodoacetateinduced osteoarthritis in rats," BMC Complementary and Alternative Medicine, vol. 18, no. 1, article 69, 2018.

[50] N. B. Ghate, D. Chaudhuri, A. Das, S. Panja, and N. Mandal, "An antioxidant extract of the insectivorous plant Drosera burmannii Vahl. alleviates Iron-induced oxidative stress and hepatic injury in mice," PLoS One, vol. 10, no. 5, article e0128221, 2015.

[51] J. Liu, D. Luo, Y. Wu et al., "The protective effect of Sonneratia apetala fruit extract on acetaminophen-induced liver injury in mice," Evidence-based Complementary and Alternative Medicine, vol. 2019, Article ID 6919834, 12 pages, 2019.

[52] A. E. El-Hadary and M. F. Ramadan, "Antioxidant traits and protective impact of Moringa oleifera leaf extract against diclofenac sodium-induced liver toxicity in rats," Journal of Food Biochemistry, vol. 43, no. 2, article e12704, 2019.

[53] A. Fahmi, N. Hassanen, M. Abdur-Rahman, and E. ShamsEldin, "Phytochemicals, antioxidant activity and hepatoprotective effect of ginger (Zingiber officinale) on diethylnitrosamine toxicity in rats," Biomarkers, vol. 24, no. 5, pp. 436-447, 2019.

[54] R. Simeonova, V. M. Bratkov, M. Kondeva-Burdina, V. Vitcheva, V. Manov, and I. Krasteva, "Experimental liver protection of n-butanolic extract of Astragalus 
monspessulanus L. on carbon tetrachloride model of toxicity in rat," Redox Report, vol. 20, no. 4, pp. 145-153, 2015.

[55] M. S. Sundaram, M. K. Neog, M. Rasool et al., "Guggulipid ameliorates adjuvant-induced arthritis and liver oxidative damage by suppressing inflammatory and oxidative stress mediators," Phytomedicine, vol. 64, article 152924, 2019.

[56] X. Tang, R. Wei, A. Deng, and T. Lei, "Protective effects of ethanolic extracts from artichoke, an edible herbal medicine, against acute alcohol-induced liver injury in mice," Nutrients, vol. 9, no. 9, p. 1000, 2017.

[57] M. Balbaa, S. A. Abdulmalek, and S. Khalil, "Oxidative stress and expression of insulin signaling proteins in the brain of diabetic rats: role of Nigella sativa oil and antidiabetic drugs," PLoS One, vol. 12, no. 5, article e0172429, 2017.

[58] P. M. D. Almeida, S. U. Kamath, P. R. Shenoy, L. K. Bernhardt, A. Kishore, and K. S. Rai, "Persistent attenuation of brain oxidative stress through aging in perinatal maternal separated rat pups supplemented with choline and docosahexaenoic acid or Clitoria ternatea aqueous root extract," Folia Neuropathologica, vol. 56, no. 3, pp. 206-214, 2018.

[59] A. R. Silva, C. D. Cerdeira, A. R. Brito et al., "Green banana pasta diet prevents oxidative damage in liver and kidney and improves biochemical parameters in type 1 diabetic rats," Archives of Endocrinology and Metabolism, vol. 60, no. 4, pp. 355-366, 2016.

[60] X. Xu, H. Lv, Z. Xia et al., "Rhein exhibits antioxidative effects similar to Rhubarb in a rat model of traumatic brain injury," BMC Complementary and Alternative Medicine, vol. 17, no. 1, article 140, 2017.

[61] M. Qiu, F. Xiao, T. Wang et al., "Protective effect of Hedansanqi Tiaozhi Tang against non-alcoholic fatty liver disease in vitro and in vivo through activating $\mathrm{Nrf} 2 / \mathrm{HO}-1$ antioxidant signaling pathway," Phytomedicine, vol. 67, article 153140, 2020.

[62] M. Long, Y. Liu, Y. Cao, N. Wang, M. Dang, and J. He, "Proanthocyanidins attenuation of chronic lead-induced liver oxidative damage in Kunming mice via the Nrf 2/ARE pathway," Nutrients, vol. 8, no. 10, p. 656, 2016.

[63] M. Muriach, M. Flores-Bellver, F. J. Romero, and J. M. Barcia, "Diabetes and the brain: oxidative stress, inflammation, and autophagy," Oxidative Medicine and Cellular Longevity, vol. 2014, Article ID 102158, 9 pages, 2014.

[64] L. Behrend, G. Henderson, and R. M. Zwacka, "Reactive oxygen species in oncogenic transformation," Biochemical Society Transactions, vol. 31, no. 6, pp. 1441-1444, 2003.

[65] Z. Lou, J. Wang, Y. Chen et al., "Linderae radix ethanol extract attenuates alcoholic liver injury via attenuating inflammation and regulating gut microbiota in rats," Brazilian Journal of Medical and Biological Research, vol. 52, no. 6, article e7628, 2019.

[66] M. Du, X. Hu, L. Kou, B. Zhang, and C. Zhang, "Lycium barbarum polysaccharide mediated the antidiabetic and antinephritic effects in diet-streptozotocin-induced diabetic Sprague Dawley rats via regulation of NF- $\kappa \mathrm{B}$," BioMed Research International, vol. 2016, Article ID 3140290, 9 pages, 2016.

[67] D. K. Morrison, "MAP kinase pathways," Cold Spring Harbor Perspectives in Biology, vol. 4, no. 11, article a011254, 2012.

[68] J. Zhao, Y. F. Qi, and Y. R. Yu, "STAT3, a key regulator in liver fibrosis," Annals of Hepatology, vol. S1665-2681, no. 20, pp. 30071-30075, 2020.
[69] A. Charras, P. Arvaniti, C. Le Dantec et al., "JAK inhibitors and oxidative stress control," Frontiers in Immunology, vol. 10, p. 2814, 2019.

[70] X. Z. Dong, Y. N. Wang, X. Tan, P. Liu, D. H. Guo, and C. Yan, "Protective effect of JXT ethanol extract on radiation-induced hematopoietic alteration and oxidative stress in the liver," Oxidative Medicine and Cellular Longevity, vol. 2018, Article ID 9017835, 12 pages, 2018.

[71] S. Selmi, K. Rtibi, D. Grami, H. Sebai, and L. Marzouki, "Lavandula stoechas essential oils protect against malathion-induces reproductive disruptions in male mice," Lipids in Health and Disease, vol. 17, no. 1, article 253, 2018.

[72] S. Jahan, T. Azad, A. Ayub et al., "Ameliorating potency of Chenopodium album Linn. and vitamin $C$ against mercuric chloride-induced oxidative stress in testes of Sprague Dawley rats," Environmental Health and Preventive Medicine, vol. 24, no. 1, article 62, 2019.

[73] W. Kim, D. W. Kim, D. Y. Yoo et al., "Antioxidant effects of Dendropanax morbifera Léveille extract in the hippocampus of mercury-exposed rats," BMC Complementary and Alternative Medicine, vol. 15, no. 1, article 247, 2015.

[74] L. Feng, X. Wang, F. Peng et al., "Walnut protein hydrolysates play a protective role on neurotoxicity induced by d-galactose and aluminum chloride in mice," Molecules, vol. 23, no. 9, p. 2308, 2018.

[75] A. N. Badr and M. A. Naeem, "Protective efficacy using capegolden berry against pre-carcinogenic aflatoxins induced in rats," Toxicology Reports, vol. 6, pp. 607-615, 2019.

[76] I. H. Bahcecioglu, M. Ispiroglu, M. Tuzcu et al., "Pistacia terebinthus coffee protects against thioacetamide-induced liver injury in rats," Acta Medica (Hradec Králové), vol. 58, no. 2, pp. 56-61, 2015.

[77] H. R. Yang, H. Lee, J. H. Kim et al., “Therapeutic effect of Rumex japonicus Houtt. on DNCB-induced atopic dermatitis-like skin lesions in Balb/c mice and human keratinocyte HaCaT cells," Nutrients, vol. 11, no. 3, p. 573, 2019.

[78] H. Yoshioka, M. Tanaka, H. Fujii, and T. Nonogaki, "Sasa veitchii extract suppresses carbon tetrachloride-induced hepato- and nephrotoxicity in mice," Environmental Health and Preventive Medicine, vol. 21, no. 6, pp. 554-562, 2016.

[79] H. Xu, L. Liu, Y. Chen et al., "The chemical character of polysaccharides from processed Morindae officinalis and their effects on anti-liver damage," International Journal of Biological Macromolecules, vol. 141, pp. 410-421, 2019.

[80] M. D. Shah, U. J. A. D'Souza, and M. Iqbal, “The potential protective effect of Commelina nudiflora L. against carbon tetrachloride $\left(\mathrm{CCl}_{4}\right)$-induced hepatotoxicity in rats, mediated by suppression of oxidative stress and inflammation," Environmental Health and Preventive Medicine, vol. 22, no. 1, article 66, 2017.

[81] U. Kukongviriyapan, V. Kukongviriyapan, P. Pannangpetch et al., "Mamao pomace extract alleviates hypertension and oxidative stress in nitric oxide deficient rats," Nutrients, vol. 7, no. 8, pp. 6179-6194, 2015.

[82] T. A. Lin, B. J. Ke, C. S. Cheng, J. J. Wang, B. L. Wei, and C. L. Lee, "Red quinoa bran extracts protects against carbon tetrachloride-induced liver injury and fibrosis in mice via activation of antioxidative enzyme systems and blocking TGF- $\beta 1$ pathway," Nutrients, vol. 11, no. 2, p. 395, 2019.

[83] M. K. Parvez, M. S. Al-Dosari, A. H. Arbab, P. Alam, M. S. Alsaid, and A. A. Khan, "Hepatoprotective effect of Solanum 
surattense leaf extract against chemical- induced oxidative and apoptotic injury in rats," BMC Complementary and Alternative Medicine, vol. 19, no. 1, article 154, 2019.

[84] D. V. Thomaz, L. F. Peixoto, T. S. de Oliveira et al., "Antioxidant and neuroprotective properties of Eugenia dysenterica leaves," Oxidative Medicine and Cellular Longevity, vol. 2018, Article ID 3250908, 9 pages, 2018.

[85] W. Zheng, Q. Wang, X. Lu et al., "Protective effects of Dracocephalum heterophyllumin ConA-induced acute hepatitis," Mediators of Inflammation, vol. 2016, Article ID 2684321, 8 pages, 2016.

[86] N. Ahmed, D. S. El-Agamy, G. A. Mohammed, H. AboHaded, M. Elkablawy, and S. R. M. Ibrahim, "Suppression of LPS-induced hepato- and cardiotoxic effects by Pulicaria petiolaris via NF- $\kappa$ B dependent mechanism," Cardiovascular Toxicology, vol. 20, no. 2, pp. 121-129, 2020.

[87] M. Raish, A. Ahmad, K. M. Alkharfy et al., "Hepatoprotective activity of Lepidium sativum seeds against D-galactosamine/lipopolysaccharide induced hepatotoxicity in animal model," BMC Complementary and Alternative Medicine, vol. 16, no. 1, article 501, 2016.

[88] F. Khan, T. J. Khan, G. Kalamegam et al., "Anti-cancer effects of Ajwa dates (Phoenix dactylifera L.) in diethylnitrosamine induced hepatocellular carcinoma in Wistar rats," BMC Complementary and Alternative Medicine, vol. 17, no. 1, article 418, 2017.

[89] İ. Bingül, C. Başaran-Küçükgergin, A. F. Aydın et al., "Blueberry treatment attenuated cirrhotic and preneoplastic lesions and oxidative stress in the liver of diethylnitrosamine-treated rats," International Journal of Immunopathology and Pharmacology, vol. 29, no. 3, pp. 426-437, 2016.

[90] E. Rouhollahi, S. Z. Moghadamtousi, N. Al-Henhena et al., "The chemopreventive potential of Curcuma purpurascens rhizome in reducing azoxymethane-induced aberrant crypt foci in rats," Drug Design, Development and Therapy, vol. 9, pp. 3911-3922, 2015.

[91] R. Liu, Q. H. Chen, J. W. Ren et al., "Ginseng (Panax ginseng Meyer) oligopeptides protect against binge drinking-induced liver damage through inhibiting oxidative stress and inflammation in rats," Nutrients, vol. 10, no. 11, p. 1665, 2018.

[92] N. Phunchago, J. Wattanathorn, and K. Chaisiwamongkol, "Tiliacora triandra, an anti-intoxication plant, improves memory impairment, neurodegeneration, cholinergic function, and oxidative stress in hippocampus of ethanol dependence rats," Oxidative Medicine and Cellular Longevity, vol. 2015, Article ID 918426, 9 pages, 2015.

[93] A. Akbari, K. Nasiri, M. Heydari, S. H. Mosavat, and A. Iraji, "The protective effect of hydroalcoholic extract of Zingiber officinale Roscoe (ginger) on ethanol-induced reproductive toxicity in male rats," Journal of Evidence-Based Complementary \& Alternative Medicine, vol. 22, no. 4, pp. 609-617, 2017.

[94] J. C. Jung, Y. H. Lee, S. H. Kim et al., "Hepatoprotective effect of licorice, the root of Glycyrrhiza uralensis Fischer, in alcohol-induced fatty liver disease," BMC Complementary and Alternative Medicine, vol. 16, article 19, 2015.

[95] M. E. Ebada, "Essential oils of green cumin and chamomile partially protect against acute acetaminophen hepatotoxicity in rats," Anais da Academia Brasileira de Ciências, vol. 90, 2 suppl 1, pp. 2347-2358, 2018.

[96] U. S. Uthaya Kumar, Y. Chen, J. R. Kanwar, and S. Sasidharan, "Redox control of antioxidant and antihepato- toxic activities of Cassia surattensis seed extract against paracetamol intoxication in mice: in vitro and in vivo studies of herbal green antioxidant," Oxidative Medicine and Cellular Longevity, vol. 2016, Article ID 6841348, 13 pages, 2016.

[97] G. Mishra, R. L. Khosa, P. Singh, and K. K. Jha, "Hepatoprotective potential of ethanolic extract of Pandanus odoratissimus root against paracetamol-induced hepatotoxicity in rats," Journal of Pharmacy \& Bioallied Sciences, vol. 7, no. 1, pp. 45-48, 2015.

[98] P. Valipour, E. Heidarian, A. Khoshdel, and M. GholamiArjenaki, "Protective effects of hydroalcoholic extract of Ferulago angulata against gentamicin-induced nephrotoxicity in rats," Iranian Journal of Kidney Diseases, vol. 10, no. 4, pp. 189-196, 2016.

[99] Y. Zhang, X. Chi, Z. Wang et al., "Protective effects of Panax notoginseng saponins on PME-induced nephrotoxicity in mice," Biomedicine \& Pharmacotherapy, vol. 116, article 108970, 2019.

[100] E. S. Kim, J. S. Lee, M. Akram et al., "Protective activity of Dendropanax morbifera against cisplatin-induced acute kidney injury," Kidney \& Blood Pressure Research, vol. 40, no. 1, pp. 1-12, 2015.

[101] S. A. Sheweita, L. S. El-Hosseiny, and M. A. Nashashibi, "Protective effects of essential oils as natural antioxidants against hepatotoxicity induced by cyclophosphamide in mice," PLoS One, vol. 11, no. 11, article e0165667, 2016.

[102] M. Kpemissi, K. Eklu-Gadegbeku, V. P. Veerapur et al., "Nephroprotective activity of Combretum micranthum G. Don in cisplatin induced nephrotoxicity in rats: in-vitro, invivo and in-silico experiments," Biomedicine \& Pharmacotherapy, vol. 116, article 108961, 2019.

[103] A. R. Moghadam, S. Tutunchi, A. Namvaran-Abbas-Abad et al., "Pre-administration of turmeric prevents methotrexate-induced liver toxicity and oxidative stress," BMC Complementary and Alternative Medicine, vol. 15, no. 1, article 246, 2015.

[104] A. Ben Saad, B. Dalel, I. Rjeibi et al., "Phytochemical, antioxidant and protective effect of cactus cladodes extract against lithium-induced liver injury in rats," Pharmaceutical Biology, vol. 55, no. 1, pp. 516-525, 2017.

[105] M. I. Khalil, I. Ahmmed, R. Ahmed et al., "Amelioration of isoproterenol-induced oxidative damage in rat myocardium by Withania somnifera leaf extract," BioMed Research International, vol. 2015, Article ID 624159, 10 pages, 2015.

[106] R. Dianita, I. Jantan, A. Z. Amran, and J. Jalil, "Protective effects of Labisia pumila var. alata on biochemical and histopathological alterations of cardiac muscle cells in isoproterenol-induced myocardial infarction rats," Molecules, vol. 20, no. 3, pp. 4746-4763, 2015.

[107] A. A. Shahat, M. S. Alsaid, S. Rafatullah et al., "Treatment with Rhus tripartita extract curtails isoproterenol-elicited cardiotoxicity and oxidative stress in rats," BMC Complementary and Alternative Medicine, vol. 16, no. 1, article 351, 2016.

[108] F. X. Kemka Nguimatio, P. B. Deeh Defo, M. Wankeu-Nya et al., "Aframomum melegueta prevents the ejaculatory complications of propylthiouracil-induced hypothyroidism in sexually experienced male rats: evidence from intravaginal and fictive ejaculations," Journal of Integrative Medicine, vol. 17, no. 5, pp. 359-365, 2019.

[109] H. Nasri, S. Hajian, A. Ahmadi et al., "Ameliorative effect of green tea against contrast-induced renal tubular cell injury," 
Iranian Journal of Kidney Diseases, vol. 9, no. 6, pp. 421-426, 2015.

[110] G. I. A. El-Rahman, A. Behairy, N. M. Elseddawy et al., "Saussurea lappa ethanolic extract attenuates triamcinolone acetonide-induced pulmonary and splenic tissue damage in rats via modulation of oxidative stress, inflammation, and apoptosis," Antioxidants, vol. 9, no. 5, p. 396, 2020.

[111] D. S. Mohale, A. S. Tripathi, A. V. Shrirao, A. G. Jawarkar, and A. V. Chandewar, "Evaluation of antioxidant effect of Nerium indicum in anxious rats," Indian Journal of Pharmacology, vol. 48, no. 4, pp. 430-433, 2016.

[112] Y. Wu, A. Qiu, Z. Yang et al., "Malva sylvestris extract alleviates the astrogliosis and inflammatory stress in LPS-induced depression mice," Journal of Neuroimmunology, vol. 336, article 577029, 2019.

[113] C. M. Lin, Y. T. Lin, T. L. Lee, Z. Imtiyaz, W. C. Hou, and M. H. Lee, "In vitro and in vivo evaluation of the neuroprotective activity of Uncaria hirsuta Haviland," Journal of Food and Drug Analysis, vol. 28, no. 1, pp. 147-158, 2020.

[114] D. Galanis, K. Soultanis, P. Lelovas et al., "Protective effect of Glycyrrhiza glabra roots extract on bone mineral density of ovariectomized rats," Biomedicine, vol. 9, no. 2, p. 8, 2019.

[115] F. P. Leung, L. M. Yung, C. Y. Ngai et al., "Chronic black tea extract consumption improves endothelial function in ovariectomized rats," European Journal of Nutrition, vol. 55, no. 5, pp. 1963-1972, 2016.

[116] A. K. Hamm, D. K. Manter, J. S. Kirkwood, L. M. Wolfe, K. Cox-York, and T. L. Weir, "The effect of hops (Humulus lupulus L.) extract supplementation on weight gain, adiposity and intestinal function in ovariectomized mice," Nutrients, vol. 11, no. 12, article E3004, 2019.

[117] M. Kaveh, A. Eidi, A. Nemati, and M. H. Boskabady, "The extract of Portulaca oleracea and its constituent, alpha linolenic acid affects serum oxidant levels and inflammatory cells in sensitized rats," Iranian Journal of Allergy, Asthma, and Immunology, vol. 16, no. 3, pp. 256-270, 2017.

[118] L. Taguchi, N. M. Pinheiro, C. R. Olivo et al., "A flavanone from Baccharis retusa (Asteraceae) prevents elastaseinduced emphysema in mice by regulating NF- $\kappa \mathrm{B}$, oxidative stress and metalloproteinases," Respiratory Research, vol. 16, no. 1, p. 79, 2015.

[119] Y. Wang, S. H. Cao, Y. J. Cui et al., "Salvia miltiorrhiza Bge. f. alba ameliorates the progression of monocrotaline-induced pulmonary hypertension by protecting endothelial injury in rats," The Tohoku Journal of Experimental Medicine, vol. 236, no. 2, pp. 155-162, 2015.

[120] R. Khlifi, A. Lahmar, Z. Dhaouefi et al., “Assessment of hypolipidemic, anti-inflammatory and antioxidant properties of medicinal plant Erica multiflora in triton WR-1339-induced hyperlipidemia and liver function repair in rats: a comparison with fenofibrate," Regulatory Toxicology and Pharmacology, vol. 107, article 104404, 2019.

[121] P. P. de Toledo Espindola, S. da Rocha Pdos, C. A. Carollo et al., "Antioxidant and antihyperlipidemic effects of Campomanesia adamantium O. Berg root," Oxidative Medicine and Cellular Longevity, vol. 2016, Article ID 7910340, 8 pages, 2016.

[122] N. S. Onyenibe, K. T. Fowokemi, and O. B. Emmanuel, “African nutmeg (Monodora myristica) lowers cholesterol and modulates lipid peroxidation in experimentally induced hypercholesterolemic male Wistar rats," International Journal of Biomedical Sciences, vol. 11, no. 2, pp. 86-92, 2015.
[123] M. Cakir, H. Duzova, I. Baysal et al., "The effect of hypericum perforatum on kidney ischemia/reperfusion damage," Renal Failure, vol. 39, no. 1, pp. 385-391, 2017.

[124] T. Caskurlu, M. Kanter, M. Erboga, Z. F. Erboga, M. Ozgul, and G. Atis, "Protective effect of Nigella sativa on renal reperfusion injury in rat," Iranian Journal of Kidney Diseases, vol. 10, no. 3, pp. 135-143, 2016.

[125] J. Godinho, A. B. de Sa-Nakanishi, L. S. Moreira et al., "Ethylacetate fraction of Trichilia catigua protects against oxidative stress and neuroinflammation after cerebral ischemia/reperfusion," Journal of Ethnopharmacology, vol. 221, pp. 109118, 2018.

[126] K. N. Sravanthi and N. R. Rao, "Cerebroprotective activity of Pentapetes phoenicea on global cerebral ischemia in rats," Indian Journal of Pharmacology, vol. 48, no. 6, pp. 694-700, 2016.

[127] L. A. Dra, S. Sellami, H. Rais et al., "Antidiabetic potential of Caralluma europaea against alloxan-induced diabetes in mice," Saudi Journal of Biological Sciences, vol. 26, no. 6, pp. 1171-1178, 2019.

[128] M. Ben Salem, R. Ben Abdallah Kolsi, R. Dhouibi et al., "Protective effects of Cynara scolymus leaves extract on metabolic disorders and oxidative stress in alloxan-diabetic rats," $B M C$ Complementary and Alternative Medicine, vol. 17, no. 1, article 328, 2017.

[129] R. Khanra, S. Dewanjee, T. K Dua et al., "Abroma augusta L. (Malvaceae) leaf extract attenuates diabetes induced nephropathy and cardiomyopathy via inhibition of oxidative stress and inflammatory response," Journal of Translational Medicine, vol. 13, no. 1, p. 6, 2015.

[130] E. I. Omodanisi, Y. G. Aboua, and O. O. Oguntibeju, “Assessment of the anti-hyperglycaemic, anti-inflammatory and antioxidant activities of the methanol extract of Moringa oleifera in diabetes-induced nephrotoxic male Wistar rats," Molecules, vol. 22, no. 4, p. 439, 2017.

[131] M. Fajri, A. Ahmadi, and R. Sadrkhanlou, "Protective effects of Equisetum arvense methanolic extract on sperm characteristics and in vitro fertilization potential in experimental diabetic mice: an experimental study," International Journal of Reproductive BioMedicine (IJRM), vol. 18, no. 2, pp. 93-104, 2020.

[132] M. El Ayed, S. Kadri, S. Smine, S. Elkahoui, F. Limam, and E. Aouani, "Protective effects of grape seed and skin extract against high-fat-diet-induced lipotoxicity in rat lung," Lipids in Health and Disease, vol. 16, no. 1, article 174, 2017.

[133] R. Budriesi, F. Vivarelli, D. Canistro et al., "Liver and intestinal protective effects of Castanea sativa Mill. bark extract in high-fat diet rats," PLoS One, vol. 13, no. 8, article e0201540, 2018.

[134] M. Raeesi, N. Eskandari-Roozbahani, and T. Shomali, "Gastro-protective effect of Biebersteinia multifida root hydromethanolic extract in rats with ethanol-induced peptic ulcer," Avicenna journal of phytomedicine, vol. 9, no. 5, pp. 410-418, 2019.

[135] K. Rtibi, M. A. Jabri, S. Selmi et al., "Gastroprotective effect of carob (Ceratonia siliqua L.) against ethanol-induced oxidative stress in rat," BMC Complementary and Alternative Medicine, vol. 15, no. 1, article 292, 2015.

[136] S. Sabiu, T. Garuba, T. Sunmonu et al., "Indomethacininduced gastric ulceration in rats: protective roles of Spondias mombin a nd Ficus exasperata," Toxicology Reports, vol. 2, pp. 261-267, 2015. 
[137] A. Sattar, A. Abdo, M. N. Mushtaq, I. Anjum, and A. Anjum, "Evaluation of gastro-protective activity of Myristica fragrans on ethanol-induced ulcer in albino rats," Anais da Academia Brasileira de Ciências, vol. 91, no. 2, article e20181044, 2019.

[138] V. R. Konda, R. Arunachalam, M. Eerike et al., "Nephroprotective effect of ethanolic extract of Azima tetracantha root in glycerol induced acute renal failure in Wistar albino rats," Journal of Traditional and Complementary Medicine, vol. 6, no. 4, pp. 347-354, 2016.

[139] A. Benhelima, Z. Kaid-Omar, H. Hemida, T. Benmahdi, and A. Addou, "Nephroprotective and diuretic effect of Nigella sativa L seeds oil on lithiasic Wistar rats," African Journal of Traditional, Complementary, and Alternative Medicines, vol. 13, no. 6, pp. 204-214, 2016.

[140] J. S. Chang, Y. J. Lee, D. A. Wilkie, and C. T. Lin, "The Neuroprotective and antioxidative effects of submicron and blended Lycium barbarum in experimental retinal degeneration in rats," The Journal of Veterinary Medical Science, vol. 80, no. 7, pp. 1108-1115, 2018.

[141] R. Cojocariu, A. Ciobica, I. M. Balmus et al., "Antioxidant capacity and behavioral relevance of a polyphenolic extract of Chrysanthellum americanum in a rat model of irritable bowel syndrome," Oxidative Medicine and Cellular Longevity, vol. 2019, Article ID 3492767, 13 pages, 2019.

[142] M. Hatipoğlu, M. Sağlam, S. Köseoğlu, E. Köksal, A. Keleş, and H. H. Esen, "The effectiveness of Crataegus orientalis M Bieber. (hawthorn) extract administration in preventing alveolar bone loss in rats with experimental periodontitis," PLoS One, vol. 10, no. 6, article e0128134, 2015.

[143] A. M. El-Kashlan, M. M. Nooh, W. A. Hassan, and S. M. Rizk, "Therapeutic potential of date palm pollen for testicular dysfunction induced by thyroid disorders in male rats," PLoS One, vol. 10, no. 10, article e0139493, 2015.

[144] Z. You, J. Sun, F. Xie et al., "Modulatory effect of fermented papaya extracts on mammary gland hyperplasia induced by estrogen and progestin in female rats," Oxidative Medicine and Cellular Longevity, vol. 2017, Article ID 8235069, 11 pages, 2017.

[145] K. Jeena, V. B. Liju, V. Ramanath, and R. Kuttan, "Protection against whole body $\gamma$-irradiation induced oxidative stress and clastogenic damage in mice by ginger essential oil," Asian Pacific Journal of Cancer Prevention, vol. 17, no. 3, pp. 1325-1332, 2016.

[146] H. A. H. Khattab, I. Z. A. Abdallah, F. M. Yousef, and E. A. Huwait, "Efficiency of borage seeds oil against gamma irradiation-induced hepatotoxicity in male rats: possible antioxidant activity," African Journal of Traditional, Complementary, and Alternative Medicines, vol. 14, no. 4, pp. 169-179, 2017.

[147] P. W. Wang, Y. C. Cheng, Y. C. Hung et al., "Red raspberry extract protects the skin against UVB-induced damage with antioxidative and anti-inflammatory properties," Oxidative Medicine and Cellular Longevity, vol. 2019, Article ID 9529676, 14 pages, 2019.

[148] Y. K. He, X. T. Cen, S. S. Liu, H. D. Lu, and C. N. He, "Protective effects of ten oligostilbenes from Paeonia suffruticosa seeds on interleukin- $1 \beta$-induced rabbit osteoarthritis chondrocytes," BMC Chemistry, vol. 13, no. 1, article 72, 2019.

[149] J. W. Lee, H. W. Ryu, S. U. Lee et al., "Pistacia weinmannifolia ameliorates cigarette smoke and lipopolysaccharide-induced pulmonary inflammation by inhibiting interleukin- 8 produc- tion and NF- $\kappa$ B activation," International Journal of Molecular Medicine, vol. 44, no. 3, pp. 949-959, 2019.

[150] G. Ateufack, E. C. Domgnim Mokam, M. Mbiantcha, R. B. Dongmo Feudjio, N. David, and A. Kamanyi, "Gastroprotective and ulcer healing effects of Piptadeniastrum africanum on experimentally induced gastric ulcers in rats," BMC Complementary and Alternative Medicine, vol. 15, no. 1, article 214, 2015.

[151] A. Nahdi, I. Hammami, R. B. Ali, O. Kallech-Ziri, A. El May, and M. V. El May, "Effect of Hypericum humifusum aqueous and methanolic leaf extracts on biochemical and histological parameters in adult rats," Biomedicine \& Pharmacotherapy, vol. 108, pp. 144-152, 2018. 